\title{
THE BEHAVIORAL AND PHYSIOLOGICAL EFFECTS OF LONG-DISTANCE TRANSLOCATION ON WESTERN RATTLESNAKES (CROTALUS OREGANUS)
}

\author{
A Thesis \\ presented to \\ the Faculty of California Polytechnic State University, \\ San Luis Obispo
}

\author{
In Partial Fulfillment \\ of the Requirements for the Degree \\ Master of Science in Biological Sciences
}

by

Kory Hayden Heiken

December 2013 
(C) 2013

Kory Hayden Heiken

ALL RIGHTS RESERVED 


\section{COMMITTEE MEMBERSHIP}

TITLE:

The behavioral and physiological effects of long-

distance translocation on Western Rattlesnakes

(Crotalus oreganus)

AUTHOR:

Kory Hayden Heiken

DATE SUBMITTED:

December 2013

COMMITTEE CHAIR: $\quad$ Emily N. Taylor, PhD

Associate Professor of Biological Sciences

COMMITTEE MEMBER: $\quad$ Sean C. Lema, PhD

Assistant Professor of Biological Sciences

COMMITTEE MEMBER: John D. Perrine, PhD

Associate Professor of Biological Sciences 


\begin{abstract}
The behavioral and physiological effects of long-distance translocation on Western

Rattlesnakes (Crotalus oreganus)
\end{abstract}

Kory Hayden Heiken

Long-distance translocation (LDT), the relocation of an animal outside of its home range, is a popular strategy for mitigating conflict between humans and venomous snakes. While LDT has been demonstrated to prevent a snake's return to the location of capture, it may result in increased mortality, magnitude and frequency of movements, and activity range sizes. Thus, it has generally been discouraged. However, the effects of LDT on stress physiology and thermoregulation have gone largely unstudied in reptiles. To elucidate these effects, we conducted an experimental LDT on Western Rattlesnakes (Crotalus oreganus) on Vandenberg Air Force base in California.

Fourteen snakes were monitored, beginning in mid July 2012 and ending in early September. Each was implanted with a radio transmitter and iButton temperature data logger within the coelomic cavity. In late August, seven snakes were translocated to similar habitat, approximately 30 kilometers away, where they were monitored for 9-13 days. Prior to translocation, all snakes were tracked every other day, while after translocation all snakes were tracked every day. A 'Before-After Control-Impact' (BACI) experimental design was used, with a dedicated control group, but also with the translocated group serving as control prior to the act of translocation.

We collected data on snake body temperatures $\left(\mathrm{T}_{\mathrm{b}}\right)$ and temperatures $\left(\mathrm{T}_{\mathrm{e}}\right)$ of physical operative temperature models (OTMs) that simulated non-thermoregulating snakes and allowed for a comparison of habitat thermal quality between our two study sites. Together, $\mathrm{T}_{\mathrm{b}}$ and $\mathrm{T}_{\mathrm{e}}$ allowed for a formal assessment of thermoregulatory effectiveness. Additionally, blood concentrations of corticosterone (CORT), the primary stress hormone in reptiles, and testosterone (T), a metric of male reproductive ability that is often negatively associated with CORT, were assayed just prior to translocation and again at the end of the study. During each of the two sampling periods, in addition to baseline hormone concentrations, stressed hormone concentrations were assayed following the application of an acute stressor (the baseline blood draw plus one hour's captivity in a plastic bucket). We also studied the effect of LDT on the CORT and T response (stressed concentration minus baseline concentration). Furthermore, we evaluated how LDT impacted a suite of behaviors related to defense and movement, as well as snake body mass and body condition index (BCI). Finally, we assessed the effects of LDT on movements and spatial use (activity range size). We sought to assess the effects of LDT on movements, spatial use, and behavior in order to facilitate comparison with other translocation studies, as well as to evaluate those impacts in a physiological context. In addition to assessing the impact of LDT on CORT and T separately, we 
evaluated a relationship between the two steroid hormones, and, using a model selection approach, we evaluated relationships between CORT and T and movements and spatial use.

The thermal quality of the habitat at our two sites did not differ and we found no effect of LDT on snake body temperature or thermoregulatory effectiveness. We found that spatial use increased following LDT, since the average $100 \%$ minimum convex polygon (MCP) activity range size of our translocated snakes was greater than that of our control snakes during the post-translocation period. However, movements (mean distance moved per day and total distance moved) were unaffected by LDT. Translocation was not found to affect snake body mass or BCI, indicating that snake energy demands did not increase as a result of LDT. Of the behaviors that we recorded, many (rattling, tongueflicking, fleeing, moving vs. stationary when found) were observed too infrequently to carry out satisfactory parametric analyses, though a qualitative assessment leads to the conclusion that LDT did not affect them. The effect of LDT on how often our snakes were visible was marginally significant, but post-hoc testing found no differences. Nonetheless, the translocated snakes tended to be visible more often than the controls, during the post-translocation period. We found no effect of LDT on the percentage of a snake's body sunlit when visible. Our translocation was not found to any CORT metric, while for $\mathrm{T}$, the only metric that was affected was the baseline concentration. Baseline $\mathrm{T}$ was found to be higher in translocated snakes than in control snakes following translocation. We found some evidence for a positive relationship between CORT and T for baseline and stressed concentrations. Our model selection procedure found little evidence for a relationship between snake movements and spatial use and either CORT or $\mathrm{T}$.

Our results are encouraging in that we did not find that LDT disrupts thermoregulation or results in a condition of chronic stress, as indicated by the CORT results. The positive effect of LDT on baseline $\mathrm{T}$ is somewhat mysterious, but studies on mammals suggest that increased $\mathrm{T}$ may aid in spatial learning and memory. Since the site that a snake is translocated to is entirely novel, an elevated capacity for spatial learning and memory could be beneficial to a translocated snake. Our finding that spatial use increased following LDT agrees with other studies of LDT in snakes, but some studies have found that movements increased following LDT, while we did not. In addition to snake movements being unaffected, we translocated our snakes within a relatively thermally benign climate in coastal central California. Translocations carried out in more extreme climates, with either cold winters or hot summers may indeed result in an effect on thermoregulation and a state of chronic stress. Consequently, we advocate further study of the physiological effects of LDT on other snake species in a variety of climates. Additionally, while it was our goal to study the short-term effects of LDT, more longterm studies, which follow the snakes through the entire active season and the winter hibernation period, may be informative. 


\section{ACKNOWLEDGMENTS}

Firstly I would like to thank my advisor and committee chair, Dr. Emily Taylor for her invaluable guidance, encouragement, and assistance, in both the lab and the field. Just as importantly, I thank Sarah Gartland, Timothy Sorrells, George Brusch IV, and Alyssa Semerdjian for their aid in the daily tracking of the snakes. Without their hard work, this project would not have been possible. I further thank George Brusch IV for his diligent efforts in using ArcGIS to obtain activity range sizes, as well as calculating mean distance moved and total distance moved for all of the snakes. I thank Julius (Tony) Frazier for his assistance in retrieving my snakes from the field and obtaining blood samples. I also thank Camilo Escallón and his advisor, Dr. Ignacio Moore, from Virginia Tech University for using a radioimmunoassay procedure to quantify corticosterone and testosterone in our blood samples. I thank Dr. Scott Steinmaus, Dr. John Walker, and Dr. Ulric Lund for their expert statistical advice. I thank Rhys Evans for his help with logistics, equipment, navigation, and field site location on Vandenberg Air Force Base. I thank the California Department of Fish and Game (permit \# SC-8159) for permission to collect the snakes and California Polytechnic State University IACUC (protocol \# 1203) for approval of the use and care of the snakes. Finally, I thank the United States Air Force, the Chicago Herpetological Society, and the California Polytechnic State University Department of Biological Sciences for funding the project. 


\section{TABLE OF CONTENTS}

Page

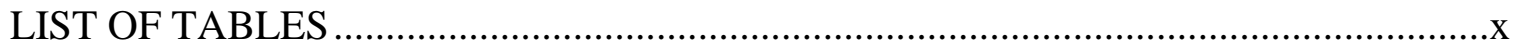

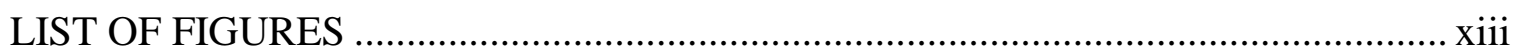

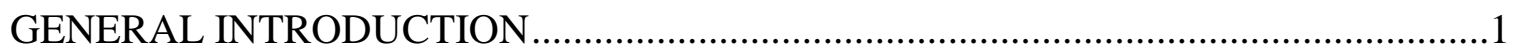

\section{CHAPTER}

I. THE EFFECTS OF LONG-DISTANCE TRANSLOCATION ON THERMOREGULATORY EFFECIVENESS, SPATIAL ECOLOGY, AND BEHAVIOR IN THE WESTERN RATTLESNAKE (CROTALUS OREGANUS) ..........................................................................5

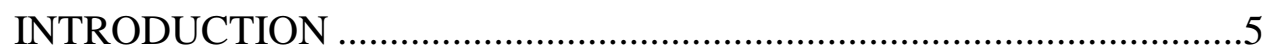

MATERIALS AND METHODS ..........................................................10

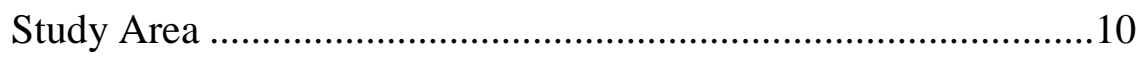

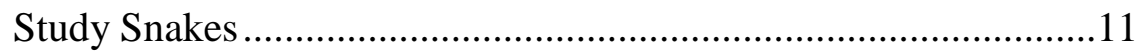

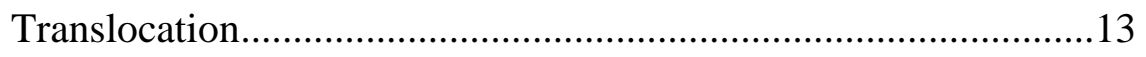

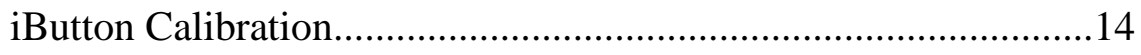

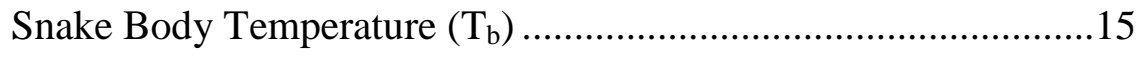

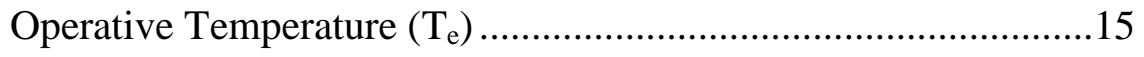

Field-selected Body Temperature Range $\left(\mathrm{T}_{\text {sel }}\right) \ldots \ldots \ldots \ldots \ldots \ldots \ldots \ldots \ldots \ldots \ldots . . . . .16$

Index of Thermoregulatory Effectiveness $\left(\mathrm{d}_{\mathrm{e}}-\mathrm{d}_{\mathrm{b}}\right)$.....................17

Body Mass Change and Body Condition Index (BCI) ...................18

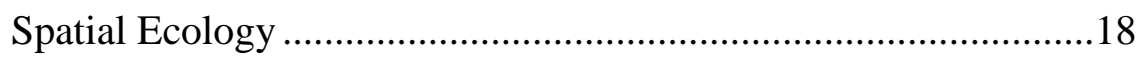

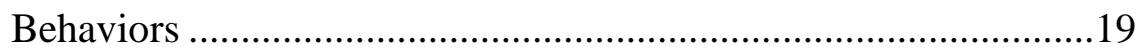

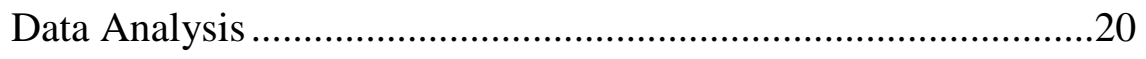


RESULTS .

Snake $\mathrm{T}_{\mathrm{b}}$

Index of Thermoregulatory Effectiveness and

Related Variables.

Body Mass Change and BCI...................................................22

Spatial Ecology …...................................................................22

Behaviors ............................................................................25

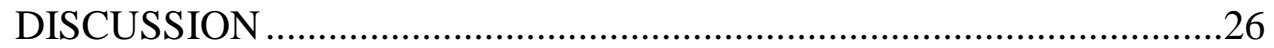

II. THE EFFECT OF LONG-DISTANCE TRANSLOCATION ON

ENDOCRINE STRESS PHYSIOLOGY IN THE

WESTERN RATTLESNAKE (CROTALUS OREGANUS) .................................38

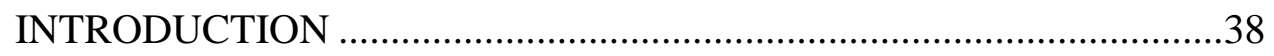

MATERIALS AND METHODS .....................................................43

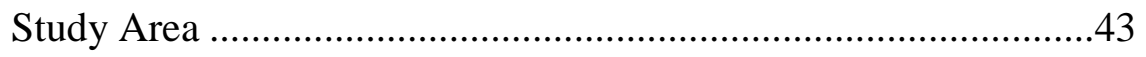

Study Snakes ................................................................. 44

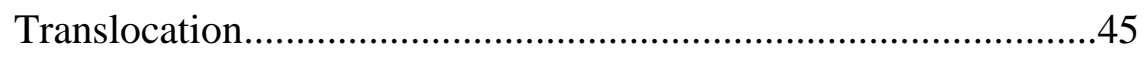

Hormone Sampling .........................................................47

Radioimmunoassay .........................................................47

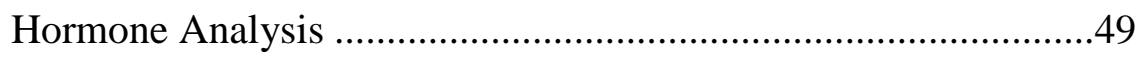

Body Mass Change and Body Condition Index (BCI) ................49

Spatial Ecology ….........................................................50

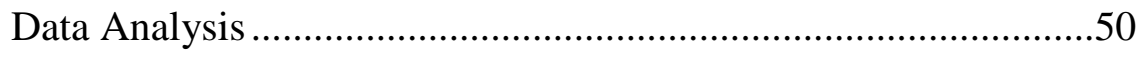

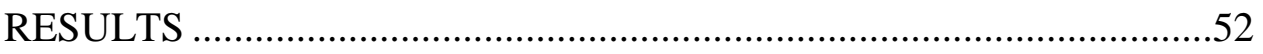

Corticosterone (CORT) ........................................................52

Testosterone $(\mathrm{T})$...............................................................53 
Body Mass Change, BCI, and Spatial Ecology Repeated

Spatial Ecology ...............................................................55

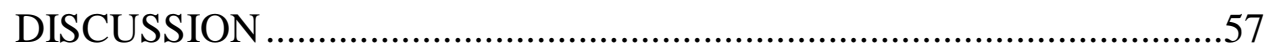

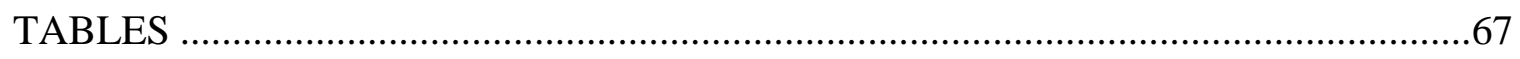

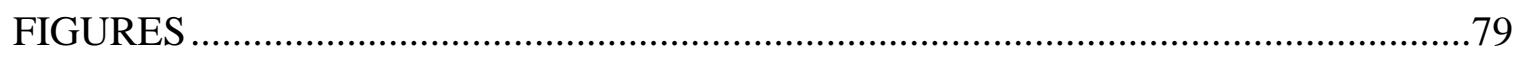

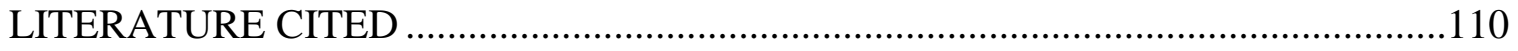

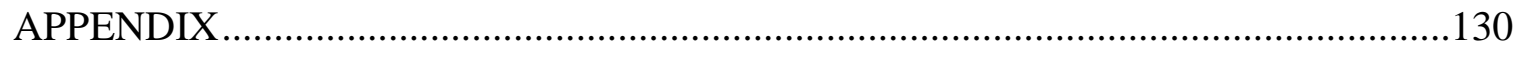




\section{LIST OF TABLES}

Table

Page

1. Results of the repeated measures analysis of snake body temperature $\left(\mathrm{T}_{\mathrm{b}}\right)$. Two treatment groups (translocated and control) were evaluated at each of two time periods (before and after translocation)

2. Results of a two-sample t-test comparing habitat thermal quality $\left(\mathrm{d}_{\mathrm{e}}\right)$ between our two sites (source and translocation) and repeated measures analyses of snake body temperature accuracy $\left(\mathrm{d}_{\mathrm{b}}\right)$ and an index of thermoregulatory effectiveness. Two treatment groups (translocated and control) were evaluated at each of two time periods (before and after translocation) .68

3. Results of the repeated measures analyses of snake body mass and body condition index (BCI). Two treatment groups (translocated and control) were evaluated at each of two time periods (before and after translocation

4. Results of regression analyses that investigated a relationship between the number of days that our snakes were tracked during the period following translocation, snake movement (mean distance moved per day and total distance moved) and spatial use (100\% MCP activity range)

5. The repeated measures analyses of snake movement (mean distance moved per day and total distance moved) and spatial use (100\% MCP activity range). Two treatment groups (translocated and control) were evaluated at each of two time periods (before and after translocation). The results of the $100 \% \mathrm{MCP}$ analysis are presented both with and 
without an outlier (snake \#7), since it altered the significance of the results .71

6. Repeated measures analyses of snake behavior. Only analyses of the proportion of instances when a snake was visible and the mean percentage of the snake's body sunlit (if visible) were possible

7. Results of the repeated measures analyses of baseline and stressed (after the application of an acute stressor) corticosterone (CORT) and the CORT response (stressed minus baseline). Two treatment groups (translocated and control) were evaluated at each of two time periods (before and after translocation). Significant covariates are included where appropriate .73

8. Results of the repeated measures analyses of baseline and stressed (following the application of an acute stressor) testosterone (T) and the T response (stressed minus baseline). Two treatment groups (translocated and control) were evaluated at each of two time periods (before and after translocation). Significant covariates are included where appropriate

9. Results of regression analyses that investigated a relationship between corticosterone (CORT) and testosterone (T) concentrations at baseline and stressed conditions (following application of an acute stressor), as well as the relationship between the CORT and T response (to the acute stressor)

10. Model selection results for $100 \%$ MCP activity range size. Models 
with $\triangle \mathrm{AICc} \leq 10.0$ are displayed. The experimental terms (group, time, group*time), potential covariates (BCI, SVL), and plasma steroidhormone (CORT or T) levels were evaluated as possible explanatory variables. Individual snake was included as a random effect in all models, in order to account for repeated measures on the same individual. Where appropriate, the F-statistic and P-value are included for the CORT and T terms .......

11. Model selection results for mean distance moved per day. Models with $\triangle \mathrm{AICc} \leq 10.0$ are displayed. The experimental terms (group, time, group*time), potential covariates (BCI, SVL), and plasma steroid hormone (CORT or T) levels were evaluated as possible explanatory variables. Individual snake was included as a random effect in all models, in order to account for repeated measures on the same individual. Where appropriate, the F-statistic and P-value are included for the CORT and $\mathrm{T}$ terms

12. Model selection results for total distance moved. Models with $\Delta \mathrm{AICc} \leq 10.0$ are displayed. The experimental terms (group, time, group*time), potential covariates (BCI, SVL), and plasma steroid hormone (CORT or T) levels were evaluated as possible explanatory variables. Individual snake was included as a random effect in all models, in order to account for repeated measures on the same individual. Where appropriate, the F-statistic and P-value are included for the CORT and T terms .78 


\section{LIST OF FIGURES}

Figure

1. Mean daily maximum $\mathrm{T}_{\mathrm{b}}$ by time (before or after translocation) and treatment group. The solid line indicates the translocated group, while the dashed line indicates the control group. Error bars are one standard error of the mean. The main effect of time was significant, with mean daily maximum $\mathrm{T}_{\mathrm{b}}$ being $2.2^{\circ} \mathrm{C}$ higher before translocation

2. Mean $d_{b}$ by time (before or after translocation) and treatment group.

The solid line indicates the translocated group, while the dashed line indicates the control group. Error bars are one standard error of the mean. The main effect of time was significant, with mean $d_{b}$ being $0.6^{\circ} \mathrm{C}$ higher before translocation. This indicates that, during that time period, the $\mathrm{T}_{\mathrm{b}}$ of all snakes deviated more from $\mathrm{T}_{\text {sel }}$ than it did during the latter part of the study, post-translocation

3. Mean thermoregulatory effectiveness by time (before or after translocation) and treatment group. The solid line indicates the translocated group, while the dashed line indicates the control group. Error bars are one standard error of the mean. The main effect of time was marginally significant. The index of thermoregulatory effectiveness was $0.3^{\circ} \mathrm{C}$ higher before translocation, indicating more effective thermoregulation during that time period

4. Mean body mass by time (before or after translocation) and treatment group. The solid line indicates the translocated group, while the dashed 
line indicates the control group. Error bars are one standard error of the mean. The main effect of time was significant, with mean body mass being $119 \mathrm{~g}$ higher at the beginning of the study than at the end of the study .82

5. Mean body condition index (BCI) by time (before or after translocation) and treatment group. The solid line indicates the translocated group, while the dashed line indicates the control group. Error bars are one standard errorof the mean. The main effect of time was significant, with mean BCI being higher at the beginning of the study than at the end of the study 83

6. Mean $100 \%$ Minimum Convex Polygon (MCP) activity range size by time (before or after translocation) and treatment group, including an outlier in the data set. The solid line indicates the translocated group, while the dashed line indicates the control group. Error bars are one standard error of the mean. The treatment group by time interaction was significant, indicating an effect of translocation on MCP size. The control group decreased in MCP size, while the translocated group did not. Post-translocation, the average 100\% MCP size for thetranslocated group was 29 times larger than that of the control group .84

7. Mean $100 \%$ Minimum Convex Polygon (MCP) activity range size by time (before or after translocation) and treatment group, excluding an outlier $(8.17 \mathrm{Ha})$ in the data set $($ mean without outlier $=0.67 \mathrm{Ha}$, 
$\mathrm{SE}=0.31$ ). The solid line indicates the translocated group, while the dashed line indicates the control group. Error bars are one standard error of the mean. Removal of the outlier nullified the marginal significance of the treatment group by time interaction, resulting in a significant main effect of time, with MCP size being 2.6 times greater during the period prior to translocation. However, it can be seen that the translocated group decreased over time to a lesser degree than the control group. In the period following translocation, the average MCP size was still 11 times greater in the translocated group than in the control group, though the individual variation within the translocated group was much greater

8. Mean distance moved per day by time (before or after translocation) and treatment group, including an outlier ( $88 \%$ increase) in the data set (average decrease of $39 \%$ without the outlier). The solid line indicates the translocated group, while the dashed line indicates the control group. Error bars are one standard error of the mean. The main effect of time was significant, with mean distance moved per day being twice as great during the period before translocation than during the period after translocation

9. Mean distance moved per day by time (before or after translocation) and treatment group, excluding an outlier in the data set. The solid line indicates the translocated group, while the dashed line indicates the control group. Error bars are one standard error of the mean. Removal 
of the outlier did not change the significance of any model term

10. Mean total distance moved by time (before or after translocation) and treatment group, including an outlier in the data set. The solid line indicates the translocated group, while the dashed line indicates the control group. Error bars are one standard error of the mean. None of the model terms were significant. However, the translocated group increased while the control group decreased. This divergence was offset by a large amount of individual variation in the translocated group during the period following translocation .88

11. Mean total distance moved by time (before or after translocation) and treatment group, excluding an outlier in the data set. The solid line indicates the translocated group, while the dashed line indicates the control group. Error bars are one standard error of the mean. None of the model terms were significant, with or without the outlier 89

12. Relative frequency of rattling by time (before or after translocation) and treatment group. The relative frequency was calculated as the number of locations on which a snake rattled, divided by the total number of locations when the snake was seen. The light grey bars indicate the translocated group, while the dark gray bars indicate the control group. Error bars are one standard error of the mean. Due to infrequent observation of rattling, parametric analysis was precluded .90

13. Relative frequency of tongue-flicking by time (before or after translocation) and treatment group. The relative frequency was 
calculated as the number of locations on which a snake tongue-flicked, divided by the total number of locations when the snake was seen. The light grey bars indicate the translocated group, while the dark gray bars indicate the control group. Error bars are one standard error of the mean. Due to infrequent observation of tongue-flicking, parametric analysis was precluded .91

14. Relative frequency of fleeing by time (before or after translocation) and treatment group. The relative frequency was calculated as the number of locations on which a snake fled, divided by the total number of locations when the snake was seen. The light grey bars indicate the translocated group, while the dark gray bars indicate the control group. Error bars are one standard error of the mean. Due to infrequent observation of fleeing, parametric analysis was precluded .92

15. Relative frequency of movement by time (before or after translocation) and treatment group. The relative frequency was calculated as the number of locations on which a snake was observed to be moving, divided by the total number of locations when the snake was seen. The light grey bars indicate the translocated group, while the dark gray bars indicate the control group. Error bars are one standard error of the mean. Due to infrequent observation of movement, parametric analysis was precluded .93

16. Relative frequency of snake sightings by time (before or after translocation) and treatment group. The relative frequency was 
calculated as the number of locations on which a snakes was seen, divided by the total number of locations, for that snake. The light grey bars indicate the translocated group, while the dark gray bars indicate the control group. Error bars are one standard error of the mean. The treatment group by time interaction was marginally significant, indicating that translocation was associated with increased visibility. During the period after translocation, the translocated group was visible 1.8 times as often as the control group. However, post-hoc testing found no significant differences

17. Mean percent body sunlit by time (before or after translocation) and treatment group. Percent body sunlit was only scored if a snake was seen when located. The light grey bars indicate the translocated group, while the dark gray bars indicate the control group. Error bars are one standard error of the mean. The treatment group by time interaction was significant. The control group was 2.8 times more sunlit during the period before translocation than it was during the period following translocation. The translocated group did not change over time. The control group was 2.9 times more sunlit than the translocated group during the pre-translocation period, though no difference existed between the two groups during the post-translocation period .95

18. Corticosterone (CORT) by time (before or after translocation) and treatment group. The baseline concentration represents that prior to 
application of the acute stressor while the stressed concentration is that following application of the acute stressor. The response represents the difference between the baseline and stressed concentrations. Error bars are one standard error of the mean. In each case (baseline, stressed, and response) a significant main effect of treatment group was observed, with CORT concentrations in the translocated group being more than twice those of the control group, across both time periods (before translocation and after translocation) .96

19. Mean baseline (prior to application of the acute stressor) corticosterone (CORT) by time (before or after translocation) and treatment group. The solid line indicates the translocated group, while the dashed line indicates the control group. Error bars are one standard error of themean. The main effect of treatment group was significant, with thetranslocated group being 2.3 times higher than the control group across both time periods. Though the treatment group by time interaction was not significant, the translocated group was higher than the control group, post-translocation

20. Mean stressed (following application of the acute stressor) corticosterone (CORT) by time (before or after translocation) and treatment group. The solid line indicates the translocated group, while the dashed line indicates the control group. Error bars are one standard error of the mean. The main effect of treatment group was significant, 
with the translocated group being 2.4 times higher than the control group across both time periods

21. Mean corticosterone (CORT) response (stressed minus baseline) by time (before or after translocation) and treatment group. The CORT response was calculated as the change in CORT from a baseline blood draw to a blood draw that occurred after application of an acute stressor. The solid line indicates the translocated group, while the dashed line indicates the control group. Error bars are one standard error of the mean. The main effect of treatment group was significant, with the translocated group being 2.3 times higher than the control group across both time periods

22. Testosterone ( $\mathrm{T}$ ) by time (before or after translocation) and treatment group. The baseline concentration represents that prior to application of the acute stressor while the stressed concentration is that following application of the acute stressor. The response represents the difference between the baseline and stressed concentrations. Error bars are onestandard error of the mean. Significant trends were only observed in baseline $\mathrm{T}$, with the trend in stressed $\mathrm{T}$ being explained by the very similar baseline trend. The two treatment groups were not found to differ before translocation in baseline $\mathrm{T}$, but, following translocation, baseline $\mathrm{T}$ was 7.3 times greater in the translocated group than in the control group 100 
23. Mean baseline (prior to application of the acute stressor) testosterone (T) by time (before or after translocation) and treatment group. The solid line indicates the translocated group, while the dashed line indicates the control group. Error bars are one standard error of the mean. The treatment group by time interaction was significant. The two groups were not significantly different before translocation, but were after translocation, with the translocated group being 7.3 times higher during that time period 101

24. Mean stressed (following application of the acute stressor) testosterone (T) by time (before or after translocation) and treatment group. The solid line indicates the translocated group, while the dashed line indicates the control group. Error bars are one standard error of the mean. There were no significant trends, as the variation in stressed $\mathrm{T}$ was explained by baseline $\mathrm{T}$ 102

25. Mean testosterone (T) response by time (before or after translocation) and treatment group. The $\mathrm{T}$ response was calculated as the change in $\mathrm{T}$ from the baseline blood draw to a blood draw that occurred after application of an acute stressor. The solid line indicates the translocated group, while the dashed line indicates the control group. Error bars are one standard error of the mean. No significant trends were observed 103

26. A plot of baseline $\mathrm{T}$ on baseline CORT. Individual snake was included as a random effect in the regression model, in order to account for 
repeated measures (before translocation and after translocation). A significant but weak positive relationship was observed, though it was driven by two influential snakes, which are displayed as open circles .104

27. A plot of stressed $\mathrm{T}$ on stressed CORT. Individual snake was included as a random effect in the regression model, in order to account for repeated measures (before translocation and after translocation). A significant but weak positive relationship was observed. The two influential snakes from the baseline regression analysis (Figure 26) are displayed as open circles. Their removal changed the significance of the regression F-test here as well (see Figure 29) .105

28. A plot of baseline $\mathrm{T}$ on baseline CORT, minus two influential snakes (see Figure 26). Individual snake was included as a random effect in the regression model, in order to account for repeated measures (before translocation and after translocation). Removal of the influential snakes nullified the significance of the regression F-test .106

29. A plot of stressed T on stressed CORT, minus two influential snakes from the baseline regression analysis (Figure 26). Individual snake was included as a random effect in the regression model, in order to account for repeated measures (before translocation and after translocation). Removal of the influential snakes nullified the significance of the regression F-test .107 
30. A plot of the $\mathrm{T}$ response on the CORT response. Individual snake was included as a random effect in the regression model, in order to account for repeated measures (before translocation and after translocation). There was no significant relationship. The two influential snakes from the baseline regression analysis (Figure 26) are displayed as open circles. Their removal did not change the significance of the regression F-test (see Figure 31) 108

31. A plot of the T response on the CORT response, minus two influential snakes from the baseline analysis (Figure 26). Individual snake was included as a random effect in the regression model, in order to account for repeated measures (before translocation and after translocation). The relationship was not significant, with or without the influential snakes. .109 


\section{GENERAL INTRODUCTION}

Long-distance translocation (LDT), the relocation of an animal outside of its home range, is typically discouraged as a tool for snake conservation and management, due to potential negative impacts on behavior and mortality (Reinert and Rupert, 1999; Nowak et al., 2002). However, LDT is likely to remain a popular management tool for two reasons. Firstly, in the context of mitigating conflict between venomous snakes and humans, LDT prevents the return of snakes to the initial conflict site, where the snake was perceived to be a threat (Reinert and Rupert, 1999; Butler et al., 2005; Brown et al., 2008). While short-distance translocation (SDT), which relocates an animal within its home range, is generally advocated as a strategy that is without negative consequences for the subject snakes (Brown et al., 2008; Brown et al., 2009, Holding et al., in press), the snakes return to the initial conflict site with such frequency that Hardy et al. (2001) ceased to recommend SDT of rattlesnakes. This phenomenon has been demonstrated in all studies of SDT of rattlesnakes, including several species. This general problem is likely to make SDT an unattractive strategy in many situations involving human-snake conflict. Secondly, beyond preventing snake fatalities when human-snake conflict arises, SDT has little utility to conservation at the population or species level. SDT moves snakes within a population, not between them, and it does not re-establish extirpated populations. On the contrary, LDT is useful in those ways to conservation. With documented snake declines (Kingsbury and Attum, 2009), such utility is likely to be necessary. King et al. (2004) have already shown that LDT of captive born snakes may 
be of use in re-establishing extirpated populations of Eastern Massasaugas (Sistrurus $c$. catenatus).

Though LDT is likely to remain a popular tool for managing snake populations, and it has been studied in a variety of species (Reinert and Rupert, 1999; Plummer and Mills, 2000; Nowak et al., 2002; Butler et al., 2005; Brown et al., 2008; Roe et al., 2010), studies have largely focused on the effects of LDT on spatial ecology (movements and activity range size) and mortality. Of the aforementioned studies, only Roe et al. (2010) incorporated study of physiological impacts of LDT, studying the impact on body temperature in Northern Water Snakes (Nerodia s. sipedon). The sources of observed mortality are often unclear in LDT studies (Reinert and Rupert, 1999; Nowak et al., 2002; Brown et al., 2008) and thus it is apparent that adding a physiological aspect to studies of LDT may be beneficial. Reinert and Rupert (1999) suggest that chronic stress, as a result of LDT and the ensuing aberrant movements, may have been to blame for some of the mortality that they observed. Furthermore, they suggest that it would be interesting to monitor concentrations of hormones associated with stress, such as corticosterone (CORT), the primary glucocorticoid in reptiles. Indeed, chronically elevated CORT could result in death via its immunosuppressive effects (Dhabhar and McEwen, 1997; French et al., 2007; Dickens et al., 2010) or by elevated exposure to predators as a result of inhibition of cognition (Bodnoff et al., 1995; McEwen and Sapolsky, 1995; de Kloet et al., 1999; Mendl, 1999). Additionally, CORT may suppress reproductive hormones (Moore et al., 1991; Manzo et al., 1994; Moore et al., 2000a; Moore and Jessop, 2003; Jones and Bell, 2004; Tokarz and Summers, 2011), leading to decreased fitness. A translocated snake with reduced fitness would be of little use to the 
resident population. However, no study of CORT, as it relates to LDT, has been carried out. Along the same lines as Roe et al. (2010), it may be informative to further study the effect of LDT on snake thermoregulation, a critical physiological process for ectothermic reptiles (Peterson et al., 1993) that may be disrupted due to the aberrant and increased movements that often follow LDT. In addition to the insufficiency of a single study on a single taxon, Roe et al. (2010) did not calculate a formal index of thermoregulatory effectiveness (Hertz et al., 1993), which would provide a better estimate of the effect on thermoregulation than snake body temperature alone.

The goal of my thesis was to investigate the effects of an experimental LDT on both stress physiology and thermoregulation, using adult male Western Rattlesnakes (Crotalus oreganus) as the study organisms. A robust Before-After Control-Impact (BACI) experimental design was used throughout. A dedicated control group was studied during the time before and after translocation, but, prior to the act of translocation, the translocated group served as another control. While my study was relatively brief, lasting less than two weeks post-translocation, aberrant movements and spatial use were expected during that period (Butler et al., 2005), and thus I expected that, if physiology was to be affected as well, that it would occur during the same time frame. Chapter one mainly addresses the effect of LDT on rattlesnake thermoregulation, while also evaluating the impact on snake body condition and a suite of behaviors. Lastly, chapter one also addresses the effect of LDT on movements and spatial use (activity range size), both to allow comparison to previous LDT studies and to provide context for my study of thermoregulation. Chapter two addresses the effects of LDT on CORT and testosterone (T), an important reproductive hormone for male reptiles. I address the two steroid 
hormones separately, as well as the relationship between the two, since chronically elevated CORT may be associated with decreased T (Moore et al., 1991; Manzo et al., 1994; Moore et al., 2000a; Moore and Jessop, 2003; Jones and Bell, 2004; Tokarz and Summers, 2011). Finally, using a model selection approach, I investigate possible relationships between movements and spatial use and CORT and T. Taken together, my two chapters provide the most comprehensive look into the physiological effects of LDT in any study on snakes. 


\section{THE EFFECTS OF LONG-DISTANCE TRANSLOCATION ON THERMOREGULATORY EFFECTIVENESS, SPATIAL ECOLOGY, AND BEHAVIOR IN THE WESTERN RATTLESNAKE (CROTALUS OREGANUS)}

\section{INTRODUCTION}

Translocation, or the relocation of wild animals within their natural range, former or current, has long been a popular tool for wildlife management, and this extends to snakes (Dodd and Seigel, 1991; Fischer and Lindenmayer, 2000; Germano and Bishop, 2008; Kingsbury and Attum, 2009). The mitigation of human-snake conflict through the relocation of nuisance animals has been the primary motivation behind snake translocation (Hardy et al., 2001; Nowak et al., 2002; Butler et al., 2005; Kingsbury and Attum, 2009). However, now that snake declines are being documented (Kingsbury and Attum, 2009), translocation has increasingly been investigated as a purely conservation tool, through the augmentation of a current population to increase its viability or the creation of a new population in a part of a species' historical range (Plummer and Mills, 2000; King et al., 2004; Kingsbury and Attum, 2009; Roe et al., 2010). Since translocation is likely to remain a popular management tool, especially for venomous snakes, it is crucial that its effects on subject animals be further studied.

Snake translocations fall into two categories, short-distance and long-distance. Short-distance translocation (SDT) is defined as relocation of a snake within its home range, while long-distance translocation (LDT) relocates a snake outside of its home range (Hardy et al., 2001). Though each is a useful strategy, each has its own pitfalls, 
tradeoffs which potentially negatively affect either the animals or management efforts. SDT tends to have minimal effects on snake spatial ecology, and no effect on stress physiology, behavior, and mortality (Brown et al., 2008; Brown et al., 2009, Holding et al., in press). Therefore, SDT is generally advocated. However, the usefulness of SDT is limited, since snakes frequently return to the initial capture area, sometimes within as little as one day (Hardy et al., 2001; Brown et al., 2008; Brown et al., 2009, Holding et al., in press). Additionally, the usefulness of SDT is likely limited to mitigation of human-snake conflict, excluding conservation efforts such as population augmentation and re-establishment of extirpated populations. In contrast to SDT, LDT has been demonstrated to prevent the return of snakes to their initial capture area and it may be useful for population level conservation efforts as well as human-snake conflict mitigation (Reinert and Rupert, 1999; King et al., 2004; Butler et al., 2005; Brown et al., 2008). However, LDT is generally not recommended as a management strategy, as it can result in increased mortality, increased magnitude and frequency of movements, and increased activity range sizes (Reinert and Rupert, 1999; Nowak et al., 2002; Butler et al., 2005; Roe et al., 2010). Increased movements and spatial use may result in greater exposure to predators and increased energy demands and may reflect a behavioral strategy to minimize the stress associated with introduction to a novel environment, as the animal searches for its original home range (Drugan et al., 1997; Dickens et al., 2010). In defense of LDT, the effects on spatial ecology can be individually variable (Nowak et al., 2002), and in some studies, the magnitudes and frequencies of movements (Plummer and Mills, 2000; Nowak et al., 2002), mortality (Butler et al., 2005; Brown et al., 2008), surface (above ground) activity and body temperature $\left(\mathrm{T}_{\mathrm{b}}\right)($ Roe et al., 2010) are 
unaffected. Additionally, whenever studied, body mass, body condition, and growth rate have been found to be unaffected (Reinert and Rupert, 1999; Nowak et al., 2002; Roe et al., 2010), and the source of observed mortality is sometimes unclear (Nowak et al., 2002; Brown et al., 2008). Adding physiological variables, which have received little study, to commonly studied spatial variables and metrics of body condition may aid in the interpretation of the varying results of previous LDT studies. As found by Nowak et al. (2002), unexplained mortality associated with LDT and increased movements, but no effect of LDT on body condition, is one instance where physiological variables may be informative. In this way, the mechanisms behind the consequences of LDT for the subject animals may be better understood. Such insight is crucial for weighing the costs and benefits of translocation, in order to assess if it is a tractable conservation management strategy for a given species or population.

One little studied physiological consequence is the effect of LDT on thermoregulation. Roe et al. (2010) conducted the only such study in reptiles, but only $\mathrm{T}_{\mathrm{b}}$ was quantified. An index of thermoregulatory effectiveness (see below), which would likely more accurately quantify the effect of LDT on thermoregulation, was not calculated and analyzed. Additionally, the Roe et al. (2010) infrequently sampled $\mathrm{T}_{\mathrm{b}}$ (as little as once per week in at least some cases), and thus may have failed to detect an effect of LDT. Reptiles, being ectotherms that often live in thermally unstable environments, are subject to body temperature variation (Peterson et al., 1993), which can have a wide range of effects on physiological processes such as metabolism (Peterson et al., 1993), strike speed (Greenwald, 1974), locomotion (Angilletta et al., 2002), immune function (Mondal and Rai, 2001), and sensory input (Werner, 1976; Stevenson et al., 1985). In 
order to minimize possible negative physiological consequences associated with body temperature variation, reptiles actively regulate their body temperature through physiological and behavioral processes (Stevenson et al., 1985; Angilletta et al., 2002; Angilletta, 2009). However, disruption of these processes may occur in snakes subjected to LDT, perhaps associated with aberrant movement patterns and microhabitat use. Over time, the issue may become physiologically taxing enough to result in poor physiological performance, or even death. To make matters worse, impairment of physiological performance, due to disruption of thermoregulation could compound with other possible negative consequences of the increased and aberrant movements that are often associated with LDT, such as increased energy demands and greater exposure to predators.

Our main goal in this study was to test the hypothesis that LDT disrupts thermoregulation in rattlesnakes. The design of this study followed a Before-After Control-Impact (BACI) experimental design, where a dedicated control group was used but also where the translocated group served as an additional control for itself by evaluating thermoregulatory parameters in these same animals prior to the act of translocation. Our study animal was the Western Rattlesnake (Crotalus oreganus). Our study location, Vandenberg Air Force Base, likely exists within the intergrade zone between the Southern Pacific Rattlesnake (C. o. helleri) and the Northern Pacific Rattlesnake (C. o. oreganus) (Klauber, 1949; Schneider, 1986; Douglas et al., 2002; Stebbins, 2003), so our study animals will henceforth be referred to as $C$. oreganus. While $C$. oreganus does not carry any special conservation status, it is widespread, venomous, and frequently comes in contact with humans, making it a prime candidate for translocation away from human inhabited areas. In addition, our results may be 
tentatively extrapolated to inform management of threatened rattlesnake species, such as Eastern Massasaugas (Sistrurus c. catenatus) and Eastern Diamondbacks (Crotalus adamanteus).

Assessment of thermoregulatory effectiveness in the face of LDT must go beyond a simple analysis of $\mathrm{T}_{\mathrm{b}}$. It is necessary to determine how accurately a snake maintains its $\mathrm{T}_{\mathrm{b}}$ within its preferred $\mathrm{T}_{\mathrm{b}}$ range, while taking into account the extent to which the snake's environment offers microhabitats that allow the snake to maintain its $\mathrm{T}_{\mathrm{b}}$ within its preferred range (i.e. the thermal quality of the habitat). Clearly, an index of thermoregulatory effectiveness that incorporates these factors is required (Hertz et al., 1993; Blouin-Demers and Weatherhead, 2001; Angilletta, 2009). Thus, if LDT disrupts thermoregulation, then $C$. oreganus subjected to LDT will differ in mean $\mathrm{T}_{\mathrm{b}}$, with higher daily maximum $\mathrm{T}_{\mathrm{b}}$ 's and lower daily minimum $\mathrm{T}_{\mathrm{b}}$ 's, when compared to control snakes. Also, the same differences will be observed when translocated snakes are compared to themselves, before they were translocated. Additionally, translocated snakes will less accurately maintain their $\mathrm{T}_{\mathrm{b}}$ within their preferred range, provided that the habitat of the source site (for control and translocated snakes) does not differ from the translocation site in thermal quality. Thus, translocated snakes should exhibit relatively lower values of the index of thermoregulatory effectiveness.

In order to facilitate comparison with other studies of LDT (Reinert and Rupert, 1999; Nowak et al., 2002; Butler et al., 2005; Brown et al., 2008; Roe et al., 2010) and SDT (Brown et al., 2009; Holding et al., in press), and to investigate possible correlation between aberrant movements and behaviors and a reduction in thermoregulatory effectiveness, we decided to determine how LDT affects a suite of behaviors, 
movements, spatial use, and energy demands. We hypothesized that LDT results in increased movements and spatial use, decreased body condition, an increase in defense behaviors, and an increase in behaviors associated with increased movements. We predicted that the act of LDT would be associated with an increase in mean distance moved per day, total distance moved, and activity range size, as well as a reduction in body mass and body condition. Furthermore, we predicted that translocated snakes would be visible more often, be found moving more often, have a greater percentage of their bodies sunlit, and would rattle, tongue-flick, and flee more often. As for the thermal analyses, these predictions were applied to a comparison of control and translocated snakes, post-translocation, as well as a comparison within the translocated group, pretranslocation to post-translocation.

\section{MATERIALS AND METHODS}

\section{Study Area}

Two sites on Vandenberg Air Force Base (VAFB), in California, U.S.A., were utilized. The two sites were chosen based on the criteria of maximizing distance and subjective habitat similarity between them (see Appendix for photos). However, beyond a comparison of the average thermal quality of microhabitats at each site (see below description of $\mathrm{d}_{\mathrm{e}}$ ), habitat similarity was not quantified. Site one (N 34.60887, $\mathrm{W}$ $120.52702^{\circ}$ ) was located on south base, at the southern end of Arguello Road, Santa Barbara County, California. That site mostly consisted of grassy, rolling hills interspersed with rock outcroppings. Various species of thistle and mustard dominated the vegetation. 
Site two (N $34.87266^{\circ}, \mathrm{W}-120.60091^{\circ}$ ) was located on north base, approximately 1,500 meters heading $19^{\circ}$ northeast from the intersection of Cuatro Road and Point Sal Road. A large complex of rock outcropping at the top of a hill dominated the center of site two, which also consisted of rolling hills. Rock outcroppings were also present on adjacent hills, and the site was primarily vegetated with wild mustard. Sites one and two served respectively as control and translocation sites and were separated by a straight-line distance of 30 kilometers.

\section{Study Snakes}

Nineteen adult male $C$. oreganus (snout to vent length range: $77-98 \mathrm{~cm}$, mean $=$ $84.8 \mathrm{~cm}, \mathrm{SD}=5.3 \mathrm{~cm}$ ) were captured during visual searches at site one between 19 April 2012 and 9 July 2012. Upon capture, each snake was transported to the Physiological Ecology of Reptiles Laboratory (PERL) at California Polytechnic State University, San Luis Obispo, California, U.S.A. There, the snakes were anesthetized by way of isoflurane (Halocarbon Production Corp., U.S.A.) inhalation and intracoelomically implanted with temperature data-loggers (Thermochron iButton, models DS 1921G and DS 1922L, Maxim Intergrated, San Jose, California, USA) and 11 gram or 13.5 gram radiotransmitters (model SI-2, Holohil Systems Ltd., Carp, Ontario, Canada). While snakes were under anesthesia, snout to vent length (SVL) and body mass were recorded. Additionally, the snakes were given an individual three color code by injecting paint into three of the rattle segments. Following surgery, snakes were given approximately 15-24 hours to recover, and were then released at site one at the exact locations where they were found. 
Once returned to the field, each snake was tracked via radio telemetry. Prior to translocation (see below), all snakes were tracked every other day, while after translocation, all snakes were tracked every day. The snakes were tracked at various times during daylight hours, with tracking order reversed on every other tracking day. Little snake activity was observed on several night tracking days. This observation, coupled with low night time temperatures (typically $5-18^{\circ} \mathrm{C}$ ) on VAFB, leads us to believe that we sufficiently documented the primarily diurnal activity of our study animals. At the end of the study, the snakes were again captured, brought into the laboratory, placed under isoflurane anesthesia, and the iButtons were surgically and their data downloaded. Body mass data were again collected at this time. This occurred on September $7^{\text {th }}$ for translocated snakes and September $8^{\text {th }}$ for control snakes. Due to one field mortality, one unexplained disappearance, and three irretrievable snakes, the sample size was reduced to $\mathrm{N}=14$ individuals $(\mathrm{n}=7$ control snakes and $\mathrm{n}=7$ translocated snakes). All snake losses, fatal or not, occurred prior to translocation. The problematic status of the one disappearance and two of the irretrievable snakes was determined well before the translocation experiment, so those snakes were excluded from treatment group assignment. The status of the one fatality (control group) and one of the irretrievable snakes (translocated group) was determined just prior to translocation. Collection and experimental use of the snakes were authorized by the California Department of Fish and Game (\# SC-8159) and California Polytechnic State University (IACUC protocol \#1203). 


\section{Translocation}

Translocation from site one to site two was considered a LDT procedure, since the $30 \mathrm{~km}$ distance between the two sites far exceeds the greatest previously utilized minimum LDT distance $(8 \mathrm{~km})$ for other species of rattlesnakes (Reinert and Rupert, 1999; Hardy et al., 2001). Furthermore, our translocation distance far exceeds the average total distance moved $(365.2 \mathrm{~m} \pm 61.9)$ by all of our study snakes during the period prior to translocation, as well as the average total distance moved $(2470.3 \mathrm{~m} \pm 283.4)$ by $C$. oreganus of another nearby population during the spring mating season when they actively search for mates (Putman et al., 2013). Thus, the spring mating season is a time when the snakes are expected to be most active. Seven snakes $(n=7)$ were selected for translocation to site two in late August of 2012, as two snakes had not moved from a large outcropping for several months, were not retrievable, and were presumed dead. Seven snakes $(n=7)$ were kept as controls at site one. Selection for translocation was a semi-random process: Following the initial random selection of these snakes, and prior to commencing any translocations, two pairs of snakes were randomly chosen to be switched between groups for the purpose of equalizing snake body mass and SVL between groups. This occurred in a sequential fashion, with two switches being the least number necessary.

Translocations began on 25 August 2012, 45 days after the last study snake was released in the field, and ended on 29 August 2012. Two snakes were translocated on 25 August, three on 26 August, one on 28 August, and one on 29 August. Translocated snakes were transported inside cloth bags in buckets and released at site two into suitable covered habitat (rocks or bushes) at the edge of the large central complex of rock 
outcroppings. In order to decrease the likelihood of interactions between snakes, release locations were separated by distances of 24-75 m. Due to the disparity in translocation dates, the snakes were tracked for a range of nine to 13 days at site two before their recapture on 7 September 2012.

\section{iButton Calibration}

Prior to surgical implantation, all 19 iButtons were calibrated against a reference thermometer (Omega HH509R digital with K-type thermocouple). Four water baths (Fisher Isotemp 205) were set up at $1{ }^{\circ} \mathrm{C}, 15^{\circ} \mathrm{C}, 30^{\circ} \mathrm{C}$, and $40^{\circ} \mathrm{C}$, with the goal of encompassing the expected range of snake $\mathrm{T}_{\mathrm{b}}$ in the field. The range of recorded uncalibrated field $\mathrm{T}_{\mathrm{b}}$ was $11-37.6^{\circ} \mathrm{C}$ (calibrated: $10.9-37^{\circ} \mathrm{C}$ ). The $0^{\circ} \mathrm{C}$ and $15^{\circ} \mathrm{C}$ baths were obtained using ice as a cooling agent, while the $30^{\circ} \mathrm{C}$ and $40^{\circ} \mathrm{C}$ baths were obtained using electrical heating. All iButtons and the reference thermometer were suspended on cheesecloth so that they did not touch the sides of the water baths. The iButtons were placed with the more sensitive side oriented upward, fully exposed to the water, while the less sensitive side rested on the cheese cloth (van Marken Lichtenbelt et al., 2006). An exposure period of 19 minutes was used for each temperature treatment, with a two minute acclimation time allowed before the start of each data collection period.

Average temperatures were calculated for each iButton and the reference

thermometer during each temperature treatment. Since the two iButton models differed in thermal resolution, all iButton temperatures were rounded to the lowest resolution of $0.5^{\circ} \mathrm{C}$ prior to averaging. A linear regression was then carried out for each iButton, with the goal of predicting the temperature of the reference thermometer from the temperature 
of the iButton (Davidson et al., 2003). This yielded a correction equation for each iButton, which was then applied to field-recorded snake $\mathrm{T}_{\mathrm{b}}$ 's.

\section{Snake Body Temperature $\left(T_{b}\right)$}

The surgically implanted iButtons were programmed to record $\mathrm{T}_{\mathrm{b}}$ every two hours. Again, prior to application of the correction equations, all recorded $\mathrm{T}_{\mathrm{b}}$ data were rounded to a resolution of $0.5^{\circ} \mathrm{C}$, the resolution of the least accurate iButton model that was used. Two $T_{b}$ datasets were compiled, one pre-translocation and one posttranslocation. Due to three iButton malfunctions, the sample size for $T_{b}$ and all related metrics was further reduced to $\mathrm{N}=11$ individuals. The pre-translocation dataset spanned the period from 12 July 2012 (the day after the last of the 18 snakes was released after surgery) to 24 August 2012 (the day prior to translocation). The post-translocation data set spanned the period from the day after a snake was released, following blood sample collection, until 6 September, the day before the translocated snakes were re-captured. Due to a lack of complete daily $\mathrm{T}_{\mathrm{b}}$ data for all snakes, 7 and 8 September and were excluded from the dataset. Mean $T_{b}$, mean daily maximum $T_{b}$, and mean daily minimum $\mathrm{T}_{\mathrm{b}}$ were calculated for each snake.

\section{Operative Temperature $\left(T_{e}\right)$}

Operative temperature $\left(T_{e}\right)$ data, approximating the equilibrium $T_{b}$ distribution of non-thermoregulating snakes, were required to assess the effectiveness of thermoregulation (Hertz et al., 1993; Blouin-Demers and Weatherhead, 2001). In order to collect $\mathrm{T}_{\mathrm{e}}$ data, physical operative temperature models (OTMs) were placed in the 
field. Each OTM consisted of a copper pipe with an iButton (model DS-1922L) suspended inside, using a cage of minimally conductive material. Each iButton was programmed to record $\mathrm{T}_{\mathrm{e}}$ every 30 minutes. To prevent air flow, the ends of each OTM were sealed with wads of aluminum foil and glue. The diameter and length of the OTMs closely matched those of a coiled adult $C$. oreganus, and the external surface of the OTMs was painted to match the reflectance of $C$. oreganus (Peterson et al., 1993; Blouin-Demers and Weatherhead, 2001). In early August, 16 OTMs were placed at each of the two sites, with the goal of encompassing the entire $T_{e}$ range during all hours of the day (Peterson et al., 1993). In order to control for diel patterns in the distribution of solar radiation across the landscape, the 16 OTMs were equally split between north and south facing slopes at each site. Two OTMs were then placed in each of four microhabitats, pre-selected as the main exposed (on dirt, on rocks) and sheltered (in burrows, under rocks) microhabitats at each site. The OTMs placed on dirt or rocks were exposed to full sunlight, while those under rocks or in burrows were always fully shaded. Our goal was to encompass the upper and lower bounds of the $\mathrm{T}_{\mathrm{e}}$ range, thus we chose a balance of microhabitats that we believed would reflect those bounds.

\section{Field-selected Body Temperature Range $\left(T_{\text {sel }}\right)$}

The assessment of thermoregulatory effectiveness also requires the estimation of the preferred $\mathrm{T}_{\mathrm{b}}$ range of the species under study (Hertz et al., 1993; Blouin-Demers and Weatherhead, 2001). The preferred $\mathrm{T}_{\mathrm{b}}$ range is often estimated using the interquartile range of $\mathrm{T}_{\mathrm{b}}$ 's selected by snakes in a laboratory thermal gradient (Hertz et al., 1993; Christian and Weavers, 1996; Blouin-Demers and Weatherhead, 2001). However, while 
captivity may relieve snakes of ecological influences on $T_{b}$, snakes may behave unnaturally when brought into captivity (Hertz et. al., 1993). Thus, we calculated the interquartile range of the $\mathrm{T}_{\mathrm{b}}$ 's of our 11 study animals from the beginning of the study (July $12^{\text {th }}$ ) until the day before translocation (August $24^{\text {th }}$ ) as field-selected body temperature $\left(\mathrm{T}_{\mathrm{sel}}\right)$. While field $\mathrm{T}_{\mathrm{b}}$ may be influenced by such factors as shedding of the integument, feeding status, mating seasons, and weather fluctuations, we believe that the long-term nature of the utilized dataset mitigates such influences.

\section{Index of Thermoregulatory Effectiveness $\left(d_{e}-d_{b}\right)$}

The index $\left(\mathrm{d}_{\mathrm{e}}-\mathrm{d}_{\mathrm{b}}\right)$ proposed by Blouin-Demers and Weatherhead (2001) was adopted for the assessment of thermoregulatory effectiveness. The accuracy of a snake's $T_{b}$ is quantified by $d_{b}$, the deviation of $T_{b}$ from $T_{\text {sel. }}$. The accuracy of the $T_{b}$ of a theoretical non-thermoregulating snake, which chooses microhabitats at random, is quantified by $d_{e}$, the deviation of average $T_{e}$ from $T_{\text {sel }}$. In essence, $d_{e}$ approximates the average thermal quality of microhabitats at a site. Daily $d_{b}$ values were calculated for each snake, by averaging the absolute values of the deviations of the bihourly $\mathrm{T}_{\mathrm{b}}$ measurements from the upper or lower limit of $\mathrm{T}_{\text {sel. }}$. Similarly, daily $\mathrm{d}_{\mathrm{e}}$ values were calculated for each site by averaging the absolute values of the deviations of each OTM's $\mathrm{T}_{\mathrm{e}}$ measurements from the upper or lower limit of $\mathrm{T}_{\text {sel. }}$. Daily indices were then calculated for each snake as the difference between that snake's $d_{b}$ value and the site's $d_{e}$ value. Thus, a positive value of the index implies thermoregulation, a value of zero implies random selection of microhabitats irrespective of their thermal quality, and a negative value implies avoidance of thermally favorable microhabitats (Blouin-Demers and Weatherhead, 2001). 
In the analyses of $d_{e}, d_{b}$, and the index of thermoregulatory effectiveness, daily averages were further averaged to obtain condensed values for individual snakes or each of the two field sites ( $\mathrm{d}_{\mathrm{e}}$ only).

Body Mass Change and Body Condition Index (BCI)

An effect of LDT on change in body mass over the course of the study was investigated. Snout-vent length was evaluated as a potential covariate. Using the initial and final mass values, a body condition index (BCI) was calculated for each snake. Residuals from a linear regression of natural log transformed initial snake mass on natural log transformed SVL served as initial BCI values. To obtain final BCI value, the predicted values from that regression were then subtracted from the natural log transformed snake body masses at the conclusion of the study (Nowak et al., 2002; Taylor et al., 2005; Brown et al., 2009).

\section{Spatial Ecology}

Each time a snake was located, GPS coordinates were recorded using a GPSmap 60CSx or eTREX Vista GPS unit (Garmin, Olathe, Kansas, USA). Accuracy for GPS locations (reported by the unit) varied from roughly three to ten meters. Using ArcGISVersion 9.0 (ESRI, Redlands, CA, U.S.A.), mean distance moved per day, total distance moved, and a 100\% minimum convex polygon (MCP) activity range were calculated for each snake during two periods, before and after translocation. The "before" period was the 12 days prior to translocation (13-24 August), and the "after" period was the 12 days after translocation (26 August -7 September). Body condition index and 
SVL were investigated as possible covariates in the spatial analyses, along with their potential two-way and three-way interactions, after it was found that LDT did not affect those variables (see Results).

\section{Behaviors}

Each time a snake was located, several behavioral variables were recorded. When possible, snakes were observed from a distance of greater than two meters in order to minimize the influence of the researcher. First, whether or not the snake was visible was recorded. Using radio telemetry, we were able to locate each snake within approximately a one meter radius, and visual searches were extensive, so we believe that this variable served as a useful surrogate for determining whether or not a snake was above or below ground. For each snake a relative frequency of visibility was calculated as the ratio of the number of times the snake was seen divided by the number of times the snake was located. Separate ratios were calculated for the period prior to translocation and for the period following translocation.

If a snake was seen, then additional behavioral parameters were recorded. The amount of the snake's dorsum that was sunlit was subjectively scored to the nearest $5 \%$, if not $0 \%$ or $100 \%$. Then, an average percentage sunlit was calculated for each snake, before and after translocation. Other recorded behaviors included whether or not the snake was moving or stationary, and if the snake rattled, tongue-flicked, or fled upon approach. Fleeing was only recorded if the snake was first observed while stationary but then showed a clear commencement of movement away as the researcher approached. Relative frequencies were calculated for all of these behaviors as the number of times the 
behavior occurred divided by the number of occasions during which the snake was seen. Again, separate ratios were calculated for the period prior to translocation and for the period following translocation. In all behavioral analyses, the average time of day during which a snake was located was investigated as a covariate. Since sightings of rare behaviors are expected to be positively correlated with the snake visibility relative frequency, the latter was also assessed as a possible covariate.

\section{Data analysis}

Unless otherwise noted, all analyses were repeated-measures ANOVA. To facilitate analysis, all daily values of response variables were condensed into means for two time periods, before translocation and after translocation. The time term in the analyses of activity range size, mean distance moved per day, and total distance moved was possibly confounded by the tracking frequency, and thus should be treated with caution. Due to the inequality in the number of days tracked that each snake was tracked during the period following translocation, especially within the translocated group, linear regression models were used to test for correlations between all spatial parameters and the number of days tracked post-translocation. Transformations (natural log or square, plus or minus a constant if necessary) of the response variable were carried out as necessary (all spatial analyses, mean daily maximum $T_{b}, d_{b}$, mean percent sunlit) to meet the assumptions of normality (assessed visually and via the Shapiro-Wilk test) and equality of variances (assessed visually and via Bartlett's and Levene's tests). Data presented in figures and as effect sizes ( \pm 1 standard error of the mean) are untransformed, while the test statistics and P-values presented in tables are for 
transformed data. Post-hoc pair-wise comparisons (Tukey's HSD, $\alpha=0.05$ ) were only carried out following a significant F-test result for the treatment group by time interaction, since only two groups were compared in all main effects tests. All analyses

were carried out using JMP Pro 10.0.1 (SAS Institute Inc., Cary, North Carolina, U.S.A.).

\section{RESULTS}

\section{Snake $T_{b}$}

The treatment group by time interaction was not significant in the analysis of mean $\mathrm{T}_{\mathrm{b}}$, and there was no significant main effect of time or treatment group (Table 1). For the analysis of mean daily minimum $\mathrm{T}_{\mathrm{b}}$, no significant treatment group by time interaction was found, and there was no significant main effect of time or of treatment group (Table 1). In the analysis of mean daily maximum $T_{b}$, the treatment group by time interaction was not significant, nor was the main effect of treatment group. However, there was a significant main effect of time, with mean daily maximum $\mathrm{T}_{\mathrm{b}}$ being $2.2^{\circ} \mathrm{C}$ higher $\left(30.88^{\circ} \mathrm{C} \pm 0.16\right.$ vs. $\left.28.70^{\circ} \mathrm{C} \pm 0.56\right)$ before translocation than after translocation (Table 1, Figure 1).

\section{Index of Thermoregulatory Effectiveness and Related Variables}

The interquartile range of field selected body temperatures, $\mathrm{T}_{\text {sel }}$, ran from $19.6^{\circ} \mathrm{C}$ to $27.4^{\circ} \mathrm{C}$. In the analysis of mean $\mathrm{d}_{\mathrm{b}}$, the time by treatment group interaction was not significant, and there was no significant main effect of treatment group. However, the main effect of time was significant (Table 2, Figure 2), with mean $d_{b}$ being $0.6^{\circ} \mathrm{C}$ higher 
$\left(1.33^{\circ} \mathrm{C} \pm 0.12\right.$ vs. $\left.0.75^{\circ} \mathrm{C} \pm 0.18\right)$ before than after translocation. A pooled variance twosample $t$-test comparing average microhabitat $d_{e}$ means found no significant difference between the two sites, meaning that the thermal quality of the two sites did not differ (Table 2). The treatment group by time interaction was not significant when analyzing mean indices of thermoregulatory effectiveness, nor was the effect of treatment group. However, there was a marginally significant effect of time, with the index being $0.3^{\circ} \mathrm{C}$ higher $\left(3.21^{\circ} \mathrm{C} \pm 0.10\right.$ vs. $\left.2.87^{\circ} \mathrm{C} \pm 0.16\right)$ after translocation (Table 2, Figure 3 ).

\section{Body Mass Change and BCI}

With SVL as a significant covariate, the time by treatment group interaction and the main effect of group, were not significant in the analysis of body mass. However, there was a significant effect of time, with mean body mass being $119 \mathrm{~g}$ higher $(567.00 \mathrm{~g} \pm$ 26.27 vs. $447.99 \mathrm{~g} \pm 17.51$ ) before translocation (Table 3, Figure 4). The analysis of BCI showed similar results, with no significant time by treatment group interaction and no significant main effect of group, but a significant main effect of time, with mean BCI being higher $(0.00 \pm 0.03$ vs. $-0.23 \pm 0.03)$ at the beginning of the study than at the end of the study (Table 3, Figure 5).

\section{Spatial Ecology}

Due to interindividual inequality in the number of days tracked, during the posttranslocation period, especially within the translocated group, linear regressions were carried out, in order to investigate correlations between all spatial parameters and the number of days tracked. In all cases, one snake was excluded from the data set, since it 
was visually an outlier in terms of all spatial parameters (see below) and its inclusion precluded satisfaction of the assumptions of parametric statistics (i.e. assumption violations could not be rectified via data transformation). Nonetheless, inclusion of the outlier did not affect the significance of any of the regression F-tests. No significant correlation was found between activity range size, mean distance moved per day, or total distance moved with the number of days tracked during the period following translocation (Table 4).

In the analysis of $100 \% \mathrm{MCP}$ activity ranges, the treatment group by time interaction was significant, as were the main effects of time and treatment group (Table 5). Tukey's HSD test found no difference between the two treatment groups before translocation, but, after translocation, the two groups diverged, with translocated snakes having 29 times greater ( 1.74 ha \pm 1.10 vs. 0.06 ha \pm 0.02$) 100 \%$ MCP activity ranges than control snakes (Figure 6). The divergence was driven by a significant average decrease in the control group's activity range sizes, while no significant time change was observed for the translocated group. An average increase in the translocated group was offset by a great amount of individual variation (Figure 6), with the SD in the translocated group being multiplied by a factor of 4.2 over time ( 2.92 versus 0.69 ha). Additionally, post-translocation, the standard deviation of the translocated group (2.92 ha) was 73 times larger than for the control group (0.04 ha). This individual variation was primarily driven by an outlier in the translocated group, post-translocation. One of the seven translocated snakes had an activity range of 8.17 ha, which was roughly four times larger than the next largest activity range in that group (mean without outlier $=0.67$ ha, $\mathrm{SE}=0.31)$. Removal of that outlier changed the significance of the treatment group by 
time interaction and the main effect of group (Table 5, Figure 7). However, mean 100\% MCP size was still roughly 11 times greater $(0.67$ ha \pm 0.31 vs. 0.06 ha \pm 0.02$)$ in the translocated group than in the control group, during the post-translocation period. A significant main effect of time remained (Table 5, Figure 7), with MCP size being 2.6 times greater ( 0.89 ha \pm 0.20 vs. 0.34 ha \pm 0.16$)$ before translocation. However, it can be seen in Figure 7 that the control group decreased more drastically, and 19 times more variation was still present in the translocated group $(\mathrm{SD}=0.76 \mathrm{ha})$ than in the control group $(\mathrm{SD}=0.04$ ha), post-translocation.

An interaction model with $\mathrm{BCI}$ and the $\mathrm{BCI}$ by treatment group interaction was used in the mean distance moved per day, since the two-way interaction was significant (Table 5). The treatment group by time interaction was not significant, and there was no significant main effect of group, but the main effect of time was found to be significant (Table 5, Figure 8), with mean distance moved per day being twice as great $(53.56 \mathrm{~m} /$ day \pm 9.69 vs. $26.52 \mathrm{~m} / \mathrm{day} \pm 7.91$ ) before translocation. The outlier in the MCP data was influential in the distance moved per day data set as well, though not significantly so (Table 5, Figure 9). Though, the outlier represented the only snake in either of the two treatment groups to increase in mean distance moved per day, and the increase was large $(88 \%)$. Without the outlier included, mean distance moved per day for the translocated group decreased by $58 \%$.

The analysis of total distance moved required an interaction between $\mathrm{BCI}$ and treatment group (Table 5). The main effect of BCI was included to maintain model hierarchy, though it was not significant. The treatment group by time interaction was not significant, nor were the main effects of treatment group and time (Table 5). However, 
the two groups did diverge over time, as expected. The translocated group increased, on average, while the control group decreased, on average (Figure 10). The analysis was also carried out without the outlier that was influential in the MCP analysis. After translocation, the outlier moved $1452.3 \mathrm{~m}$, an increase of $318 \%$ of the pre-translocation total distance moved, while, without the outlier, the translocated group, on average, moved $281.3 \mathrm{~m}(\mathrm{SE}=55.4)$ meters post-translocation, decreasing by $30 \%$ of the pretranslocation total distance moved. Removal of the outlier did not change the significance of any of the experimental model terms. However, the trends in the data changed, with both groups decreasing over time, on average, in total distance moved per day (Figure $11)$.

\section{Behaviors}

Several behaviors (rattling, tongue-flicking, fleeing, and movement, if seen) happened so infrequently that reasonable analyses of the data were precluded. The frequencies for many snakes were zero, and the assumptions of parametric statistics could not be met. Regardless, as it can be seen in Figures 12-15, there were no detectable differences between groups or times. Analyses of frequency of visibility and percent sunlit if seen were possible, however. For the frequency of visibility, the treatment group by time interaction was marginally significant (Table 6). However, Tukey's HSD posthoc testing found no significant differences between groups at either or the two times, or within groups, over time. Nonetheless, the trend was for the translocated snakes to increase in frequency of visibility from before to after translocation, while the control snakes decreased slightly (Figure 16). Thus, post-translocation, the translocated group 
was visible nearly 1.8 times as often $(0.50 \pm 0.08$ vs. $0.27 \pm 0.06)$ as the control group.

For the percentage of body sunlit, the treatment group by time interaction was significant (Table 6). Tukey's HSD tests found that the control group decreased significantly over time (2.8 times greater before translocation, $28.49 \% \pm 3.83$ vs. $10.23 \% \pm 3.22$ ), while the translocated group did not significantly change. A significant difference between the treatment groups was also found prior to translocation, with the control group being 2.9 times $(28.49 \% \pm 3.83$ vs. $9.67 \% \pm 3.03)$ more sunlit (Figure 17).

\section{DISCUSSION}

Our hypothesis that LDT disrupts thermoregulation was not supported, as the interaction between treatment group and time was not significant for any of the thermal analyses. No effect of LDT was found on mean, daily maximum, and daily minimum $T_{b}$, $T_{b}$ accuracy $\left(d_{b}\right)$, and an index of thermoregulatory effectiveness. As we predicted, the average thermal quality of the four measured microhabitats $\left(d_{e}\right)$ did not differ between the two sites. While we did not quantify and compare microhabitat availability at our two sites, we chose to measure thermally extreme microhabitats, which presumably represent the upper and lower bounds of the $\mathrm{T}_{\mathrm{e}}$ range. Thus, we believe that other less thermally extreme microhabitats are also similar in regards to $\mathrm{T}_{\mathrm{e}}$ when compared between the two sites. Our results suggest that, provided that average microhabitat thermal quality is well matched between source and translocation sites, $C$. oreganus maintains a similar thermoregulatory effectiveness following LDT, at least within two weeks posttranslocation, a time during which the novelty of the translocation site is likely to elicit 
aberrancy in movements, microhabitat use, and thus thermoregulation. Butler et al. (2005) found that, during a month when over half of the translocated snakes were released, the disparity in distance moved between resident and translocated snakes was greatest. Our results corroborate those of Roe et al. (2010), who found that LDT did not affect the $\mathrm{T}_{\mathrm{b}}$ of Northern Water Snakes (Nerodia s. sipedon) when they were tracked for an entire year (active season through hibernation). Roe et al. (2010) found that the translocated N. s. sipedon maintained their active season $\mathrm{T}_{\mathrm{b}}$ within their preferred $\mathrm{T}_{\mathrm{b}}$ range (interquartile $\mathrm{T}_{\mathrm{b}}$ range from a laboratory thermal gradient, see Brown and Weatherhead, 2000), suggesting that the snakes were effectively thermoregulating. Thus, all evidence to date suggests that LDT does not impact snake thermoregulation.

However, while our study and that of Roe et al. (2010) provide encouraging support for the robustness of effective thermoregulation in the aftermath of LDT, both studies are not without their unique limitations. Roe et al. (2010) sampled $\mathrm{T}_{\mathrm{b}}$ only once per week during the active season and once every two weeks during hibernation ingress and they did not analyze a formal index of thermoregulatory effectiveness. Thus, due to infrequent $T_{b}$ sampling and no quantification of impact of LDT on thermoregulatory effectiveness, it is possible that Roe et al. (2010) failed to detect an effect of LDT. Unlike a study on Timber Rattlesnakes (C. horridus) in the temperate forests of Pennsylvania (Reinert and Rupert, 1999), we did not find a significant effect of LDT on mean distance moved per day and total distance moved. Reinert and Rupert (1999) found that, during their first active season following LDT, when compared with resident males, translocated male $C$. horridus exhibited nearly a three fold increase in total distance moved and more than three times the mean distance moved per day. Their male sample 
size was similar to ours, with six translocated males being compared to seven control males. Additionally, an LDT study on Australian Tiger Snakes (Notechis scutatus) found a significant difference mean distance travelled per movement between translocated and resident snakes, with translocated snakes moving more than twice as far on average. Eight (four males and four females) translocated snakes and with six (four males and two females) residents were studied for over a year (Butler et al., 2005). Thus, had we observed a more extreme effect of LDT on movements, we may have observed an effect of LDT on thermoregulation. However, considerable variation in mean distance moved per day and total distance moved did exist in our data, and when each was included as a covariate in the analysis of thermoregulatory effectiveness it was not found to be significant. While the significance of our activity range analysis hinged on the inclusion of one outlier, the average activity range size for our translocated snakes was over 11 times greater than for control snake during the post-translocation period, even after removal of the outlier. Reinert and Rupert (1999) found a similar (ten fold) difference in activity range size between translocated and control snakes. Thus, we observed no effect of LDT on thermoregulation in spite of arguably elevated spatial use.

While no significant interactions were detected in any of the thermal analyses, indicating that the control and translocated snakes did not change differently over time, it can be seen in Figures 1 and 2 that the control group decreased to a greater degree in mean daily maximum $T_{b}$ and mean $d_{b}$. The translocated snakes were also found above ground more often than the control snakes post-translocation. Though this behavioral difference was only marginally significant, it was obvious to us in the field, and may have had physiological influence that translated into the observed differences in daily 
maximum $T_{b}$ and $d_{b}$ during the post-translocation period. We cautiously interpret these data due to the low sample sizes for this study, especially for the control group in the thermal analyses. Additionally, the fact that the untransformed standard error for the translocated snakes was actually greater than that for the control snakes in the analyses of $d_{b}$ and thermoregulatory effectiveness, post-translocation, suggests a considerable amount of individual variation in $\mathrm{d}_{\mathrm{b}}$ and thermoregulatory effectiveness in response to translocation.

The main effect of time on mean daily maximum $T_{b}$, mean $d_{b}$, and the index of thermoregulatory effectiveness was unexpected and highlights the importance of the control group in this study. Mean daily maximum $\mathrm{T}_{\mathrm{b}}$ and $\mathrm{d}_{\mathrm{b}}$ decreased with time while thermoregulatory effectiveness increased, and the trends may be related for the three variables. Average maximum $\mathrm{T}_{\mathrm{b}}$ decreased, across both groups, from $30.9^{\circ} \mathrm{C}$ to $28.6^{\circ} \mathrm{C}$, converging on the upper range of $\mathrm{T}_{\text {sel }}, 27.4^{\circ} \mathrm{C}$. Since no significant concomitant changes were observed in mean daily minimum $T_{b}$ and overall mean $T_{b}$, the decrease in average daily maximum $\mathrm{T}_{\mathrm{b}}$ may have been associated with an overall reduction in deviations from $T_{\text {sel }}$, and thus a net reduction in $d_{b}$. The lack of a difference in $d_{e}$ between the two sites would have thus resulted in a net increase in thermoregulatory effectiveness. Such an increase over time, which was marginally significant, can be seen in Figure 3. The time trend in the thermal analyses is peculiar in light of the lack of a significant overall time reduction in the proportion of snake sightings above ground, and the percentage of body sunlit, when a snake was seen. The observed trends in $T_{b}, d_{b}$, and thermoregulatory effectiveness could be related to seasonal trends in behavior and physiology, especially pertaining to reproduction. Crotalus oreganus, including a nearby population on 
Chimineas Ranch in the Carrizo Plain Ecological Reserve in central California, mates and undergoes spermatogenesis in late summer, coinciding with the timing of our study (Aldridge, 2002; Lind et al., 2010). An alternative hypothesis explaining the observed time trend in maximum $T_{b}$ and $d_{b}$ is that there was an effect of the capture, handling, and blood sampling, which took place immediately before translocation for all snakes.

However, such a phenomenon would be unlikely in light of the finding that weekly shortdistance translocations of $C$. oreganus similarly had no significant effects on a suite of physiological parameters and behaviors (Holding et al., in press).

Our second hypothesis, that LDT results in increased movements, spatial use, and energy demands, was partially supported. No effect of LDT was found on mean distance moved per day, total distance moved, body mass, or BCI, showing that LDT in this study did not increase movements or energy demands to the point where body reserves declined. However, a significant divergence in spatial use, indicated by $100 \%$ MCP activity range sizes, between the translocated and control groups was associated with translocation (Figure 6). The significance of the time divergence in activity range size between the two groups was nullified by removal of an outlier. After removal of the outlier, the two groups were no longer found to diverge over time in activity range size (Figure 7). Additionally, we observed an expected, though non-significant, trend in the total distance moved data, wherein the translocated group increased over time while the control group decreased (Figure 10). However, this trend was driven by the same outlier snake, being the only one to increase greatly over time in total distance moved. A significant decrease over time was observed in mean distance moved per day, both with and without the outlier (Figures 8 and 9). It is possible that the decrease in movement and 
activity range (minus the outlier), over time, were, like the time trend in the thermal analyses, correlated with reproductive phenology or behavioral modification as a result of capture, handling, and blood sampling.

However, even after removal of the outlier, the translocated snakes showed a lesser decrease in activity range over time than the control group, suggesting that translocation did counteract the time trend in activity range size. The high amount of individual variation in MCP size within the translocated group, relative to the control group, post-translocation, likely contributed to this phenomenon (Figure 6). Even with removal of the outlier, a large amount of that variation remained. It can be seen that, minus the outlier, the variation in the translocated group, post-translocation, was similar to that in both treatment groups, pre-translocation, while the variation in the control group, post-translocation, was much lower (Figure 7). Clearly, something had affected the control snakes. High individual variability in activity range size may be a natural thing for C. oreganus, as Putman et al. (2013) observed such variability in a population on Chimineas Ranch.

Overall, the results of the spatial analyses demonstrate that LDT may not always affect the spatial ecology of rattlesnakes to the degree shown by Reinert and Rupert (1999). In that study, described above, every metric of spatial use and movements was significantly increased for translocated snakes. Like ours, a study by Nowak et al. (2002) on $C$. atrox in the Sonoran Desert of Arizona failed to find strong evidence for an increase in movements and spatial use following LDT. Four snakes (three males and one female) were translocated in 1995 and three snakes (two males and one female) were translocated in 1996. In each instance, the snakes were followed from August through 
December and the translocation distance was $2 \mathrm{~km}$, which is described as LDT but defined by Hardy and Greene (1999) as SDT. Like ours, it was a BACI study, with translocated snakes being compared both with themselves (pre-translocation) and to a dedicated control group of identical size. Due to individual variation in $100 \% \mathrm{MCP}$ activity range size following LDT (four individuals greatly increased while two decreased), LDT was not found to significantly impact activity range size. Along the same lines, the outlier in our spatial analyses demonstrates that individual responses to LDT in movement and spatial use can vary, though not to the same degree seen by Nowak et al. (2002). In congruence with our findings, total distance moved was not found to be affected by LDT. Mean distance moved per day was found to differ between the two treatment groups following translocation and within the translocated group, from before to after translocation. However, this was only true for the 1995 translocations, but not for the 1996 translocations. Individual variation, small sample sizes (thee or four snakes), and environmental variation were possible causes for the interannual difference in results. Our findings are further supported by Plummer and Mills (2000), who studied LDT of Eastern Hognose Snakes (Heterodon platirhinos) in open forest in Arkansas. Eight control snakes were compared with eight translocated snakes. Each snake was monitored for one active season (April to October). The translocated snakes showed no difference in mean distance moved per day relative to controls. The average life expectancy of translocated snakes during an active season was roughly one third that of controls, although mortality was the same in the two groups. This suggests that mean distance moved per day may not be a good gauge of translocation success, at least in regards to survivorship. Due to the short-term nature of our study, any conclusions, 
comparisons, and generalizations based on the results of our spatial analyses should be treated with caution. All of the aforementioned studies on LDT of snakes have been of a more long-term nature, following the study animals for at least one active season. Had we tracked the two groups longer, post-translocation, we may have observed a greater difference between them, at least in MCP size. In addition to disparities in tracking duration and interspecific and interpopulational variation, interannual and interseasonal climatic variation and variation between age classes in responses to LDT make generalization and comparisons between studies difficult.

While our finding that LDT does not affect body mass and BCI agrees with the findings of other studies on LDT in snakes (Reinert and Rupert, 1999; Nowak et al., 2002), the significant main effect of time on body mass and BCI may be cause for concern. The average mass loss for the snakes was over 100 grams, a figure which is undoubtedly biological significant, when the average initial mass of 567 grams is considered. It seems odd for such a drastic decrease in body condition to have happened during the active season, and it is possible that radio transmitter and iButton implantation hindered the snakes in some major way. This seems unlikely in light of the fact that the implanted radio transmitters and iButtons never exceeded $4 \%$ of snake body mass, which is considered a low-risk value (Beck, 1995; Hardy and Greene, 1999; Dugan et al., 2008). While we can only speculate, it is possible that other extrinsic biotic and abiotic factors may have been at play. For instance, it may have been an exceptionally dry summer, prey population sizes or activity may have been reduced, or a combination of the two may have affected snake body condition. However, it should be reiterated that our two groups 
did not change differently in body mass or BCI over time, thus the considerable changes were not due to LDT.

Our study is one of the first to quantify the effects of LDT on behaviors recorded while tracking the snakes in the field. Some of the behaviors (tongue flicking, fleeing, rattling, moving) occurred too infrequently to meet the assumptions of parametric statistical analysis. However, a qualitative assessment of those data leads to the conclusion that there was no effect of LDT: snakes rarely exhibited these behaviors regardless of whether or not they were translocated. The marginal significance of the treatment group by time interaction in the analysis of snake visibility was not supported by post-hoc testing, suggesting that LDT does not affect the time snakes spend above ground. This agrees with the finding that LDT of Northern Water Snakes (Nerodia s. sipedon) did not affect surface activity during the active season (Roe et al., 2010). However, due to natural differences in behavior and habitat between $C$. oreganus and $N$. s. sipedon, an intertaxonomic difference in the effect of LDT on surface activity is plausible. Additionally, disparity in the frequency of behavioral observations and study duration may have accounted for the differing results. Roe et al. (2010) observed their translocated snakes once per week during an entire active season while we observed our snakes daily for less than two weeks post-translocation. The observed trend in our data (Figure 16) showed the predicted effect of translocation, suggesting that LDT is associated with snakes spending more time above ground, and the trend was noticeable in the field. If we had a larger sample size, we may have indeed observed a statistically significant effect of LDT on this behavior. While a significant time by treatment group interaction was found for the analysis of percent body sunlit, this was mostly driven by a 
decrease over time in the control group, while the increase in the translocated group was small (Figure 17). This suggests that the act of translocation did not impact this behavior either. However, the large decrease over time, within the control group, is peculiar, and may be related to the possible lurking variables posited to explain the time trends in the spatial and thermal analyses. Thus, we conclude that LDT did not affect any of the recorded behaviors. This conclusion matches that of Holding et al. (in press), who found that SDT on a nearby population of $C$. oreganus also failed to affect frequency of the same behaviors. As ambush predators, rattlesnakes rely on crypsis, not only to find food, but to avoid predation. Since visual detectability, the amount of a snake's body sunlit, and the propensity to tongue-flick, rattle, or flee after a disturbance are all related to crypsis, we conclude that crypsis in $C$. oreganus is apparently robust to both SDT and LDT, provided that the animals are translocated to a suitable environment.

While the importance of integrating physiology into conservation biology (Stevenson, 2006; Tracy et al., 2006; Wikelski and Cook, 2006) and the importance of translocation to reptile conservation (Dodd and Seigel, 1991; Germano and Bishop, 2008) have been well established, few studies have related thermal biology to reptile translocations (Besson and Cree, 2010; Roe et al., 2010; DeGregorio et al., 2012). This study is one of two to examine the direct effect of translocation (either SDT or LDT) on reptile thermoregulation (Roe et al., 2010). Our results are encouraging, in that we found no effect of LDT on snake $\mathrm{T}_{\mathrm{b}}$ and thermoregulatory effectiveness. However, the effects of our translocation on spatial ecology were not as extreme as those of other studies Reinert and Rupert, 1999; Butler et al., 2005) in that spatial use, but not movement, was affected, and we studied a population of rattlesnakes in a relatively thermally benign 
geographic locality, during the active season. The climate in coastal central California is less seasonally variable than it is for inland populations, with neither summers nor winters experiencing extreme temperatures. Thus, more aberrant spatial use and movements, coupled with more extreme temperatures, could result in a reduction in thermoregulatory effectiveness. Additionally, no mortality was observed in our translocated snakes, so any opportunity to investigate a correlation between mortality and a reduction in thermoregulatory effectiveness was precluded. Reinert and Rupert (1999) found that the increased mortality in Timber Rattlesnakes (Crotalus horridus) that were subjected to LDT was largely associated with overwintering in a geographic area with harsh winters. In areas with harsh, cold winters, during which temperatures may drop below the freezing point, it is more crucial that snakes find shelter, and locating suitable shelter may be more difficult, as a snake may have to travel deeper under the surface to insulate itself. The same could be true for desert animals, which, during the summer, may regularly be driven to their critical thermal maxima if deep shelter is not found. Thus, harsh weather may greatly exacerbate any negative effects of aberrant movements and spatial use on $\mathrm{T}_{\mathrm{b}}$ and thermoregulatory effectiveness, putting snakes in serious risk of mortality. The difficulty of finding a suitable hibernaculum in localities with harsh winters may be the driving force behind the high hibernaculum fidelity exhibited by both colubrids and viperids at high latitudes (Prior et al., 2001; Harvey and Weatherhead, 2006; Smith et al., 2009), even with long (663-781 meters on average) dispersal distances from the hibernaculum (Brown and Parker, 1976). This high hibernaculum fidelity could contribute to increased and aberrant movements and spatial use, as translocated snakes struggle to find their way back to their usual hibernaculum, rather than attempting to 
locate a novel one. Consequently, the success of LDT procedures may not only depend on matching habitats and environments between source and translocation sites, but also on the severity and variability of environmental temperatures that translocated snakes are exposed to. Roe et al. (2010) studied N. s. sipedon at a locality where winters are harsh. They observed elevated mortality in LDT snakes relative to control snakes, but observed no difference in $\mathrm{T}_{\mathrm{b}}$ between the two groups. However, the source of the observed mortality was unclear and an effect of LDT on $\mathrm{T}_{\mathrm{b}}$ was not tested for during the winter hibernation period. Monthly thermal analyses were only conducted through the active season until October, during the hibernation ingress period. Nonetheless translocated $N$. s. sipedon tended to be more surface active late in the year, during the hibernation ingress period (October), perhaps in search of their former hibernacula, but did not differ from controls in $T_{b}$. Thus, the literature has yet to establish that harsh winters negatively impact LDT success, though it seems likely. In conclusion, our results suggest that behavior and thermoregulation in rattlesnakes are not impacted by LDT, at least in the short-term. We advocate further study, potentially over longer time periods and in a variety of climates to determine how snakes are affected by the common management practice of translocation. 


\section{THE EFFECTS OF LONG-DISTANCE TRANSLOCATION ON ENDOCRINE STRESS PHYSIOLOGY IN THE WESTERN RATTLESNAKE (CROTALUS}

OREGANUS)

\section{INTRODUCTION}

Translocation, or the relocation of wild animals within their former or current natural range, has long been a popular tool for the management of a wide variety of wildlife including snakes (Dodd and Seigel, 1991; Cope and Waller, 1995; Fischer and Lindenmayer, 2000; Lenain, 2001; Germano and Bishop, 2008; Kingsbury and Attum, 2009; Troy, 2013). The mitigation of human-snake conflict through the relocation of nuisance animals is the primary motivation behind snake translocation (Hardy et al., 2001; Nowak et al., 2002; Butler et al., 2005; Kingsbury and Attum, 2009). However, now that snake declines are being documented (Kingsbury and Attum, 2009), translocation is increasingly being used as a conservational tool, to augment a current population to increase its viability or to create a new population in a part of a species' historical range (Plummer and Mills, 2000; King et al., 2004; Kingsbury and Attum, 2009; Roe et al., 2010). Since translocation is likely to remain a popular management tool, especially for venomous snakes, it is crucial that its effect on subject animals be further studied.

Snake translocations fall into two categories, short-distance and long-distance. Short-distance translocation (SDT) is defined as relocation of a snake within its home range, while long-distance translocation (LDT) relocates a snake outside of its home 
range (Hardy et al., 2001). Both are useful management tools, but each comes with its own unique tradeoffs, with either the animals or management efforts being potentially negatively affected. SDT tends to have minimal effects on snake spatial ecology, and no effect on stress physiology, behavior, or mortality (Brown et al., 2008; Brown et al., 2009 , Holding et al., in press). Therefore, SDT is generally advocated. However, the usefulness of SDT is limited, since snakes frequently return to the initial capture area, sometimes within as little as one day (Hardy et al., 2001; Brown et al., 2008; Brown et al., 2009, Holding et al., in press). Additionally, the usefulness of SDT is likely limited to mitigation of human-snake conflict, excluding conservation efforts such as population augmentation and re-establishment of extirpated populations. In contrast to SDT, LDT has been demonstrated to prevent the return of snakes to their initial capture area, and it may be useful for population level conservation efforts as well as human-snake conflict mitigation (Reinert and Rupert, 1999; King et al., 2004; Butler et al., 2005; Brown et al., 2008). However, LDT is generally not recommended as a management strategy, as snakes moved outside their home ranges typically show elevated rates of mortality, an increased magnitude and frequency of movements, and increased activity range sizes (Reinert and Rupert, 1999; Nowak et al., 2002; Butler et al., 2005; Roe et al., 2010). Increased movements and spatial use may result in greater exposure to predators and increased energy demands and may reflect a behavioral strategy to minimize the stress associated with introduction to a novel environment, as the animal searches for its original home range (Drugan et al., 1997; Dickens et al., 2010). In defense of LDT, the effects on spatial ecology can be less severe for some individuals (Nowak et al., 2002), and in some studies, the magnitudes and frequencies of movements (Plummer and Mills, 
2000; Nowak et al., 2002), mortality (Butler et al., 2005; Brown et al., 2008), surface (above ground) activity and body temperature (Roe et al., 2010) are unaffected. Additionally, body mass, body condition, and growth rate have, whenever monitored, been found to be unaffected (Reinert and Rupert, 1999; Nowak et al., 2002; Roe et al., 2010), and the source of observed mortality is sometimes unclear (Nowak et al., 2002; Brown et al., 2008). Apparently, the consequences of LDT for snakes are complex and other variables, especially those pertaining to physiology, may be at play. Fully understanding those consequences, and the mechanisms behind them, is crucial when it comes to weighing the costs and benefits of translocation and assessing whether or not it is a tractable conservation management strategy for a given species or population.

One impact of LDT, with potentially far-reaching physiological consequences, is the effect of LDT on snake stress physiology. Elevated blood plasma concentration of corticosterone (CORT), the primary glucocorticoid hormone of reptiles, has been commonly used as an indicator of physiological stress, a snake's physiological response to potentially harmful stimuli. More generally, stress encompasses an organism's behavioral response as well (Moore et al., 1991; Jones and Bell, 2004; Bailey et al., 2009; Tokarz and Summers, 2011; Drake et al., 2012). In response to an acute stressor, a rapid elevation in circulating concentrations of CORT can benefit the animal by mobilizing energy stores and shifting physiological processes to best cope with the stressor. However, chronically elevated CORT concentrations can become detrimental to the animal (Dickens et al., 2010), as prolonged elevation of CORT can result in immunosuppression (Dhabhar and McEwen, 1997; French et al., 2007; Dickens et al., 2010), decreased cognitive abilities (Bodnoff et al., 1995; McEwen and Sapolsky, 1995; 
de Kloet et al., 1999; Mendl, 1999) and decreased secretion of reproductive hormones, such as testosterone (T) in male reptiles (Moore et al., 1991; Manzo et al., 1994; Moore et al., 2000a; Moore and Jessop, 2003; Jones and Bell, 2004; Tokarz and Summers, 2011). Thus, chronic physiological stress can result in trade-offs that adversely affect fitness. As previously discussed, chronic stress may be linked to increased movements by translocated animals (Drugan et al., 1997; Dickens et al., 2010), and a chronically stressed animal may respond differently, physiologically, to an acute stressor. For instance, the CORT response to an acute stressor (the increase in CORT over baseline concentration) is often enhanced in chronically stressed animals (Dickens et al., 2010).

Translocation exposes animals to several potential stressors, including capture, handling, transportation, and introduction to a novel environment. Additionally, habituation to the novel environment may not happen quickly. Thus, translocation has the potential to generate conditions of chronic stress, where CORT concentrations remain elevated for some time (Dickens et al., 2010). One previous study with Northern Pacific Rattlesnakes (Crotalus oreganus) did not find any effect of repeated SDT, either on baseline blood concentrations of CORT or T, or on the response of CORT or T to an acute stressor, suggesting a lack of chronic stress and no impairment of reproduction (Holding et al., in review). However, no such study has yet been carried out on LDT in rattlesnakes or any other squamate reptile.

Our main goal in this study was to test the hypothesis that LDT results in a condition of chronic physiological stress in Crotalus oreganus, a member of the Western Rattlesnake clade. Rattlesnakes were translocated at Vandenberg Air Force Base near Lompoc, California, USA. This geographic locations falls within the intergrade zone 
between the Southern Pacific Rattlesnake (C. o. helleri) and the Northern Pacific Rattlesnake (C. o. oreganus) (Klauber, 1949; Schneider, 1986; Douglas et al., 2002; Stebbins, 2003), so our study animals will henceforth be referred to as $C$. oreganus. A 'Before-After Control-Impact' (BACI) experimental design was used, with a dedicated control group, but also with the translocated group serving as control prior to the act of translocation. We used baseline CORT concentration and the CORT response to an acute stressor as metrics of chronic stress. We predicted that snakes subjected to LDT would exhibit higher baseline CORT and a greater CORT response relative to control snakes. We also predicted that, for the translocated snakes, both baseline CORT and the CORT response would be greater post-translocation, when compared to these same measures pre-translocation.

We also investigated the effects of translocation on movements, spatial use, and testosterone (T), a metric of reproductive ability in males. Elevated $\mathrm{T}$ is associated with mating behavior and spermatogenesis in several rattlesnake species and other pit vipers (Schuett, 1997; Schuett et al., 2002; Taylor et al., 2004; Schuett et al., 2005; Graham et al., 2008; Lind et al., 2010). In garter snakes (Thamnophis sp.), T may not be required to elicit reproductive behavior, but it is still associated with spermatogensis (Moore and Lindzey, 1992) and thus reproduction. Physiological stress from LDT may reduce T concentrations, and may also be associated with an increase in mean distance moved per day, total distance moved, and activity range size, as well as a reduction in body mass and body condition. Again, these predictions apply to a comparison of translocated snakes with control snakes, as well as a comparison within the translocated group, posttranslocation versus pre-translocation. We also hypothesized that there is a negative 
relationship between CORT and $\mathrm{T}$ in $C$. oreganus. Such a relationship has been demonstrated in baseline CORT and T concentrations in the Timber Rattlesnake $(C$. horridus) (Lutterschmidt et al., 2009) and in stressed concentrations in other squamate reptiles (Moore et al., 1991; Manzo et al., 1994; Moore et al., 2000a; Jones and Bell, 2004). We therefore predicted that we would find such a relationship in baseline and stressed concentrations of the two steroid hormones, as well as their response to the acute stressor, regardless of whether or not the snakes were translocated.

\section{MATERIALS AND METHODS}

\section{Study Area}

Two sites on Vandenberg Air Force Base (VAFB), in California, U.S.A., were utilized. The two sites were chosen based on the criteria of maximizing distance and subjective habitat similarity between them (see Appendix for photos). However, beyond a comparison of the average thermal quality of microhabitats at each site (see description of $d_{e}$ in Chapter 1), habitat similarity was not quantified. Site one (N 34.60887, W $120.52702^{\circ}$ ) was located on south base, at the southern end of Arguello Road, Santa Barbara County, California. That site mostly consisted of grassy, rolling hills interspersed with rock outcroppings. Various species of thistle and mustard dominated the vegetation. Site two ( $\mathrm{N} 34.87266^{\circ}, \mathrm{W}-120.60091^{\circ}$ ) was located on north base, approximately 1,500 meters heading $19^{\circ}$ northeast from the intersection of Cuatro Road and Point Sal Road. A large complex of rock outcropping at the top of a hill dominated the center of site two, which also consisted of rolling hills. Rock outcroppings were also present on adjacent 
hills, and the site was primarily vegetated with wild mustard. Sites one and two served respectively as control and translocation sites and were separated by a straight-line distance of 30 kilometers.

Study Snakes

Nineteen adult male $C$. oreganus (range: $77-98 \mathrm{~cm}$ snout to vent length, mean $=$ $84.8 \mathrm{~cm}, \mathrm{SD}=5.3 \mathrm{~cm}$ ) were captured during visual searches at site one between 19 April 2012 and 9 July 2012. Upon capture, each snake was transported to the Physiological Ecology of Reptiles Laboratory (PERL) at California Polytechnic State University, San Luis Obispo, California, U.S.A. There, the snakes were anesthetized by way of isoflurane (Halocarbon Production Corp., U.S.A.) inhalation and intracoelomically implanted with temperature data-loggers (Thermochron iButton, models DS $1921 \mathrm{G}$ and DS 1922L, Maxim Intergrated, San Jose, California, USA) and 11 gram or 13.5 gram radiotransmitters (model SI-2, Holohil Systems Ltd., Carp, Ontario, Canada). While snakes were under anesthesia, snout to vent length (SVL) and body mass were recorded. Additionally, the snakes were given an individual three color code by injecting paint into three of the rattle segments. Following surgery, snakes were given approximately 15-24 hours to recover, and were then released at site one at the exact locations where they were found.

Once returned to the field, each snake was tracked via radio telemetry. Prior to translocation (see below), all snakes were tracked every other day, while after translocation, all snakes were tracked every day. The snakes were tracked at various times during daylight hours, with tracking order reversed on every other tracking day. 
Little snake activity was observed on several night tracking days. This observation, coupled with low night time temperatures (typically $5-18^{\circ} \mathrm{C}$ ) on VAFB, leads us to believe that we sufficiently documented the primarily diurnal activity of our study animals. At the end of the study, the snakes were again captured, brought into the laboratory, placed under isoflurane anesthesia, and the iButtons were surgically retrieved and their data downloaded. Body mass data were again collected at this time. This occurred on September $7^{\text {th }}$ for translocated snakes and September $8^{\text {th }}$ for control snakes. Due to one field mortality, one unexplained disappearance, and three irretrievable snakes, the sample size was reduced to $\mathrm{N}=14$ individuals $(\mathrm{n}=7$ control snakes and $\mathrm{n}=7$ translocated snakes). All snake losses, fatal or not, occurred prior to translocation. The problematic status of the one disappearance and two of the irretrievable snakes was determined well before the translocation experiment, so those snakes were excluded from treatment group assignment. The status of the one fatality (control group) and one of the irretrievable snakes (translocated group) was determined just prior to translocation. Collection and experimental use of the snakes were authorized by the California Department of Fish and Game (\# SC-8159) and California Polytechnic State University (IACUC protocol \# 1203).

\section{Translocation}

Translocation from site one to site two was considered a LDT procedure, since the $30 \mathrm{~km}$ distance between the two sites far exceeds the greatest previously utilized minimum LDT distance $(8 \mathrm{~km})$ for other species of rattlesnakes (Reinert and Rupert, 1999; Hardy et al., 2001). Furthermore, our translocation distance far exceeds the average 
total distance moved $(365.2 \mathrm{~m} \pm 61.9)$ by all of our study snakes during the period prior to translocation, as well as the average total distance moved $(2470.3 \mathrm{~m} \pm 283.4)$ by $C$. oreganus of another nearby population during the spring mating season when they actively search for mates (Putman et al., 2013). Thus, the spring mating season is a time when the snakes are expected to be most active. Seven snakes $(n=7)$ were selected for translocation to site two in late August of 2012, as two snakes had not moved from a large outcropping for several months, were not retrievable, and were presumed dead. Seven snakes $(n=7)$ were kept as controls at site one. Selection for translocation was a semi-random process: Following the initial random selection of these snakes, and prior to commencing any translocations, two pairs of snakes were randomly chosen to be switched between groups for the purpose of equalizing snake body mass and SVL between groups. This occurred in a sequential fashion, with two switches being the least number necessary.

Translocations began on 25 August 2012, 45 days after the last study snake was released in the field, and ended on 29 August 2012. Two snakes were translocated on 25 August, three on 26 August, one on 28 August, and one on 29 August. Translocated snakes were transported inside cloth bags in buckets and released at site two into suitable covered habitat (rocks or bushes) at the edge of the large central complex of rock outcroppings. In order to decrease the likelihood of interactions between snakes, release locations were separated by distances of 24-75 m. Due to the disparity in translocation dates, the snakes were tracked for a range of nine to 13 days at site two before their recapture on 7 September 2012. 


\section{Hormone Sampling}

Just prior to translocation and again at the conclusion of the study blood was collected from all 14 snakes for the purpose of quantifying plasma concentrations of $\mathrm{T}$ and CORT. Blood was collected from the caudal vein with heparinized syringes. During each of the two sampling periods (before translocation: 25-28 August 2012; after translocation: 7-8 Sept 2012), two samples were collected, the first to obtain baseline hormone concentrations and the second after the application of an acute stressor, to measure hormonal stress reactivity. We collected baseline blood samples as quickly as possible (mean $=3.78 \mathrm{~min}$, range $1-12 \mathrm{~min}$ ). Bleed time was recorded to be evaluated as a covariate in the analysis of baseline hormone concentrations. Following collection of the baseline blood sample, snakes were subjected to an acute stressor in the form of one hour of restraint in a cloth bag inside an opaque 9.5 liter plastic bucket (Holding et al., in press). Blood samples were stored in an opaque bag, out of sunlight, while in the field. Even with high environmental temperatures $\left(40^{\circ} \mathrm{C}\right.$ for up to 24 hours before centrifugation), Taylor and Schuett (2004) suggest that such treatment does not impact steroid hormones. Samples were then refrigerated at approximately $4^{\circ} \mathrm{C}$. Within 24 hours of collection, all samples were centrifuged to separate the plasma, which was stored at $20^{\circ} \mathrm{C}$.

\section{Radioimmunoassay}

Plasma CORT and T concentrations were quantified using a standard radioimmunoassay procedure, following extraction and chromatographic separation (Lind et al., 2010). A volume of $10 \mu \mathrm{l}$ of plasma was used in all instances. For individual 
extraction efficiency determination, we equilibrated each sample overnight with 2,000 counts per min (CPM) of tritiated steroid. Each sample was extracted with $5 \mathrm{ml}$ of distilled dichloromethane with the dichloromethane phase removed and dried in a warm water bath, under a stream of nitrogen gas, and re-suspended in 10\% ethyl acetate in isooctane. For the removal of neutral lipids and isolation of individual steroids, all samples were transferred to diatomaceous earth (Celite, Sigma) columns for chromatographic separation. Neutral lipids and other steroids were eluted with $2 \mathrm{ml}$ of isooctane and discarded. Testosterone and CORT were eluted with either $2 \mathrm{ml}$ of $20 \%$ ethyl acetate in isooctane, or $2.5 \mathrm{ml}$ of $50 \%$ ethyl acetate in isooctane, respectively. Samples were then dried in a $40^{\circ} \mathrm{C}$ water bath under nitrogen gas, re-suspended in $600 \mu 1$ phosphate buffered saline, and maintained overnight at $4^{\circ} \mathrm{C}$.

Individual extraction efficiency for each steroid was determined from $100 \mu \mathrm{l}$ of the sample while $200 \mu \mathrm{l}$ of the sample was allocated to each of two duplicates for the assay. Mean recoveries were $60.36 \%$ for $\mathrm{T}$ and $58.12 \%$ for CORT. Serial dilutions for the standard curves were performed in triplicate $(\mathrm{T}$ curve range $=500-1 \mathrm{pg}$; CORT curve range $=2000-4 \mathrm{pg})$. All samples were incubated overnight with $100 \mu \mathrm{l}$ of antiserum $(\mathrm{T}$ : T-3003, Wien Laboratories, Succasunna, NJ; CORT: Esoterix Endocrinology, Calabasas Hills, CA) and $100 \mu \mathrm{l}$ of tritiated $\left({ }^{3} \mathrm{H}\right)$ steroid. Unbound steroid was separated using dextran-coated charcoal and the bound steroid decanted into scintillation vials. Samples were counted on a liquid scintillation counter and final concentrations corrected for individual extraction efficiency. Intra-assay coefficients of variation (CV) were 3.04\% for $\mathrm{T}$ and $11.33 \%$ for CORT. 


\section{Hormone Analysis}

The baseline sample from one snake (snake \#12), before translocation, was lost while in the field. However, the other data for that snake were used in all hormone analyses. Due to time constraints on the duration of the study, two snakes (one each from the translocated and control groups) had to be dug up from burrows in order to obtain the second set of blood samples. Thus, unless noted otherwise, all analyses that incorporated the experimental variables (group, time, group by time interaction) were carried out with and without these two animals, in order to determine if the circumstances involved in the sampling of these snakes had any effect on the analyses. It was determined that the exclusion affected only the results for baseline CORT (without $\mathrm{T}_{\mathrm{b}}$ covariate) and baseline T. So, in those cases, results are presented with and without the exclusion. However, it should be noted that the exclusion did not affect the significance of the effect of translocation.

We investigated the effects of translocation on baseline and stressed (after application of the acute stressor) CORT and T, as well as the CORT and T response to the acute stressor. The response was calculated as the magnitude of change from baseline to stressed concentrations. Additionally, for baseline and stressed concentrations, as well as the stress response, we investigated a possible relationship between CORT and T.

\section{Body Mass Change and Body Condition Index (BCI)}

The influence of LDT on snake body mass and body condition index (BCI) was evaluated. See Chapter 1 for more description. 


\section{Spatial Ecology}

See Chapter 1 for a description of the methods.

\section{Data Analysis}

Unless otherwise noted, all analyses were repeated-measures ANOVA. In the analyses of CORT and T, time of blood sampling and the nearest body temperature $\left(\mathrm{T}_{\mathrm{b}}\right)$ measurement prior to blood sampling were investigated as possible covariates. Body temperature has been shown to affect baseline and stressed CORT in Children's Pythons (Antaresia childreni) (Dupoué et al., 2013) and diel variation in baseline CORT is common in vertebrates, including reptiles such as Carolina Anoles (Anolis carolinensis) (Summers and Norman, 1988) and Marine Iguanas (Amblyrhynchus cristatus) (Woodley et al., 2003). Additionally, CORT is known to influence T in squamate reptiles (Moore and Jessop, 2003), including rattlesnakes (Taylor et al., 2004; Lutterschmidt et al., 2009). Therefore, sampling $\mathrm{T}_{\mathrm{b}}$ and sampling time could affect $\mathrm{T}$ as well. Due to faulty iButton temperature data-loggers (see Chapter 1 methods), inclusion of the $T_{b}$ covariate reduced the sample size by three snakes. Thus, in cases where the $T_{b}$ covariate was found to be significant, the results are presented both with and without the covariate.

A mixed effects regression model was used to investigate a possible relationship between CORT and $\mathrm{T}$ within both the baseline samples and stressed samples, and as the response change between these testing conditions. Individual snake was included as a random effect in order to account for dependence between repeated measures, and CORT was the explanatory variable while $\mathrm{T}$ was the response variable. Transformations (natural $\log$, square root, or cube root) of the response variable were carried out as necessary 
(hormone and spatial analyses) to meet the assumptions of normality (assessed visually and via the Shapiro-Wilk test) and equality of variances (assessed visually and via Bartlett's and Levene's tests). All presented data (tables and figures) are untransformed. Post-hoc pair-wise comparisons (Tukey's HSD, $\alpha=0.05$ ) were only carried out following a significant F-test result for the treatment group by time interaction, since only two groups were compared in all main effects tests.

For the analysis of activity range size, mean distance moved per day, and total distance moved, several candidate models that investigated possible correlations with CORT and $\mathrm{T}$ concentrations were evaluated using the Akaike Information Criterion, corrected for small samples (AICc) (Burnham and Anderson, 2002). Snake \#12's pretranslocation data were excluded from the analyses when they were compared via AICc because we lost the pre-translocation baseline blood sample. Since models can only be compared if they utilize the exact same dataset, this exclusion was necessary. The two snakes that were dug up were included in all cases in which AICc values were calculated. Models were deemed to be comparable (i.e. equally well supported as the best model, of those compared) if their $\Delta \mathrm{AICc}$ was $\leq 2.0$. There was some support for models with a $\Delta \mathrm{AICc} \leq 4.0$ and considerably less support for models with greater $\Delta \mathrm{AICc}$ values, with those having a value > 10.0 having essentially no support (Burnham and Anderson, 2002). The full experimental models (including treatment group, time, and the treatment group by time interaction) were evaluated, with and without significant covariate terms (BCI or SVL, interactions allowed), if applicable. The full experimental models were also evaluated with the addition of CORT, $\mathrm{T}$, and the CORT by $\mathrm{T}$ interaction, one term at a time, in a hierarchical fashion. Finally, CORT, T, and the CORT by T interaction were 
evaluated without any of the experimental variables, but allowing the aforementioned covariates. However, in all models, individual snake was kept as a random variable to account for the dependence in the repeated measures data. Interactions between the potential covariates (BCI or SVL) and CORT or T were not considered. All analyses were carried out using JMP Pro 10.0.1 (SAS Institute Inc., Cary, North Carolina, U.S.A.).

\section{RESULTS}

\section{Corticosterone (CORT)}

In the analysis of baseline CORT (prior to application of the acute stressor), the main effect of group was significant, with the translocated group being 2.3 times higher $(66.70 \mathrm{ng} / \mathrm{ml} \pm 12.98$ vs. $28.98 \mathrm{ng} / \mathrm{ml} \pm 6.56)$ than the control group (Table 7, Figures 18 and 19). The treatment group by time (before or after translocation) interaction and the main effect of time were not significant (Table 7). Though the interaction term was not significant, the divergence in CORT between the two groups was greater after translocation occurred (Figures 18 and 19), with the translocated group being greater. Exclusion of the two snakes that had to be dug up for the final blood sampling changed the main effect of group to being marginally non-significant (Table 7). The significance of the two other experimental model terms was unaffected. Sampling $T_{b}$ was found to be a significant covariate in the analysis of baseline CORT. However, inclusion of the covariate did not alter the significance of any of the experimental model terms (Table 7).

The analysis of stressed CORT (following application of the acute stressor) included baseline CORT and the interaction of baseline CORT and time as significant 
covariate terms (Table 7). Again, there was a significant effect of treatment with stressed CORT concentrations in the translocated group being, on average, 2.4 times higher $(344.68 \mathrm{ng} / \mathrm{ml} \pm 43.99$ vs. $145.29 \mathrm{ng} / \mathrm{ml} \pm 32.86)$ than in the control group (Figures 18 and 20), but no effect of time or treatment by time interaction (Table 7). Both sampling $\mathrm{T}_{\mathrm{b}}$ and sampling time were found to be significant covariates in the analysis of stressed CORT. Their inclusion nullified the significance of the baseline CORT term and the baseline CORT by time interaction. Thus, those terms were removed from the model. However, inclusion of sampling $\mathrm{T}_{\mathrm{b}}$ and sampling time did not alter the significance of any of the experimental model terms (Table 7).

The analysis of the CORT response (stressed CORT minus baseline CORT) included baseline CORT and the interaction of baseline CORT and time as significant covariate terms (Table 7). Again, the main effect of treatment group was significant, with the translocated group being, on average, 2.3 times higher $(264.58 \mathrm{ng} / \mathrm{ml} \pm 40.45 \mathrm{vs}$. $116.31 \mathrm{ng} / \mathrm{ml} \pm 28.88$ ) than the control group (Figures 18 and 21 ), while the treatment group by time interaction $\left(F_{1,13.46}=1.78, P=0.2049\right)$ and the main effect of time $\left(F_{1,11.80}\right.$ $=2.38, \mathrm{P}=0.1495)$ were not significant.

\section{Testosterone $(T)$}

In the analysis of baseline $\mathrm{T}$ (prior to application of the acute stressor), the treatment group by time interaction and the main effect of treatment group were significant, while the main effect of time was not significant (Table 8, Figures 22 and 23). Exclusion of the two snakes that had to be dug up for the final blood sampling changed the significance of the main effect of time, but not either of the other two models terms. 
(Table 8). Tukey's HSD post-hoc testing found that the two groups were not significantly different before translocation, while the translocated group had 7.3 times higher (48.63 $\mathrm{ng} / \mathrm{ml} \pm 9.35$ vs. $6.65 \mathrm{ng} / \mathrm{ml} \pm 1.78$ ) baseline $\mathrm{T}$ post-translocation, even though neither group was found to change significantly over time (Table 8, Figures 22 and 23). It should also be noted that individual variation in baseline $\mathrm{T}$ was much greater in the translocated group than the control group, post-translocation.

The analysis of stressed $\mathrm{T}$ (following application of the acute stressor) included baseline $\mathrm{T}$ as a significant covariate. The treatment group by time interaction, the main effect of time, and the main effect of treatment group were not significant (Table 8). While it can be seen in Figures 22 and 24 that there appears to be an interaction, the trends in stressed $\mathrm{T}$ were explained by the very similar trends in baseline $\mathrm{T}$.

In the analysis of the $\mathrm{T}$ response (change from baseline to stressed condition), the treatment group by time interaction, the main effect of time, and the main effect of treatment group were not significant (Table 8). There was a great deal of individual variation in $\mathrm{T}$ response within the translocated group, post-translocation (Figures 22 and 25). While this variation shows a tendency towards a decrease in the $\mathrm{T}$ response following translocation, contrasting with the mild increase observed in the control group, it was largely driven by three snakes, one of which exhibited a large positive $\mathrm{T}$ response $(+17.17 \mathrm{ng} / \mathrm{ml})$, while the other two showed a large negative response $(-13.55,-20.82$ $\mathrm{ng} / \mathrm{ml})$. For perspective, after removal of the aforementioned three snakes, the range of the $\mathrm{T}$ response in the translocated group, post-translocation, was -3.92 to $3.25 \mathrm{ng} / \mathrm{ml}$, with a mean of $-0.31 \mathrm{ng} / \mathrm{ml}$. 


\section{The Relationship between CORT and T}

A significant but weak positive relationship between baseline CORT and baseline

T was found (Table 9, Figure 25), as well as a significant but weak positive relationship between stressed CORT and stressed T (Table 9, Figure 26). The significance of the baseline analysis was largely driven by two influential data points (both translocated snakes, post-translocation). Exclusion of those data points resulted in a non-significant relationship (Table 9, Figure 28). Excluding them from the stressed analysis changed its significance as well (Table 9, Figure 29) though they did not appear to be as influential in the regression plot. No relationship was found between the CORT response and the T response (Table 9, Figure 30). Removal of the aforementioned influential data points did not affect the analysis (Table 9, Figure 31).

\section{Body Mass Change, BCI, and Spatial Ecology Repeated Measures Analyses}

Since there were no significant treatment group by time interactions, neither body mass nor BCI were affected by LDT. See the results section of Chapter 1 for more detail.

\section{Spatial Ecology}

Neither mean distance moved per day or total distance moved were affected by LDT, as indicated by no treatment group by time interactions in Chapter 1. Activity range size was affected by LDT, with the translocated group's 100\% MCP size being 29 times (1.74 ha \pm 1.10 vs. 0.06 ha \pm 0.02$)$ greater than the control group during the posttranslocation period. However, the significance of the effect of LDT on activity range size was nullified by removal of an outlier. See Chapter 1 for more details. 
With inclusion of an outlier in activity range size (snake \#7, see Chapter 1), neither CORT nor T were good predictors of MCP activity range size, with or without the inclusion of the experimental variables. According to AICc, the best model was the experimental model, which only included the treatment group, time, and the treatment group by time interaction. The second best model contained only T, snake, and BCI as variables. Though the effect of $\mathrm{T}$ approached significance, the $\triangle \mathrm{AICc}$ value was 3.55 , and so it was not comparable with the experimental model. The third best model contained CORT, snake, and $\mathrm{BCI}$ as variables, with a $\triangle \mathrm{AICc}$ of 3.71 . The positive effect of CORT was marginally non-significant. See Table 10 for a summary of all models with a $\triangle \mathrm{AICc}$ of 10.0 or less.

With an outlier included in the dataset (snake \#7, see Chapter 1), neither CORT nor $\mathrm{T}$ were good predictors of mean distance moved per day, with or without the inclusion of the experimental variables. According to AICc, the best model included the experimental variables, as well as a main effect of $\mathrm{BCI}$ and an interaction between $\mathrm{BCI}$ and treatment group. The second best model contained only the experimental variables, with a $\triangle \mathrm{AICc}$ value of 2.45 , so it was not comparable with the experimental model. The third and fourth best models contained only snake, BCI and either CORT $(\triangle \mathrm{AICc}=$ $3.42)$ or $\mathrm{T}(\triangle \mathrm{AICc}=4.64)$ as explanatory variables. However, in each of those two models, neither CORT nor T were significant predictors of total distance moved. Thus, there was some support for the second and third best models. See Table 11 for a summary of all models with a $\triangle \mathrm{AICc}$ of 10.0 or less.

Again, with inclusion of an outlier (snake \#7, see Chapter 1), neither CORT nor T were good predictors of total distance moved. The best model was the experimental 
model, with a main effect of BCI and the BCI by treatment group interaction included. A model containing only the experimental variables was comparable $(\triangle \mathrm{AICc}=1.63)$. Models that contained only snake, $\mathrm{BCI}$ and $\mathrm{CORT}(\triangle \mathrm{AICc}=0.27)$ or snake, $\mathrm{BCI}$ and $\mathrm{T}$ $(\triangle \mathrm{AICc}=1.75)$ were also found to be comparable to the best of the assessed models. However, in each of those two models, neither CORT nor T were found to be significant predictors of total distance moved. The next best models, with some support, contained snake and either CORT $(\triangle \mathrm{AICc}=2.30)$ or $\mathrm{T}(\triangle \mathrm{AICc}=3.14)$ as explanatory variables. Again, neither CORT nor T were found to be significant predictors of total distance moved. Since inclusion of a BCI covariate along with either a CORT or T term resulted in better models than if the BCI covariate was excluded, the BCI covariate added more to the model than either CORT or T. See Table 12 for a summary of all models with a $\triangle \mathrm{AICc}$ of 10.0 or less.

\section{DISCUSSION}

We failed to find support for the hypothesis that LDT results in a condition of chronic physiological stress in rattlesnakes. A lack of significant treatment group by time interactions indicated no effect of LDT on baseline CORT, stressed CORT or the response of CORT concentrations to an acute confinement stressor. These results agree with the findings of Holding et al. (in press) who found that repeated SDT did not affect baseline CORT, stressed CORT, or the CORT response in another population of $C$. oreganus. Lending support to the notion that neither repeated SDT nor LDT results in a condition of chronic stress in rattlesnakes, Drake et al. (2012) found that, using a model 
selection approach in a multi-year study, LDT treatment was not a good predictor of baseline CORT in Desert Tortoises (Gopherus agassizii). However, while the rattlesnakes we studied, as well as those studied by Holding et al. (in press), exhibited a pronounced CORT response, Drake et al. (2012) failed to elicit a natural CORT response in $G$. agassizii and had to administer exogenous ACTH to elicit a detectable changes in plasma CORT concentrations. This suggests a difference in sensitivity of the hypothalamicpituitary-adrenal (HPA) axis between Crotalus and Gopherus, bringing into question the generalization of the results of Drake et al. (2012) to rattlesnakes. Interpopulational variation in the CORT response to an acute stressor has been documented in Western Fence Lizards (Sceloporus occidentalis) and the Common Garter Snake (Thamnophis sirtalis) (Dunlap and Wingfield, 1995; Moore et al., 2001; Moore and Jessop, 2003). Thus, it may be difficult to make generalizations at any taxonomic level in reptiles.

Baseline CORT remained essentially constant in the control group, while an increase over time was observed in the translocated group, albeit with a relatively large amount of individual variation in that group, post-translocation. It is possible that, with a greater sample size, or if we had sampled the snakes again at a later date, we would have observed a statistically significant difference in baseline CORT (Figures 18 and 19). It is also possible that natural seasonal variation in CORT may have contributed to a lack of statistical significance in all measures of CORT (baseline, stressed, response). Seasonal variation in CORT has been demonstrated in rattlesnakes, including C. oreganus, with CORT generally being suppressed during the mating season in males (Lutterschmidt $e t$ al.; 2009; Holding et al., in press). Though we did not observe such a phenomenon, the extent of the mating season in VAFB C. oreganus is unclear and seasonal variation in 
CORT associated with mating is context dependent in reptiles and amphibians, not conforming to a single norm (Moore and Jessop, 2003). For instance, in some squamates, baseline CORT is elevated during the breeding season (Wilson and Wingfield, 1992, 1994; Moore et al., 2001).

Our data showed little support for a relationship between baseline CORT concentrations and movements and spatial use. The strongest support came from the total distance moved and 100\% MCP activity range model selection (Tables 10 and 12). However, a model that contained a CORT term was only comparable with the best model for total distance moved. We conclude that the movements and spatial use of our translocated snakes were not related to baseline CORT. Thus, any increased movements and spatial use were not associated with increased energy mobilization or chronic stress. That snake BCI and body mass were not impacted by LDT (see Chapter 1) supports the conclusion that movements and spatial use were not related to CORT, and thus not related to energy mobilization (Moore et al., 2000b). However, the impact of our LDT on movements and spatial use was not as extreme as that observed by Reinert and Rupert (1999) in their study of male Timber Rattlesnakes (C. horridus) in the forests of Pennsylvania (see Chapter 1). Most importantly, we did not observe increased movements in our translocated snakes, while Reinert and Rupert (1999) did. Mobilization of energy stores as a result of increased CORT would be expected to be associated with increased movements, not simply an increased activity range size. In the study by Reinert and Rupert (1999) we would then expect a reduction in snake BCI following translocation (Moore et al., 2000b), yet this was not the case. As a possible explanation for the independence of body condition from movement, Miles et al. (2007) found that in 
Side-blotched Lizards (Uta stansburiana), chronically elevated CORT increased stamina and decreased recovery time following exercise yet decreased resting metabolic rate, perhaps as a means of conserving energy. In this context, if we had observed an increase in the movements of our snakes associated with LDT, a positive relationship between CORT and movements may have occurred, even in the absence of decreased body condition following translocation. Thus, further research on the relationship between movements and baseline CORT is warranted in reptiles, especially in studies of LDT.

We also failed to find support for our prediction that translocation would result in decreased $\mathrm{T}$, as a product of chronic stress. We found a significant increase in baseline $\mathrm{T}$ in translocated snakes (Table 8, Figures 22 and 23). While there appeared to be a similar association for stressed T (Figures 22 and 24), it was non-significant because the variation in stressed $\mathrm{T}$ was explained by baseline $\mathrm{T}$. Though no significant trend was found in the $\mathrm{T}$ response, there was a relatively large amount of individual variation in the translocated group, post-translocation (Figure 25). The baseline T results are most interesting in that, though the translocated and control groups diverged over time, the divergence was the opposite of what we predicted. The reason behind the relationship between elevated baseline $\mathrm{T}$ and LDT may be linked to a positive relationship between $\mathrm{T}$ and spatial learning and memory. It has been demonstrated in mice (Pyter et al., 2006) rats (Sandstrom et al., 2006; Leonard and Winsauer, 2011; Spritzer et al., 2011; McConnell et al., 2012; Hawley et al., 2013) and humans (Janowsky et al., 1994; Moffat and Hampson, 1996; Postma et al., 2000; Silverman et al., 1999; Cherrier et al., 2001; Cherrier et al., 2006; Burkitt et al., 2007) that baseline T is positively correlated with spatial learning and memory (but see Naghdi et al., 2003; Naghdi et al., 2005; 
Khorshidahmad et al, 2012). Even though the impact of LDT on our snakes' movements and spatial use was marginal, the snakes were moving about in a new environment in site two. In contrast to site one, which was likely largely familiar to them, every bit of site two was completely foreign to our translocated snakes. Thus, any movements that the translocated snakes made required them to learn new topography and remember where key beneficial habitat features (e.g., rodent burrows and other suitable cover) were located. Given the observed trends in mammals and the context of LDT, it is possible that the act of navigating through a new environment stimulated the release of $\mathrm{T}$ in our snakes. Unequivocally, further study is needed to elucidate the relationship between baseline $\mathrm{T}$ and spatial learning and memory, especially in reptiles.

The increase in baseline $\mathrm{T}$ associated with LDT raises the question of whether or not baseline $\mathrm{T}$ was correlated with any of the spatial parameters that we quantified. Our best-fit model selection results provided little support for a relationship between baseline $\mathrm{T}$ and any of the measured spatial parameters. For total distance moved, a model that included a non-significant $\mathrm{T}$ term was equally well supported as the best model $(\triangle \mathrm{AICc} \leq$ 2.0) (Table 12). In the case of $100 \%$ MCP activity range size there was some support for a model that included a marginally non-significant $\mathrm{T}$ term (Table 10), while for mean distance moved per day there was little support for a model that contained a nonsignificant $\mathrm{T}$ term (Table 11). Furthermore, of our three movement parameters, only $100 \%$ MCP activity range size increased in association with LDT. Even then, the significance of the relationship depended on the inclusion or exclusion of one snake, which was an outlier in all of the movement analyses (see Chapter 1) Though not presented in our results, exclusion of that same snake from the analysis of baseline $\mathrm{T}$ did 
not change the significance of the effect of LDT. Thus, though there was a clear T increase associated with LDT, there was no clear concomitant increase in movement and spatial use, suggesting that a true relationship between $\mathrm{T}$ and movements and spatial use was unlikely.

Given that male C. oreganus search for their mates (Ashton, 2003; Jenkins and Peterson, 2005; Putman et al., 2013), elevated baseline T is expected to be associated with increased movements and spatial use in this species, but not in the context of translocation. However, it has been shown that natural baseline $\mathrm{T}$ concentrations were positively associated with $100 \%$ MCP activity range size, mean distance moved per day, total distance moved, and maximum distance moved in another population of $C$. oreganus, during the early summer, when mating behavior did not occur (Julius Frazier, unpublished data). However, experimental elevation of baseline T (via exogenous implants), to an average concentration similar to that during a period of spermatogenesis and mating did not increase any of the spatial parameters. A threshold of approximately $70 \mathrm{ng} / \mathrm{ml}$ was observed, beyond which increased $\mathrm{T}$ was not associated with increased movements or activity range size. The average baseline $\mathrm{T}$ concentration of our translocated snakes, post-translocation $(48.6 \mathrm{ng} / \mathrm{ml} \pm 9.4)$, fell between the natural early summer average and that of the snakes with the $\mathrm{T}$ implants, being roughly halfway between the two (Julius Frazier, unpublished data). Based on the average baseline T of our translocated snakes and the threshold concentration (Julius Frazier, unpublished data), it would be expected that baseline T would be positively associated with movements and spatial use in our snakes, yet we found no association. 
Overall, we failed to find support for our prediction that there would be a negative relationship between CORT and T. Instead, we found a weak positive relationship between baseline CORT and T and between stressed CORT and T. However, in both cases, the statistical significance of the relationship between the two hormones was dependent upon the same two snakes, which appeared to be influential points in the analysis of the relationship between baseline $\mathrm{T}$ and CORT. Thus, the biological significance of the relationship between CORT and $\mathrm{T}$ is questionable. The lack of a statistically significant relationship between the response of CORT and T, regardless of snake omission, further supports the biological insignificance of the relationship between CORT and $\mathrm{T}$ in general. While our results go against those of most previous studies (see introduction), the relationship between CORT and T is context dependent and variable in reptiles (Moore and Jessop, 2003). While elevated baseline T may be vital for reproduction, which occurred during our study, and may aid in spatial learning and memory, especially following LDT, an associated elevation of baseline CORT may mobilize energy reserves to fuel exploratory movements or energetically costly reproductive behaviors, such as the mate searching (Ashton, 2003; Moore and Jessop, 2003; Jenkins and Peterson, 2005; Putman et al., 2013). However, we found only weak evidence for relationships between base The positive relationship that we found between baseline CORT and $\mathrm{T}$ is incongruent with the findings of other studies on rattlesnakes, in which a negative relationship (Lutterschmidt $e t$. al., 2009) or no relationship (Taylor $e t$ al., 2004; Holding et al., in press) was found. However, a positive association between baseline CORT and T was found in male Red-spotted Garter Snakes (Thamnophis sirtalis) (Moore et al., 2000b) and in another population of C. oreganus (Julius Frazier, 
unpublished data), though, in the latter case, the trend was marginally non-significant. A positive relationship between baseline CORT and $\mathrm{T}$ has also been found in birds that were administered with exogenous T (Ketterson et al., 1991).

While ours is not the first study of the effects of LDT on stress physiology in reptiles (Drake et al., 2012), it is the first on snakes and the first to investigate a relationship between LDT and steroid hormones associated with reproduction. Our study on $C$. oreganus adds to the general knowledge of how human-wildlife interactions can impact stress physiology, and provides valuable guidance in the mitigation of conflict between this widespread venomous species and humans, with which it frequently comes into contact. By studying some of the same spatial and physiological variables, our study facilitates comparison with other SDT (Brown et al., 2008; Brown et al., 2009; Holding et al., in press) and LDT (Reinert and Rupert, 1999; Nowak et al., 2002; Butler et al., 2005; Brown et al., 2008) studies on snakes, allowing better informed management decisions. Additionally, though C. oreganus is a species of little conservation concern, our results may be tentatively extrapolated to inform management of threatened rattlesnake species, such as Eastern Massasaugas (Sistrurus c. catenatus) and Eastern Diamondbacks (C. adamanteus).

In summary, we did not find any of the predicted effects of LDT on CORT, T, body mass, or BCI. Of the spatial variables, only 100\% MCP activity range size increased as predicted, though the effect of LDT was marginal. In many cases, we may have failed to detect an effect of LDT due to small sample sizes and short study duration. However, studying the effects of LDT over the short-term was our goal, and we demonstrated that $C$. oreganus does not undergo a condition of physiological stress 
during the period immediately following LDT. We found an unprecedented association between LDT and elevated baseline T, which may have been explained by movements, the extent of spatial use, or CORT concentrations. However, the trends in our data showed those explanations to be unlikely. Alternatively, the elevated baseline T may have been a product of increased demands placed on spatial learning and memory by LDT, due to introduction to a totally novel environment. However, no relationship between $\mathrm{T}$ and spatial learning and memory has been investigated in reptiles. Thus, further study is certainly warranted. We also found some evidence for a positive relationship between CORT and $\mathrm{T}$ that is incongruous with other studies on rattlesnakes (Taylor et al., 2004; Lutterschmidt et al., 2009), highlighting the fact that the relationship between CORT and T can vary by season and taxon (Moore et al., 2000a, 2000b; Moore and Jessop, 2003). Due to such variability, coupled with the fact that the HPA axis varies in sensitivity, regarding the magnitude of the CORT stress response, in reptiles (Dunlap and Wingfield, 1995; Moore et al., 2001; Moore and Jessop, 2003; Drake et al., 2012; Holding et al., in press), further study of the effects of LDT on stress and sex steroid hormones in a variety of reptile taxa is warranted. The importance of integrating physiology into conservation biology (Stevenson, 2006; Tracy et al., 2006; Wikelski and Cook, 2006) and the importance of translocation to reptile conservation (Dodd and Seigel, 1991; Germano and Bishop, 2008) have been well established. Given the paucity of studies conducted to date on how translocation affects stress physiology and previous findings that reptiles exhibit considerable variation in their HPA stress reactivity, even within a species (Moore et al., 2000a, 2000b), it is crucial that future studies continue to 
examine the effects of translocation on snakes, especially given that translocation may only increase in prevalence as a management strategy for these and other reptiles. 


\section{TABLES}

Table 1: Results of the repeated measures analysis of snake body temperature $\left(T_{b}\right)$. Two treatment groups (translocated and control) were evaluated at each of two time periods (before and after translocation).

\begin{tabular}{|c|c|c|}
\hline Response variable & Model term & Test statistic and P-value \\
\hline mean $\mathrm{T}_{\mathrm{b}}$ & group*time & $\mathrm{F}_{1,9}=0.75, \mathrm{P}=0.4081$ \\
\hline mean $\mathrm{T}_{\mathrm{b}}$ & group & $\mathrm{F}_{1,9}=0.06, \mathrm{P}=0.8108$ \\
\hline mean $\mathrm{T}_{\mathrm{b}}$ & time & $\mathrm{F}_{1,9}=2.89, \mathrm{P}=0.1231$ \\
\hline mean daily minimum $\mathrm{T}_{\mathrm{b}}$ & group*time & $\mathrm{F}_{1,9}=3.10, \mathrm{P}=0.1120$ \\
\hline mean daily minimum $\mathrm{T}_{\mathrm{b}}$ & group & $\mathrm{F}_{1,9}=0.58, \mathrm{P}=0.4647$ \\
\hline mean daily minimum $\mathrm{T}_{\mathrm{b}}$ & time & $\mathrm{F}_{1,9}=4.03, \mathrm{P}=0.0756$ \\
\hline mean daily maximum $\mathrm{T}_{\mathrm{b}}$ & group*time & $\mathrm{F}_{1,9}=3.11, \mathrm{P}=0.1113$ \\
\hline mean daily maximum $\mathrm{T}_{\mathrm{b}}$ & group & $\mathrm{F}_{1,9}=4.10, \mathrm{P}=0.0736$ \\
\hline mean daily maximum $\mathrm{T}_{\mathrm{b}}$ & time & $\mathrm{F}_{1,9}=19.78, \mathrm{P}=0.0016$ \\
\hline
\end{tabular}


Table 2: Results of a two-sample t-test comparing habitat thermal quality $\left(\mathrm{d}_{\mathrm{e}}\right)$ between our two sites (source and translocation) and repeated measures analyses of snake body temperature accuracy $\left(\mathrm{d}_{\mathrm{b}}\right)$ and an index of thermoregulatory effectiveness. Two treatment groups (translocated and control) were evaluated at each of two time periods (before and after translocation).

\begin{tabular}{|c|c|c|}
\hline Response variable & Model term & Test statistic and P-value \\
\hline $\mathrm{d}_{\mathrm{e}}$ & site & $\mathrm{T}_{14}=0.01, \mathrm{P}=0.9921$ \\
\hline $\mathrm{d}_{\mathrm{b}}$ & group*time & $\mathrm{F}_{1,9}=3.44, \mathrm{P}=0.0964$ \\
\hline $\mathrm{d}_{\mathrm{b}}$ & group & $\mathrm{F}_{1,9}=0.59, \mathrm{P}=0.4623$ \\
\hline $\mathrm{d}_{\mathrm{b}}$ & time & $\mathrm{F}_{1,9}=19.68, \mathrm{P}=0.0016$ \\
\hline thermoregulatory index & group*time & $\mathrm{F}_{1,9}=0.74, \mathrm{P}=0.4122$ \\
\hline thermoregulatory index & group & $\mathrm{F}_{1,9}=0.08, \mathrm{P}=0.7899$ \\
\hline thermoregulatory index & time & $\mathrm{F}_{1,9}=5.27, \mathrm{P}=0.0473$ \\
\hline
\end{tabular}


Table 3: Results of the repeated measures analyses of snake body mass and body condition index (BCI). Two treatment groups (translocated and control) were evaluated at each of two time periods (before and after translocation).

\begin{tabular}{|c|c|c|}
\hline Response variable & Model term & Test statistic and P-value \\
\hline body mass & SVL & $\mathrm{F}_{1,11}=15.77, \mathrm{P}=0.0022$ \\
\hline body mass & group*time & $\mathrm{F}_{1,12}=0.93, \mathrm{P}=0.3548$ \\
\hline body mass & group & $\mathrm{F}_{1,11}=0.31, \mathrm{P}=0.5896$ \\
\hline body mass & time & $\mathrm{F}_{1,12}=54.70, \mathrm{P}<0.0001$ \\
\hline BCI & group*time & $\mathrm{F}_{1,12}=2.52, \mathrm{P}=0.1381$ \\
\hline BCI & group & $\mathrm{F}_{1,12}=0.45, \mathrm{P}=0.5132$ \\
\hline BCI & time & $\mathrm{F}_{1,12}=77.95, \mathrm{P}<0.0001$ \\
\hline
\end{tabular}


Table 4: Results of regression analyses that investigated a relationship between the number of days that our snakes were tracked during the period following translocation, snake movement (mean distance moved per day and total distance moved) and spatial use (100\% MCP activity range).

\begin{tabular}{|c|l|c|}
\hline Response variable & Model term & $\mathbf{R}^{2}$, test statistic and P-value \\
\hline $100 \%$ MCP & days tracked & $\mathrm{R}^{2}=0.02, \mathrm{~F}_{1,1}=0.25, \mathrm{P}=0.6263$ \\
\hline mean distance per day & days tracked & $\mathrm{R}^{2}=0.05, \mathrm{~F}_{1,1}=0.56, \mathrm{P}=0.4710$ \\
\hline total distance & days tracked & $\mathrm{R}^{2}=0.03, \mathrm{~F}_{1,1}=0.30, \mathrm{P}=0.5951$ \\
\hline
\end{tabular}


Table 5: The repeated measures analyses of snake movement (mean distance moved per day and total distance moved) and spatial use (100\% MCP activity range). Two treatment groups (translocated and control) were evaluated at each of two time periods (before and after translocation). The results of the $100 \% \mathrm{MCP}$ analysis are presented both with and without an outlier (snake \#7), since it altered the significance of the results.

\begin{tabular}{|c|c|c|}
\hline Response variable & Model term & Test statistic and P-value \\
\hline $100 \%$ MCP & group*time & $\mathrm{F}_{1,12}=5.80, \mathrm{P}=0.0331$ \\
\hline $100 \% \mathrm{MCP}$ & group & $\mathrm{F}_{1,12}=4.85, \mathrm{P}=0.0479$ \\
\hline $100 \% \mathrm{MCP}$ & time & $\mathrm{F}_{1,12}=8.95, \mathrm{P}=0.0112$ \\
\hline $100 \% \mathrm{MCP}$ (no outlier) & group*time & $\mathrm{F}_{1,12}=4.27, \mathrm{P}=0.0632$ \\
\hline $100 \% \mathrm{MCP}$ (no outlier) & group & $\mathrm{F}_{1,12}=3.29, \mathrm{P}=0.0969$ \\
\hline $100 \%$ MCP (no outlier) & time & $\mathrm{F}_{1,12}=16.42, \mathrm{P}=0.0019$ \\
\hline mean distance per day & BCI*group & $\mathrm{F}_{1,21.16}=5.55, \mathrm{P}=0.0282$ \\
\hline mean distance per day & group*time & $\mathrm{F}_{1,20.66}=1.31, \mathrm{P}=0.2657$ \\
\hline mean distance per day & group & $\mathrm{F}_{1,10.68}=2.53, \mathrm{P}=0.1410$ \\
\hline mean distance per day & time & $\mathrm{F}_{1,20.66}=7.48, \mathrm{P}=0.0125$ \\
\hline total distance & BCI*group & $\mathrm{F}_{1,21.46}=4.72, \mathrm{P}=0.0411$ \\
\hline total distance & group*time & $\mathrm{F}_{1,20.89}=0.94, \mathrm{P}=0.3433$ \\
\hline total distance & group & $\mathrm{F}_{1,10.53}=2.56, \mathrm{P}=0.1391$ \\
\hline total distance & time & $\mathrm{F}_{1,20.89}=1.35, \mathrm{P}=0.2585$ \\
\hline
\end{tabular}


Table 6: Repeated measures analyses of snake behavior. Only analyses of the proportion of instances when a snake was visible and the mean percentage of the snake's body sunlit (if visible) were possible.

\begin{tabular}{|c|c|c|}
\hline Response variable & Model term & Test statistic and P-value \\
\hline visibility & group*time & $\mathrm{F}_{1,12}=5.21, \mathrm{P}=0.0415$ \\
\hline visibility & group & $\mathrm{F}_{1,12}=2.50, \mathrm{P}=0.1399$ \\
\hline visibility & time & $\mathrm{F}_{1,12}=0.33, \mathrm{P}=0.5768$ \\
\hline$\%$ sunlit if seen & group*time & $\mathrm{F}_{1,12}=16.81, \mathrm{P}=0.0015$ \\
\hline$\%$ sunlit if seen & group & $\mathrm{F}_{1,12}=1.87, \mathrm{P}=0.1962$ \\
\hline$\%$ sunlit if seen & time & $\mathrm{F}_{1,12}=2.00, \mathrm{P}=0.1828$ \\
\hline
\end{tabular}


Table 7: Results of the repeated measures analyses of baseline and stressed (after the application of an acute stressor) corticosterone (CORT) and the CORT response (stressed minus baseline). Two treatment groups (translocated and control) were evaluated at each of two time periods (before and after translocation). Significant covariates are included where appropriate.

\begin{tabular}{|c|c|c|}
\hline Response variable & Model term & Test statistic and P-value \\
\hline baseline & group*time & $\mathrm{F}_{1,11.68}=0.26, \mathrm{P}=0.6167$ \\
\hline baseline & group & $\mathrm{F}_{1,11.77}=8.59, \mathrm{P}=0.0128$ \\
\hline baseline & time & $\mathrm{F}_{1,11.68}=0.22, \mathrm{P}=0.6474$ \\
\hline baseline $($ minus two dug up snakes $)$ & group & $\mathrm{F}_{1,9.98}=4.91, \mathrm{P}=0.0510$ \\
\hline baseline $\left(\mathrm{T}_{\mathrm{b}}\right.$ covariate data set $)$ & sampling $\mathrm{T}_{\mathrm{b}}$ & $\mathrm{F}_{1,15.93}=4.66, \mathrm{P}=0.0464$ \\
\hline baseline $\left(\mathrm{T}_{\mathrm{b}}\right.$ covariate data set $)$ & group*time & $\mathrm{F}_{1,9.72}=0.06, \mathrm{P}=0.8078$ \\
\hline baseline $\left(\mathrm{T}_{\mathrm{b}}\right.$ covariate data set $)$ & group & $\mathrm{F}_{1,11.01}=5.06, \mathrm{P}=0.0459$ \\
\hline baseline $\left(\mathrm{T}_{\mathrm{b}}\right.$ covariate data set $)$ & time & $\mathrm{F}_{1,8.60}=0.04, \mathrm{P}=0.8514$ \\
\hline stressed & baseline & $\mathrm{F}_{1,13.12}=23.58, \mathrm{P}=0.0003$ \\
\hline stressed & baseline $*$ time & $\mathrm{F}_{1,16.75}=6.57, \mathrm{P}=0.0203$ \\
\hline stressed & group*time & $\mathrm{F}_{1,13.27}=0.95, \mathrm{P}=0.3479$ \\
\hline stressed & group & $\mathrm{F}_{1,11.24}=10.50, \mathrm{P}=0.0077$ \\
\hline stressed & time & $\mathrm{F}_{1,11.57}=2.17, \mathrm{P}=0.1675$ \\
\hline rtressed $\left(\mathrm{T}_{\mathrm{b}}\right.$ covariate data set $)$ & sampling $\mathrm{T}_{\mathrm{b}}$ & $\mathrm{F}_{1,14.15}=13.08, \mathrm{P}=0.0028$ \\
\hline stressed $\left(\mathrm{T}_{\mathrm{b}}\right.$ covariate data set $)$ & sampling time & $\mathrm{F}_{1,12.21}=9.16, \mathrm{P}=0.0104$ \\
\hline stressed $\left(\mathrm{T}_{\mathrm{b}}\right.$ covariate data set $)$ & group*time & $\mathrm{F}_{1,7.94}=0.07, \mathrm{P}=0.7995$ \\
\hline stressed $\left(\mathrm{T}_{\mathrm{b}}\right.$ covariate data set $)$ & group & $\mathrm{F}_{1,10.08}=6.45, \mathrm{P}=0.0292$ \\
\hline stressed $\left(\mathrm{T}_{\mathrm{b}}\right.$ covariate data set $)$ & time & $\mathrm{F}_{1,8.12}=1.27, \mathrm{P}=0.2918$ \\
\hline response & baseline & $\mathrm{F}_{1,13.17}=13.58, \mathrm{P}=0.0027$ \\
\hline response & baseline $*$ time & $\mathrm{F}_{1,16.67}=7.77, \mathrm{P}=0.0128$ \\
\hline response & group*time & $\mathrm{F}_{1,13.46}=1.78, \mathrm{P}=0.2049$ \\
\hline response & group & $\mathrm{F}_{1,11.41}=10.45, \mathrm{P}=0.0076$ \\
\hline response & time & $\mathrm{F}_{1,11.80}=2.38, \mathrm{P}=0.1495$ \\
\hline
\end{tabular}


Table 8: Results of the repeated measures analyses of baseline and stressed (following the application of an acute stressor) testosterone $(\mathrm{T})$ and the $\mathrm{T}$ response (stressed minus baseline). Two treatment groups (translocated and control) were evaluated at each of two time periods (before and after translocation). Significant covariates are included where appropriate.

\begin{tabular}{|c|c|c|}
\hline Response variable & Model term & Test statistic and P-value \\
\hline baseline & group*time & $\mathrm{F}_{1,12.01}=8.51, \mathrm{P}=0.0129$ \\
\hline baseline & group & $\mathrm{F}_{1,12.29}=11.50, \mathrm{P}=0.0052$ \\
\hline baseline & time & $\mathrm{F}_{1,12.01}=0.94, \mathrm{P}=0.3514$ \\
\hline baseline (minus two dug up snakes) & time & $\mathrm{F}_{1,9.70}=6.28, \mathrm{P}=0.0318$ \\
\hline stressed & baseline & $\mathrm{F}_{1,21.96}=95.50, \mathrm{P}<0.0001$ \\
\hline stressed & group*time & $\mathrm{F}_{1,14.69}=1.64, \mathrm{P}=0.2198$ \\
\hline stressed & group & $\mathrm{F}_{1,14.59}=0.02, \mathrm{P}=0.9002$ \\
\hline stressed & time & $\mathrm{F}_{1,12}=3.81, \mathrm{P}=0.0747$ \\
\hline response & group*time & $\mathrm{F}_{1,11.27}=0.39, \mathrm{P}=0.5469$ \\
\hline response & group & $\mathrm{F}_{1,11.42}=0.00, \mathrm{P}=0.9523$ \\
\hline response & time & $\mathrm{F}_{1,11.27}=1.07, \mathrm{P}=0.3225$ \\
\hline
\end{tabular}


Table 9: Results of regression analyses that investigated a relationship between corticosterone (CORT) and testosterone (T) concentrations at baseline and stressed conditions (following application of an acute stressor), as well as the relationship between the CORT and T response (to the acute stressor).

\begin{tabular}{|c|c|c|}
\hline Response variable & Model term & $\mathbf{R}^{2}$, test statistic and P-value \\
\hline baseline T & baseline CORT & $\mathrm{R}^{2}=0.19, \mathrm{~F}_{1,22.93}=4.48, \mathrm{P}=0.0454$ \\
\hline baseline T (minus two influential snakes) & baseline CORT & $\mathrm{R}^{2}=0.02, \mathrm{~F}_{1,21.85}=0.33, \mathrm{P}=0.5713$ \\
\hline stressed T & stressed CORT & $\mathrm{R}^{2}=0.16, \mathrm{~F}_{1,22.64}=4.76, \mathrm{P}=0.0397$ \\
\hline stressed T (minus two influential snakes) & stressed CORT & $\mathrm{R}^{2}=0.10, \mathrm{~F}_{1,23.98}=2.85, \mathrm{P}=0.1043$ \\
\hline T response & CORT response & $\mathrm{R}^{2}=0.00, \mathrm{~F}_{1,24.97}=0.05, \mathrm{P}=0.8235$ \\
\hline T response (minus two influential snakes) & CORT response & $\mathrm{R}^{2}=0.00, \mathrm{~F}_{1,22.85}=0.09, \mathrm{P}=0.7628$ \\
\hline
\end{tabular}


Table 10: Model selection results for $100 \%$ MCP activity range size. Models with $\Delta \mathrm{AICc} \leq 10.0$ are displayed. The experimental terms (group, time, group*time), potential covariates (BCI, SVL), and plasma steroid hormone (CORT or T) levels were evaluated as possible explanatory variables. Individual snake was included as a random effect in all models, in order to account for repeated measures on the same individual. Where appropriate, the F-statistic and P-value are included for the CORT and T terms.

\begin{tabular}{|c|c|c|c|c|}
\hline Model Terms & $\begin{array}{c}\text { snake } \\
\text { group } \\
\text { time } \\
\text { group*time }\end{array}$ & $\begin{array}{c}\text { snake } \\
\mathrm{T} \\
\mathrm{BCI}\end{array}$ & $\begin{array}{c}\text { snake } \\
\text { CORT } \\
\mathrm{BCI}\end{array}$ & $\begin{array}{c}\text { snake } \\
\text { group } \\
\text { time } \\
\text { group*time } \\
\mathrm{T}\end{array}$ \\
& & & & \\
& & & & \\
\hline AICc & 108.38 & 111.93 & 112.09 & 118.19 \\
\hline DAICc & 0 & 3.55 & 3.71 & 9.81 \\
\hline CORT F-statistic & N/A & N/A & $\mathrm{F}_{1,22.05}=4.07$ & N/A \\
\hline CORT P-value & N/A & N/A & $\mathrm{P}=0.0561$ & N/A \\
\hline T F-statistic & N/A & $\mathrm{F}_{1,20.31}=3.55$ & N/A & $\mathrm{F}_{1,21.13}=0.15$ \\
\hline T P-value & N/A & $\mathrm{P}=0.0739$ & N/A & $\mathrm{P}=0.7048$ \\
\hline
\end{tabular}


Table 11: Model selection results for mean distance moved per day. Models with $\triangle \mathrm{AICc}$ $\leq 10.0$ are displayed. The experimental terms (group, time, group*time), potential covariates (BCI, SVL), and plasma steroid hormone (CORT or T) levels were evaluated as possible explanatory variables. Individual snake was included as a random effect in all models, in order to account for repeated measures on the same individual. Where appropriate, the F-statistic and P-value are included for the CORT and T terms.

\begin{tabular}{|c|c|c|c|c|}
\hline Model Terms & $\begin{array}{c}\text { snake } \\
\text { BCI } \\
\text { BCI* group } \\
\text { group } \\
\text { time } \\
\text { group*time }\end{array}$ & $\begin{array}{c}\text { snake } \\
\text { group } \\
\text { time } \\
\text { group } * \text { time }\end{array}$ & $\begin{array}{c}\text { snake } \\
\text { BCI } \\
\text { CORT }\end{array}$ & $\begin{array}{c}\text { snake } \\
\mathrm{BCI} \\
\mathrm{T}\end{array}$ \\
\hline AICc & 76.09 & 78.54 & 79.51 & 80.73 \\
\hline$\Delta \mathrm{AICc}$ & 0 & 2.45 & 3.42 & 4.64 \\
\hline CORT F-statistic & N/A & N/A & $\mathrm{F}_{1,23.96}=2.87$ & N/A \\
\hline CORT P-value & N/A & N/A & $\mathrm{P}=0.1030$ & N/A \\
\hline T F-statistic & N/A & N/A & N/A & $\mathrm{F}_{1,24}=0.81$ \\
\hline T P-value & N/A & N/A & N/A & $\mathrm{P}=0.3757$ \\
\hline
\end{tabular}


Table 12: Model selection results for total distance moved. Models with $\triangle \mathrm{AICc} \leq 10.0$ are displayed. The experimental terms (group, time, group*time), potential covariates (BCI, SVL), and plasma steroid hormone (CORT or T) levels were evaluated as possible explanatory variables. Individual snake was included as a random effect in all models, in order to account for repeated measures on the same individual. Where appropriate, the Fstatistic and P-value are included for the CORT and T terms.

\begin{tabular}{|c|c|c|c|c|c|c|}
\hline Model Terms & $\begin{array}{c}\text { snake } \\
\text { group } \\
\text { time } \\
\text { group*time } \\
\text { BCI } \\
\text { BCI*group }\end{array}$ & $\begin{array}{c}\text { snake } \\
\text { BCI } \\
\text { CORT }\end{array}$ & $\begin{array}{c}\text { snake } \\
\text { group } \\
\text { time } \\
\text { group*time }\end{array}$ & $\begin{array}{c}\text { snake } \\
\text { BCI } \\
\mathrm{T}\end{array}$ & $\begin{array}{c}\text { snake } \\
\text { CORT }\end{array}$ & $\begin{array}{c}\text { snake } \\
\text { T }\end{array}$ \\
& & & & & & \\
& & & & & & \\
\hline AICc & 76.12 & 76.39 & 77.75 & 77.87 & 78.42 & 79.26 \\
\hline$\Delta$ AICc & 0 & 0.27 & 1.63 & 1.75 & 2.30 & 3.14 \\
\hline CORT F-statistic & N/A & $\mathrm{F}_{1,23.19}=3.52$ & N/A & N/A & $\mathrm{F}_{1,23.55}=2.34$ & N/A \\
\hline CORT P-value & N/A & $\mathrm{P}=0.0731$ & N/A & N/A & $\mathrm{P}=0.1393$ & N/A \\
\hline T F-statistic & N/A & N/A & N/A & $\mathrm{F}_{1,23.71}=1.15$ & N/A & $\mathrm{F}_{1,23.73}=0.55$ \\
\hline T P-value & N/A & N/A & N/A & $\mathrm{P}=0.2939$ & N/A & $\mathrm{P}=0.4671$ \\
\hline
\end{tabular}




\section{FIGURES}

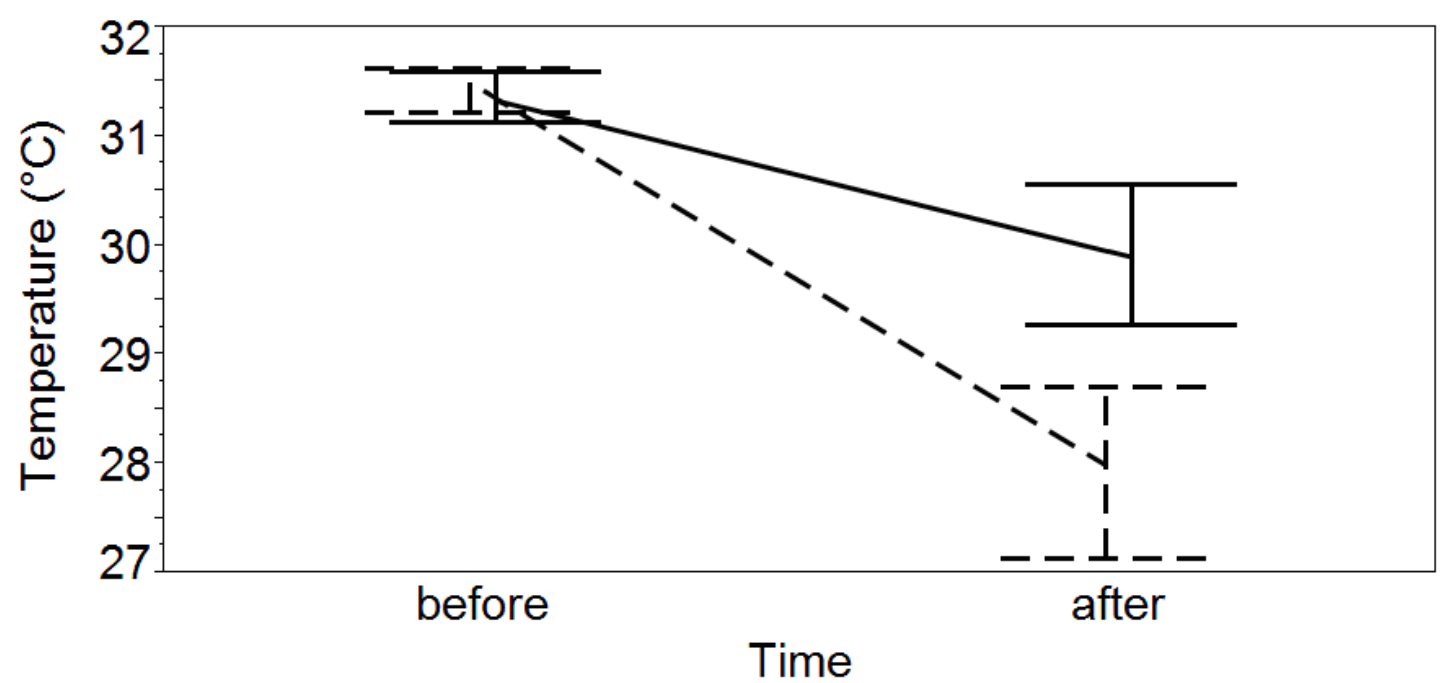

Figure 1: Mean daily maximum $\mathrm{T}_{\mathrm{b}}$ by time (before or after translocation) and treatment group. The solid line indicates the translocated group, while the dashed line indicates the control group. Error bars are one standard error of the mean. The main effect of time was significant, with mean daily maximum $\mathrm{T}_{\mathrm{b}}$ being $2.2^{\circ} \mathrm{C}$ higher before translocation. 


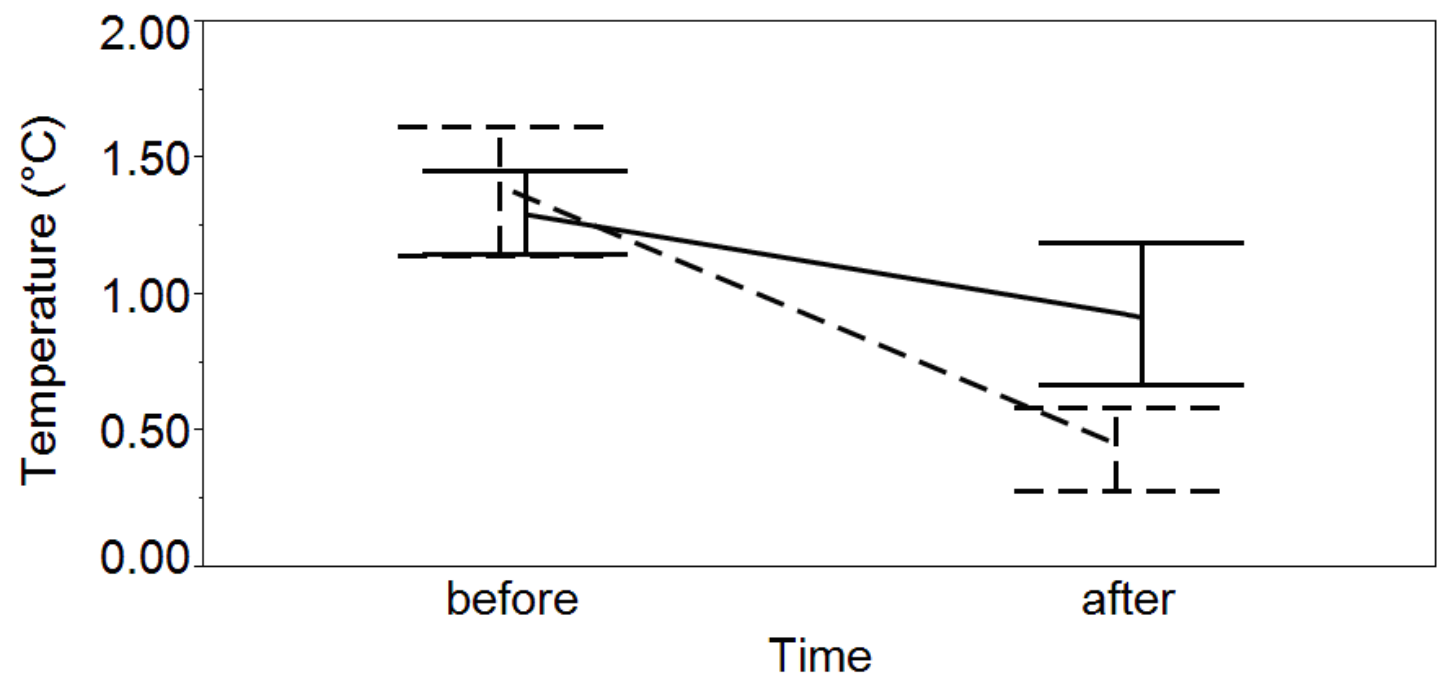

Figure 2: Mean $d_{b}$ by time (before or after translocation) and treatment group. The solid line indicates the translocated group, while the dashed line indicates the control group. Error bars are one standard error of the mean. The main effect of time was significant, with mean $\mathrm{d}_{\mathrm{b}}$ being $0.6^{\circ} \mathrm{C}$ higher before translocation. This indicates that, during that time period, the $T_{b}$ of all snakes deviated more from $T_{\text {sel }}$ than it did during the latter part of the study, post-translocation. 


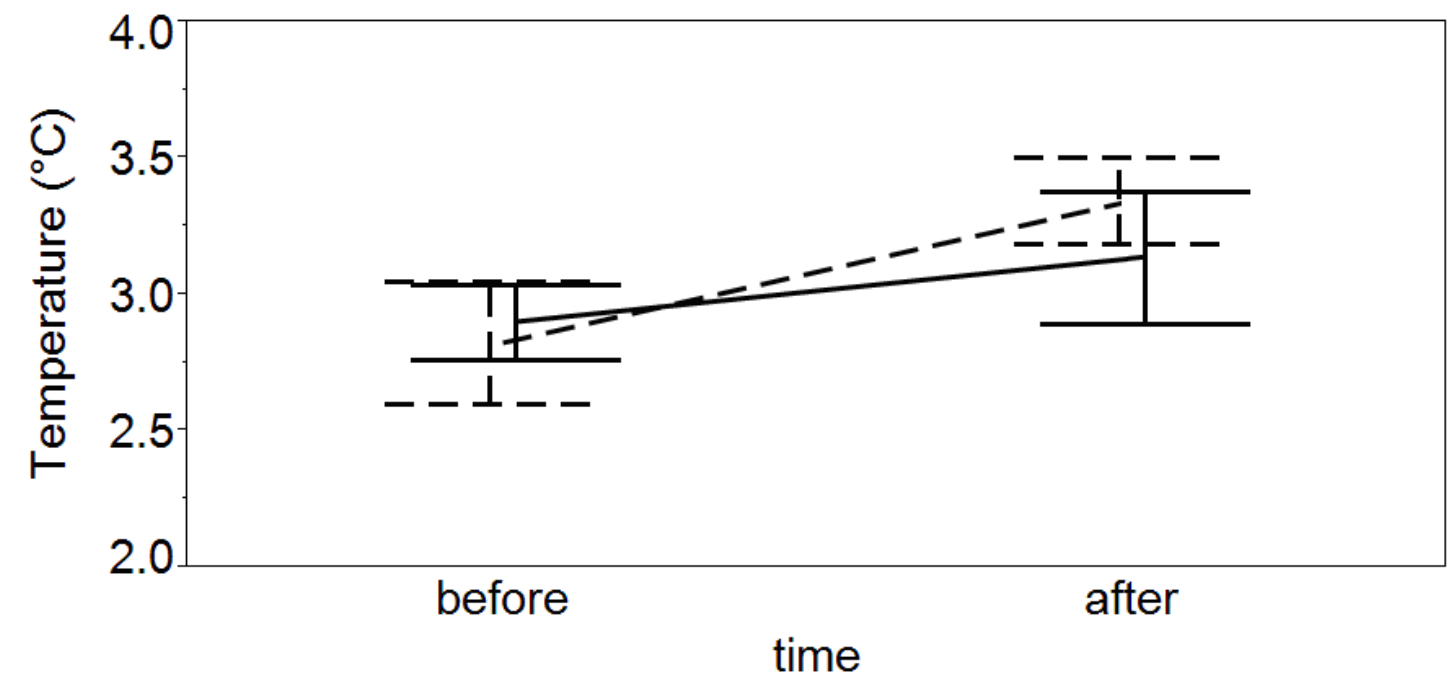

Figure 3: Mean thermoregulatory effectiveness by time (before or after translocation) and treatment group. The solid line indicates the translocated group, while the dashed line indicates the control group. Error bars are one standard error of the mean. The main effect of time was marginally significant. The index of thermoregulatory effectiveness was $0.3^{\circ} \mathrm{C}$ higher before translocation, indicating more effective thermoregulation during that time period. 


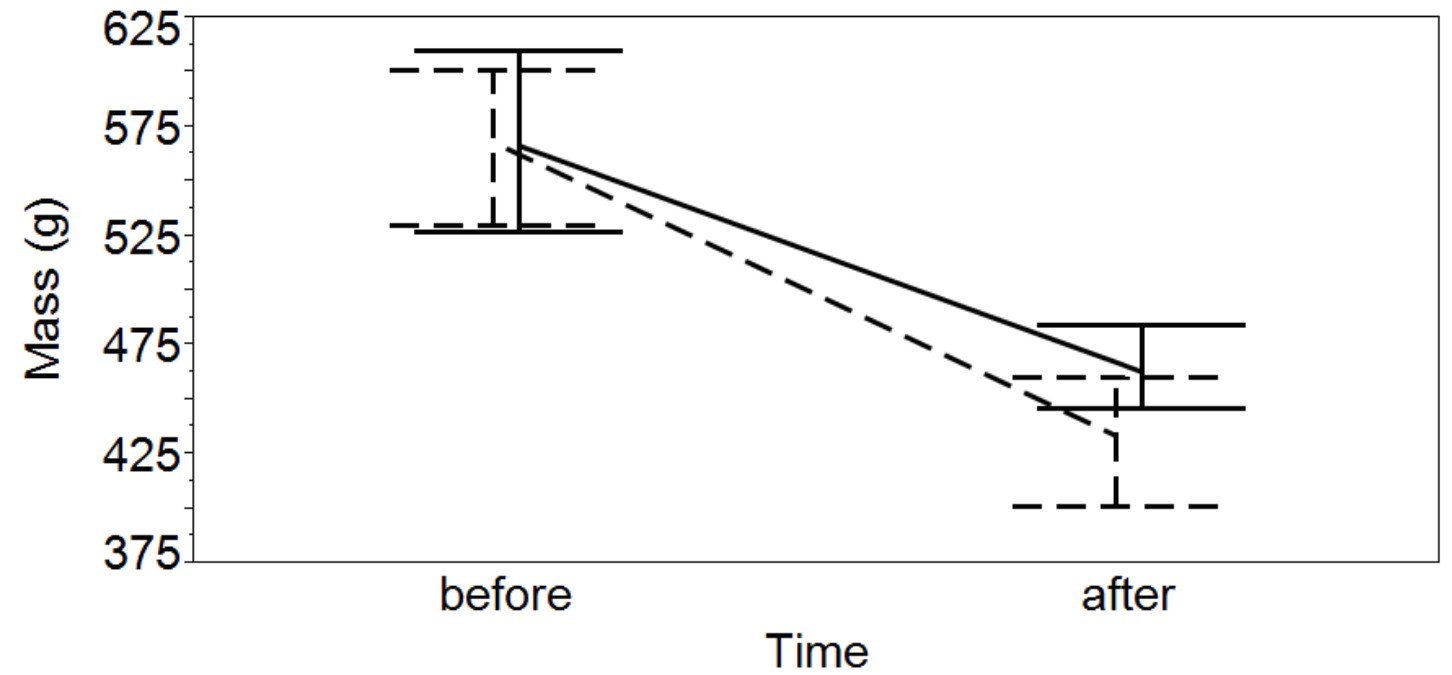

Figure 4: Mean body mass by time (before or after translocation) and treatment group. The solid line indicates the translocated group, while the dashed line indicates the control group. Error bars are one standard error of the mean. The main effect of time was significant, with mean body mass being $119 \mathrm{~g}$ higher at the beginning of the study than at the end of the study. 


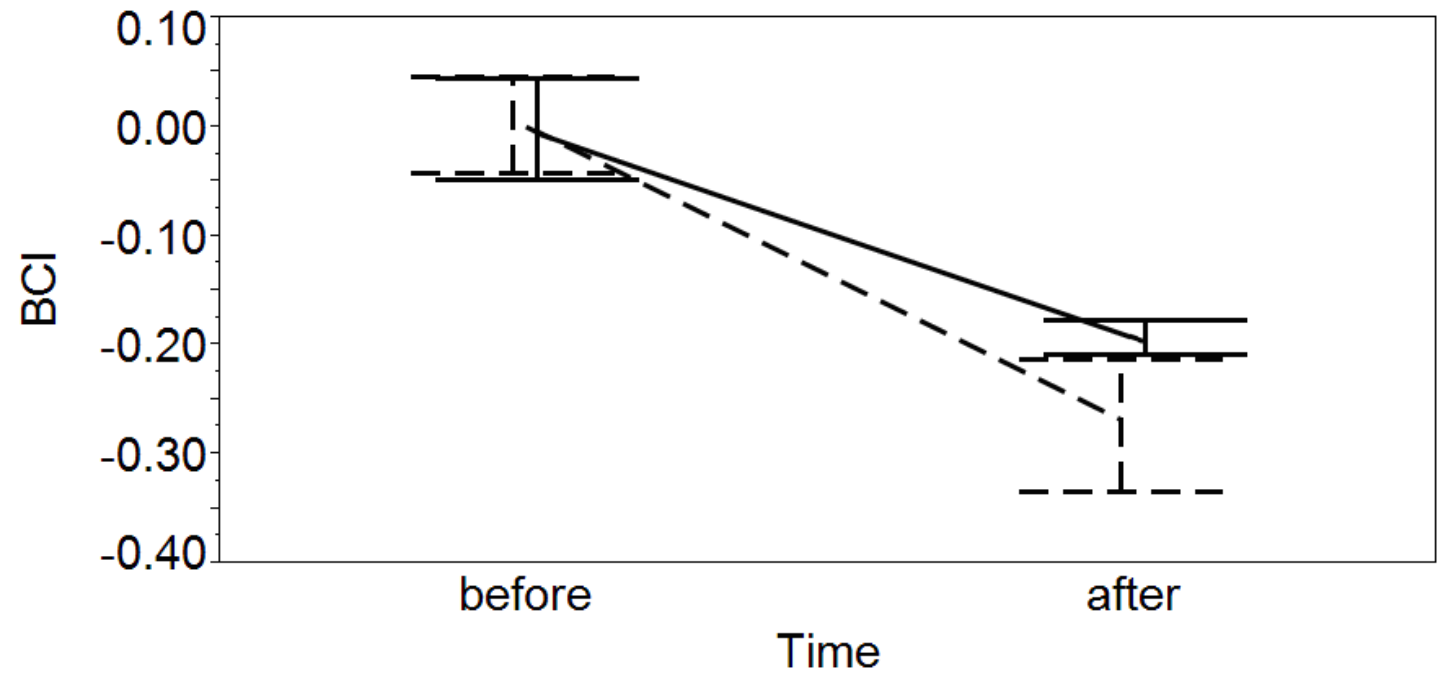

Figure 5: Mean body condition index (BCI) by time (before or after translocation) and treatment group. The solid line indicates the translocated group, while the dashed line indicates the control group. Error bars are one standard error of the mean. The main effect of time was significant, with mean BCI being higher at the beginning of the study than at the end of the study. 


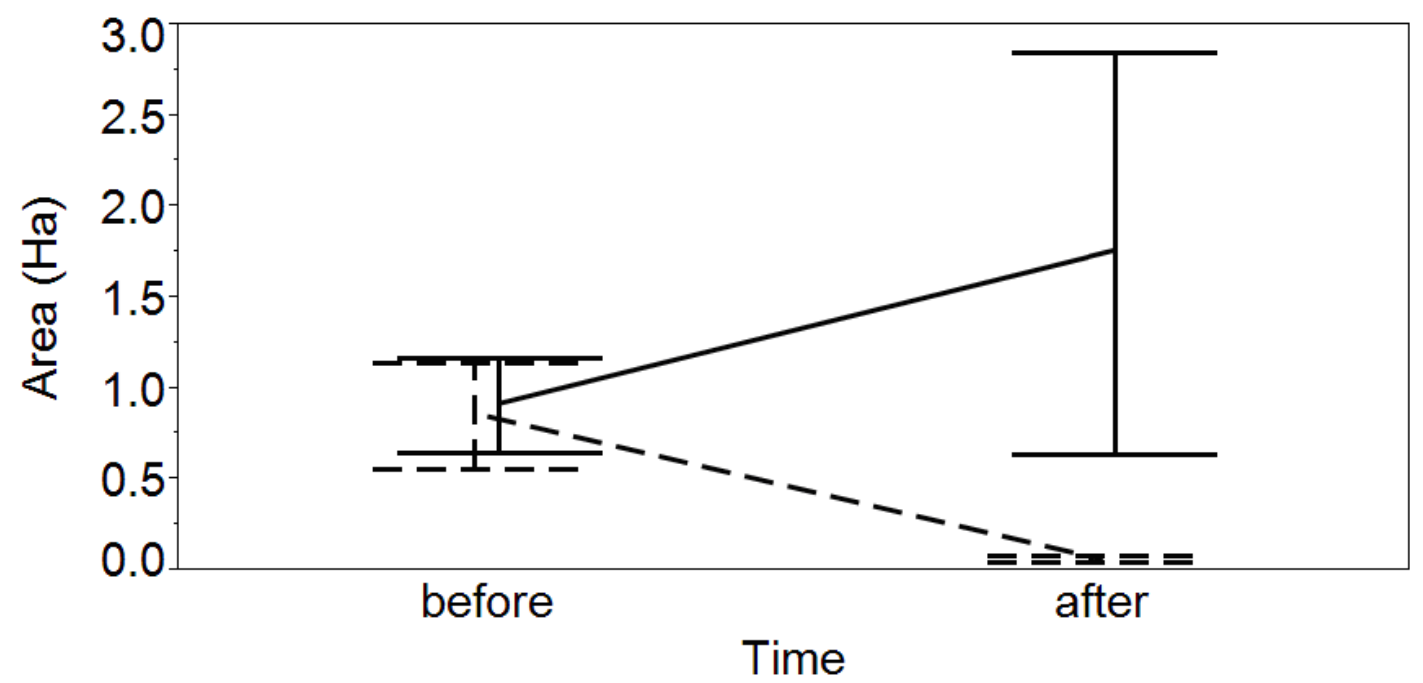

Figure 6: Mean 100\% Minimum Convex Polygon (MCP) activity range size by time (before or after translocation) and treatment group, including an outlier in the data set. The solid line indicates the translocated group, while the dashed line indicates the control group. Error bars are one standard error of the mean. The treatment group by time interaction was significant, indicating an effect of translocation on MCP size. The control group decreased in MCP size, while the translocated group did not. Post-translocation, the average 100\% MCP size for the translocated group was 29 times larger than that of the control group. 


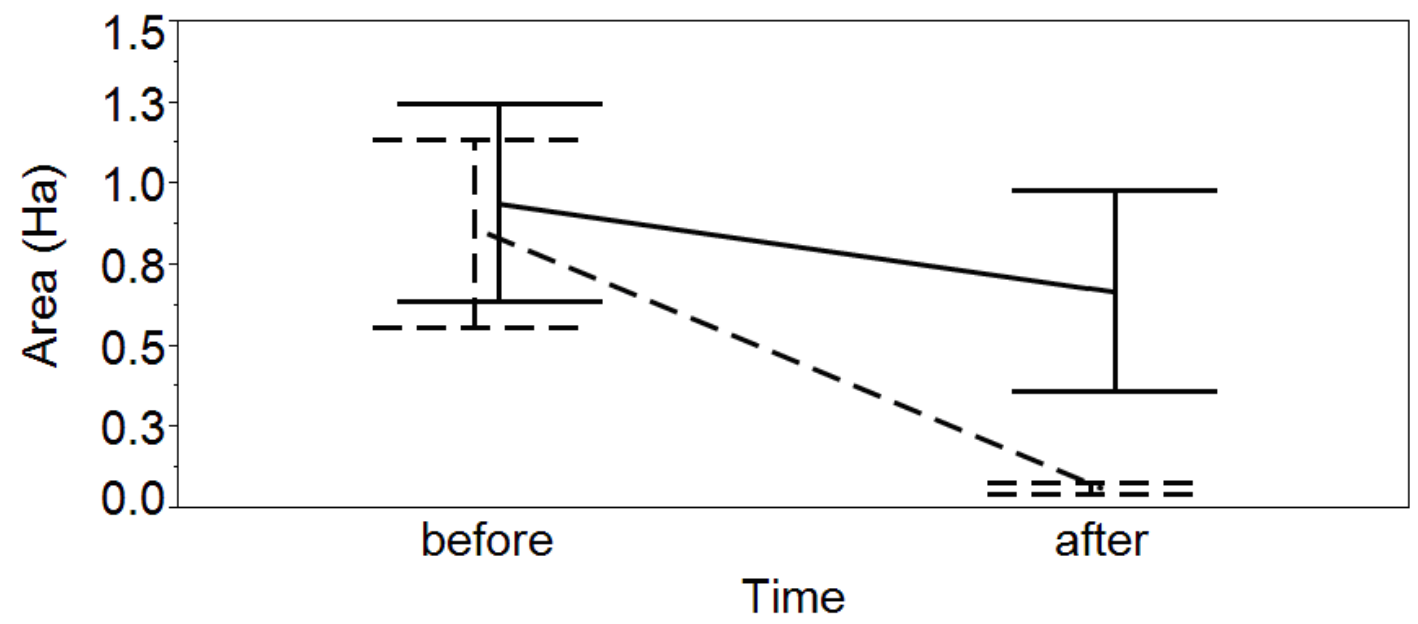

Figure 7: Mean 100\% Minimum Convex Polygon (MCP) activity range size by time (before or after translocation) and treatment group, excluding an outlier $(8.17 \mathrm{Ha})$ in the data set (mean without outlier $=0.67 \mathrm{Ha}, \mathrm{SE}=0.31$ ). The solid line indicates the translocated group, while the dashed line indicates the control group. Error bars are one standard error of the mean. Removal of the outlier nullified the marginal significance of the treatment group by time interaction, resulting in a significant main effect of time, with MCP size being 2.6 times greater during the period prior to translocation. However, it can be seen that the translocated group decreased over time to a lesser degree than the control group. In the period following translocation, the average MCP size was still 11 times greater in the translocated group than in the control group, though the individual variation within the translocated group was much greater. 


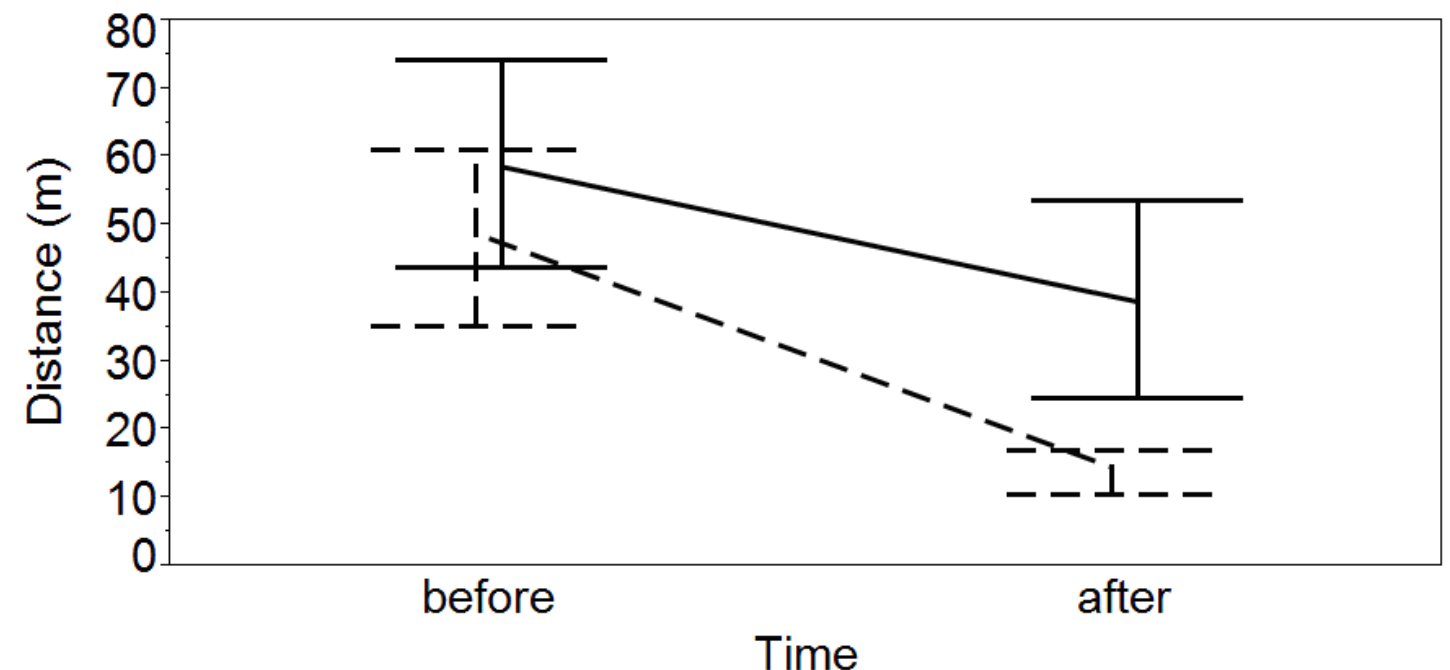

Figure 8: Mean distance moved per day by time (before or after translocation) and treatment group, including an outlier ( $88 \%$ increase) in the data set (average decrease of $39 \%$ without the outlier). The solid line indicates the translocated group, while the dashed line indicates the control group. Error bars are one standard error of the mean. The main effect of time was significant, with mean distance moved per day being twice as great during the period before translocation than during the period after translocation. 


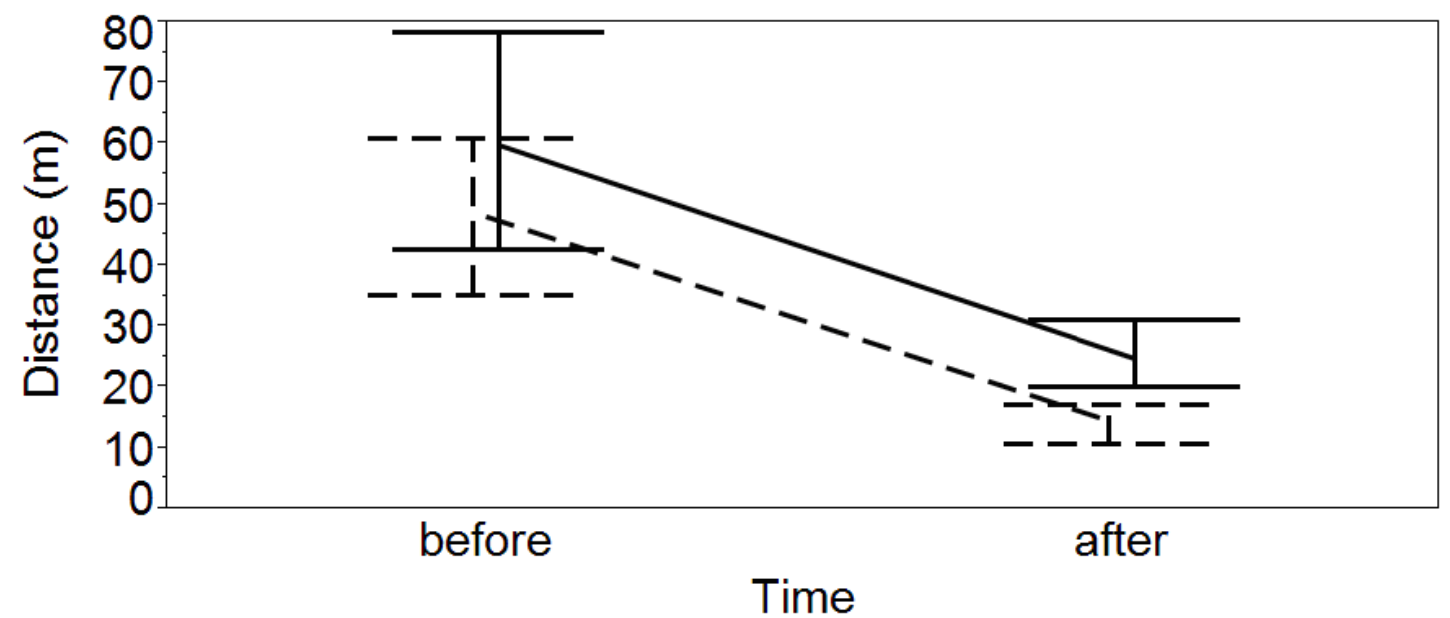

Figure 9: Mean distance moved per day by time (before or after translocation) and treatment group, excluding an outlier in the data set. The solid line indicates the translocated group, while the dashed line indicates the control group. Error bars are one standard error of the mean. Removal of the outlier did not change the significance of any model term. 


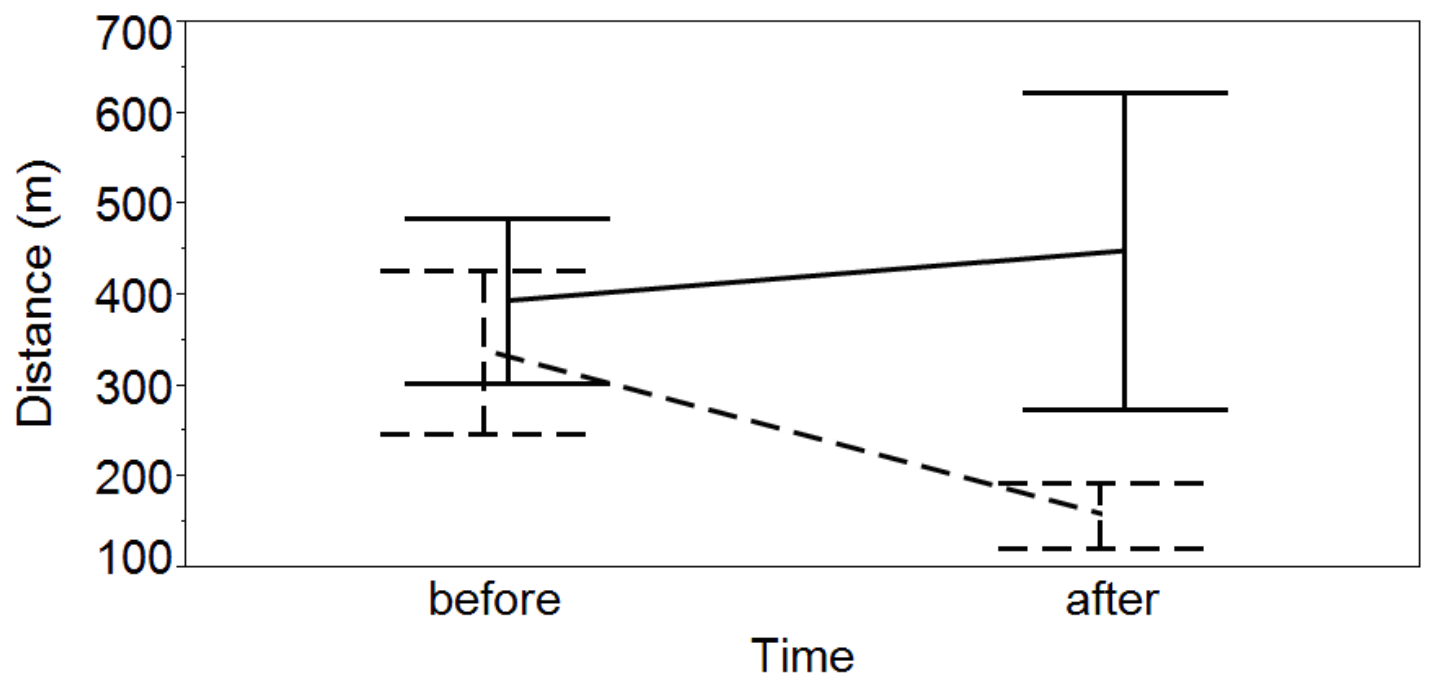

Figure 10: Mean total distance moved by time (before or after translocation) and treatment group, including an outlier in the data set. The solid line indicates the translocated group, while the dashed line indicates the control group. Error bars are one standard error of the mean. None of the model terms were significant. However, the translocated group increased while the control group decreased. This divergence was offset by a large amount of individual variation in the translocated group during the period following translocation. 


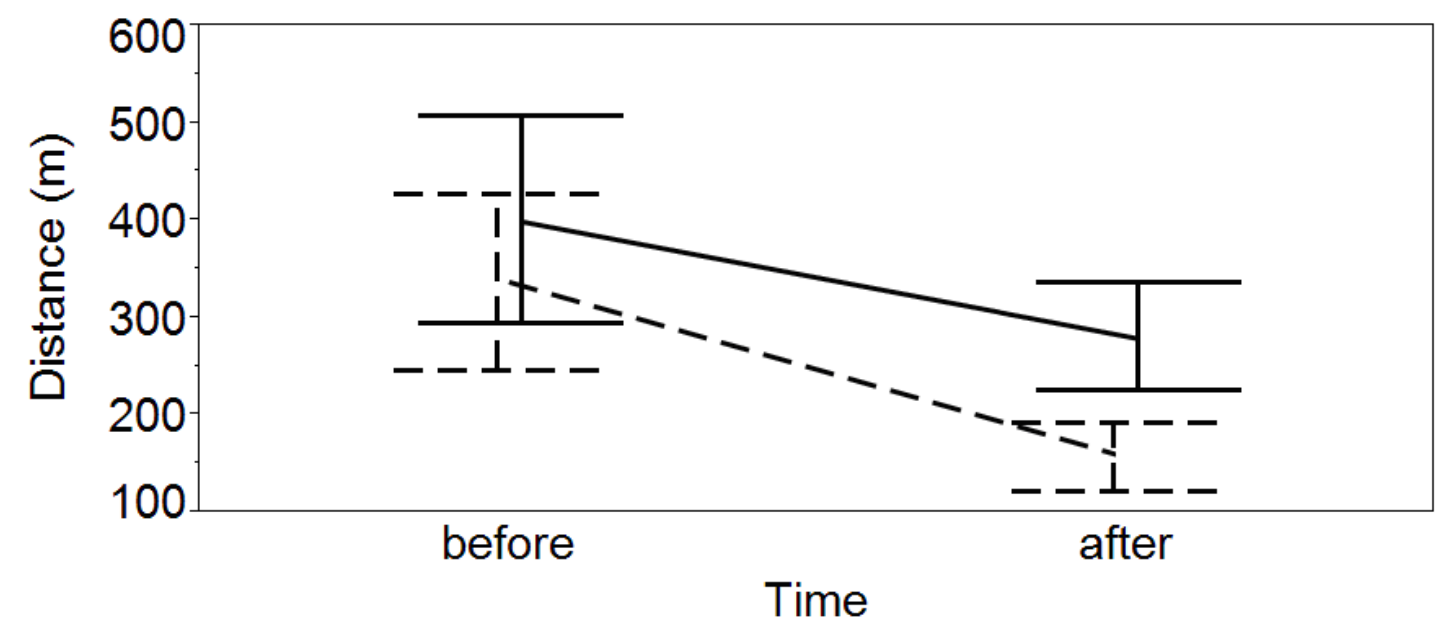

Figure 11: Mean total distance moved by time (before or after translocation) and treatment group, excluding an outlier in the data set. The solid line indicates the translocated group, while the dashed line indicates the control group. Error bars are one standard error of the mean. None of the model terms were significant, with or without the outlier. 


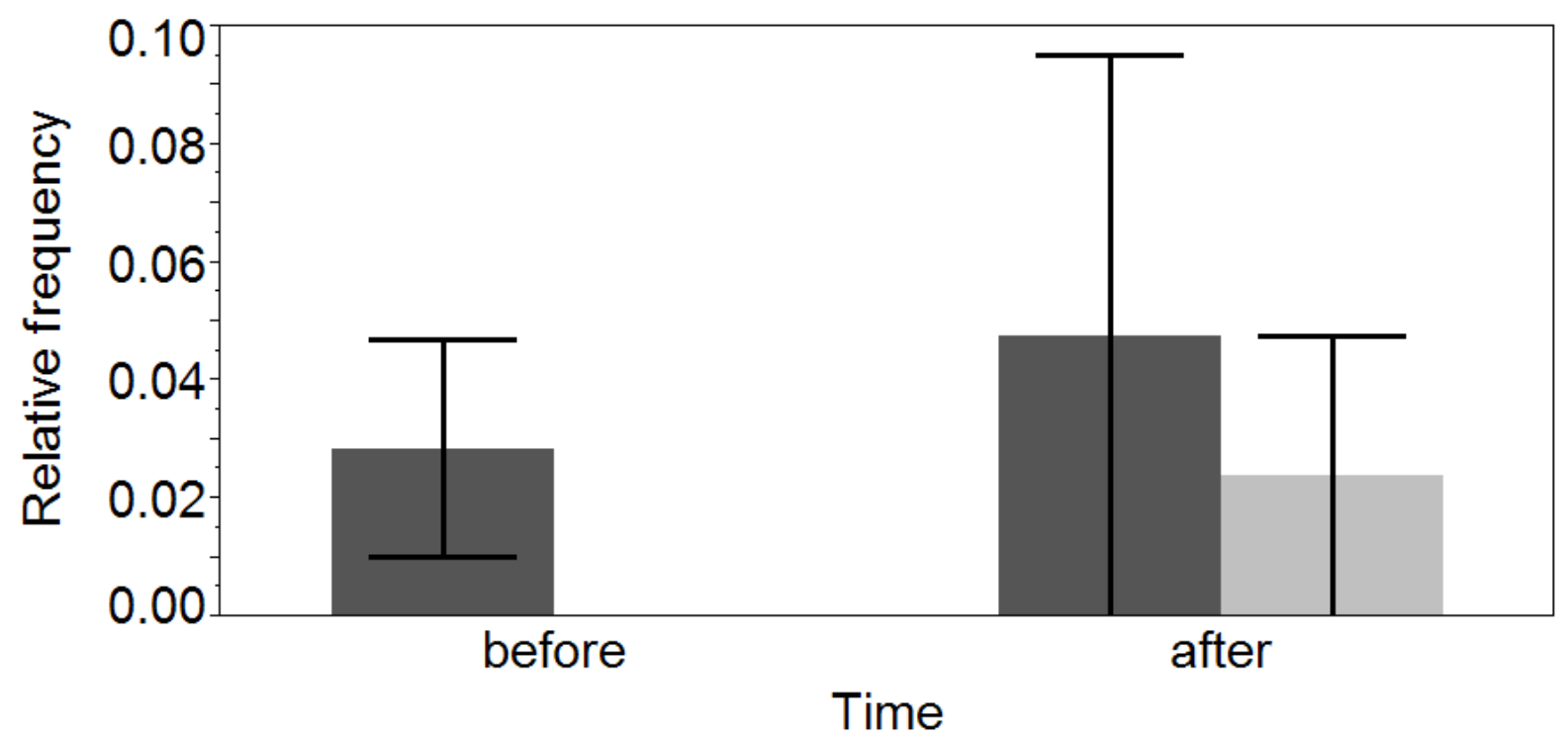

Figure 12: Relative frequency of rattling by time (before or after translocation) and treatment group. The relative frequency was calculated as the number of locations on which a snake rattled, divided by the total number of locations when the snake was seen. The light grey bars indicate the translocated group, while the dark gray bars indicate the control group. Error bars are one standard error of the mean. Due to infrequent observation of rattling, parametric analysis was precluded. 


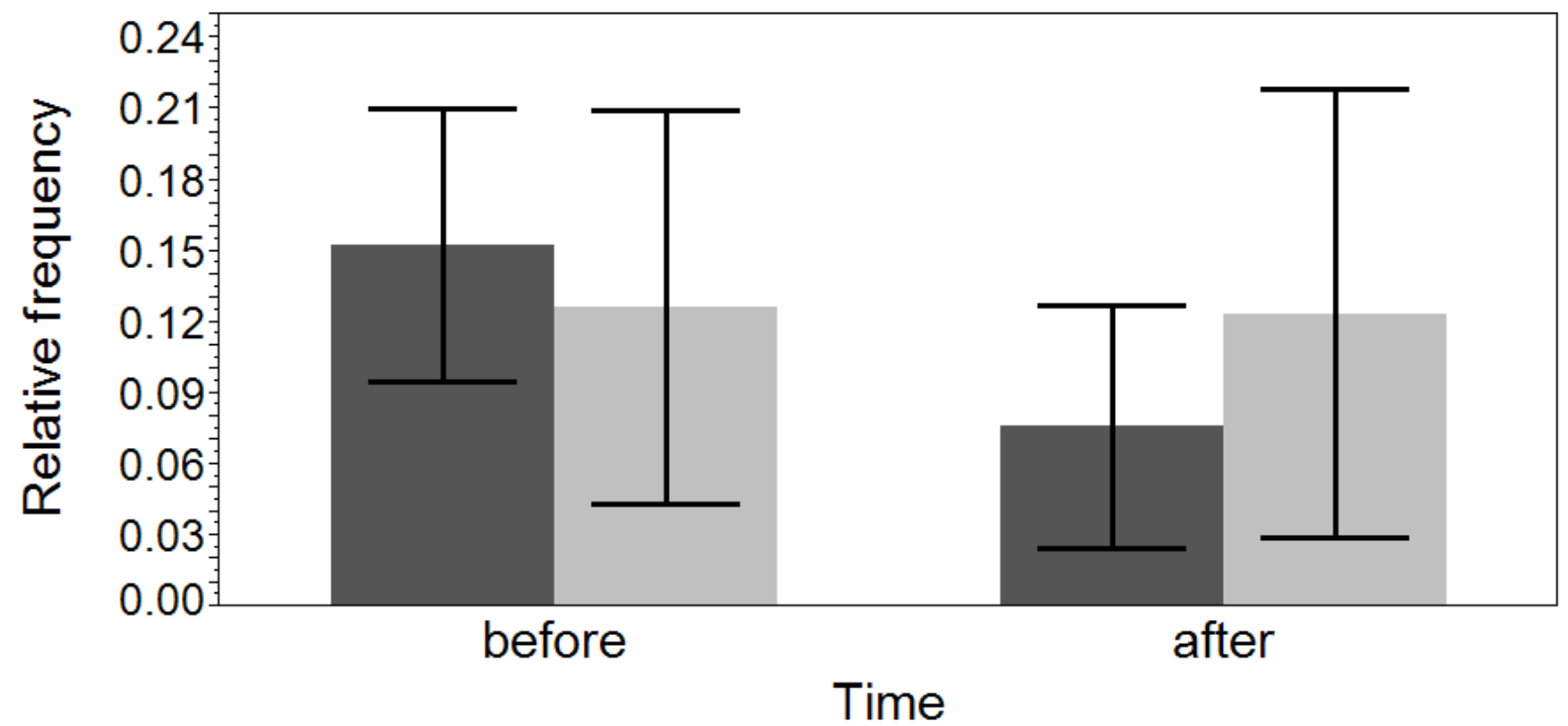

Figure 13: Relative frequency of tongue-flicking by time (before or after translocation) and treatment group. The relative frequency was calculated as the number of locations on which a snake tongue-flicked, divided by the total number of locations when the snake was seen. The light grey bars indicate the translocated group, while the dark gray bars indicate the control group. Error bars are one standard error of the mean. Due to infrequent observation of tongue-flicking, parametric analysis was precluded. 


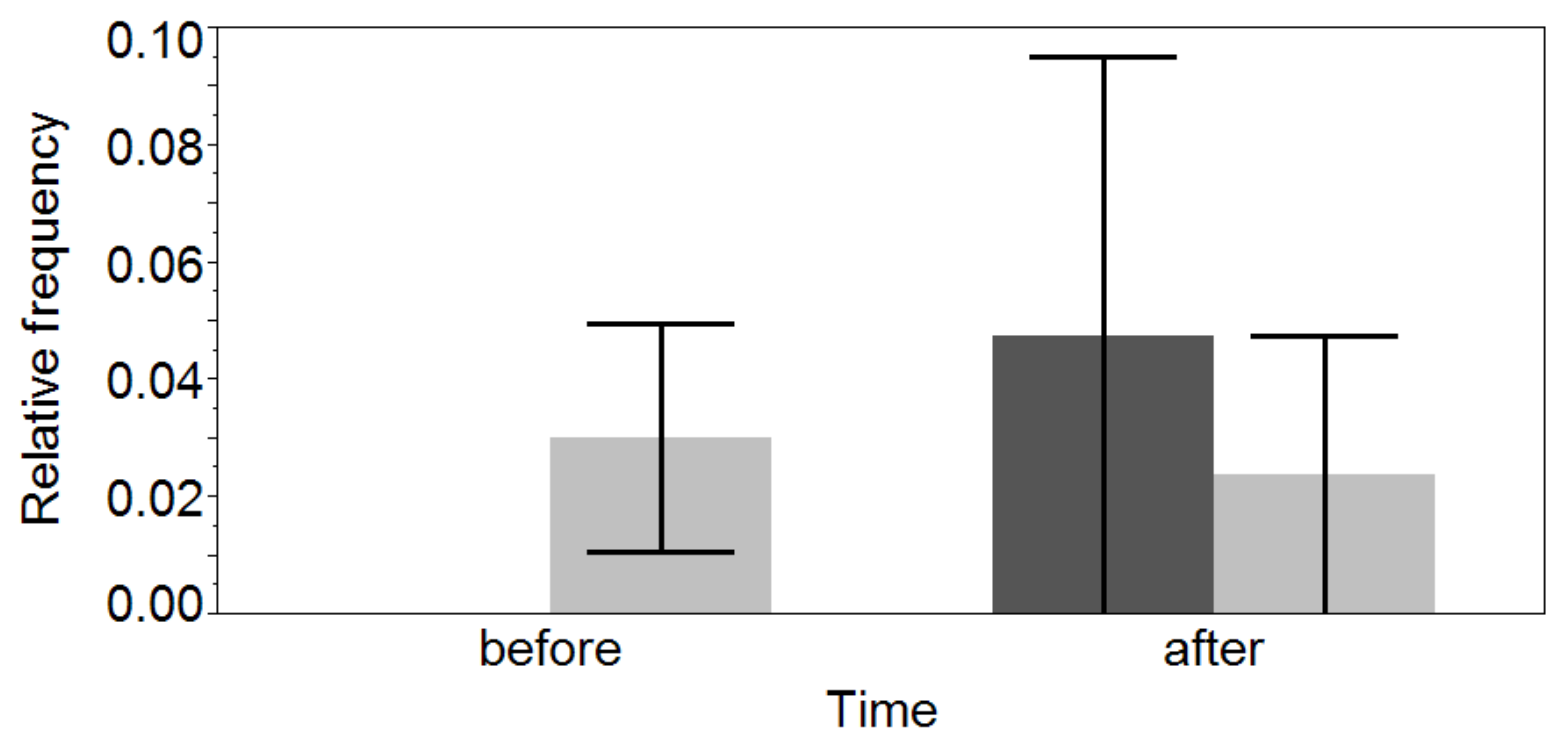

Figure 14: Relative frequency of fleeing by time (before or after translocation) and treatment group. The relative frequency was calculated as the number of locations on which a snake fled, divided by the total number of locations when the snake was seen. The light grey bars indicate the translocated group, while the dark gray bars indicate the control group. Error bars are one standard error of the mean. Due to infrequent observation of fleeing, parametric analysis was precluded. 


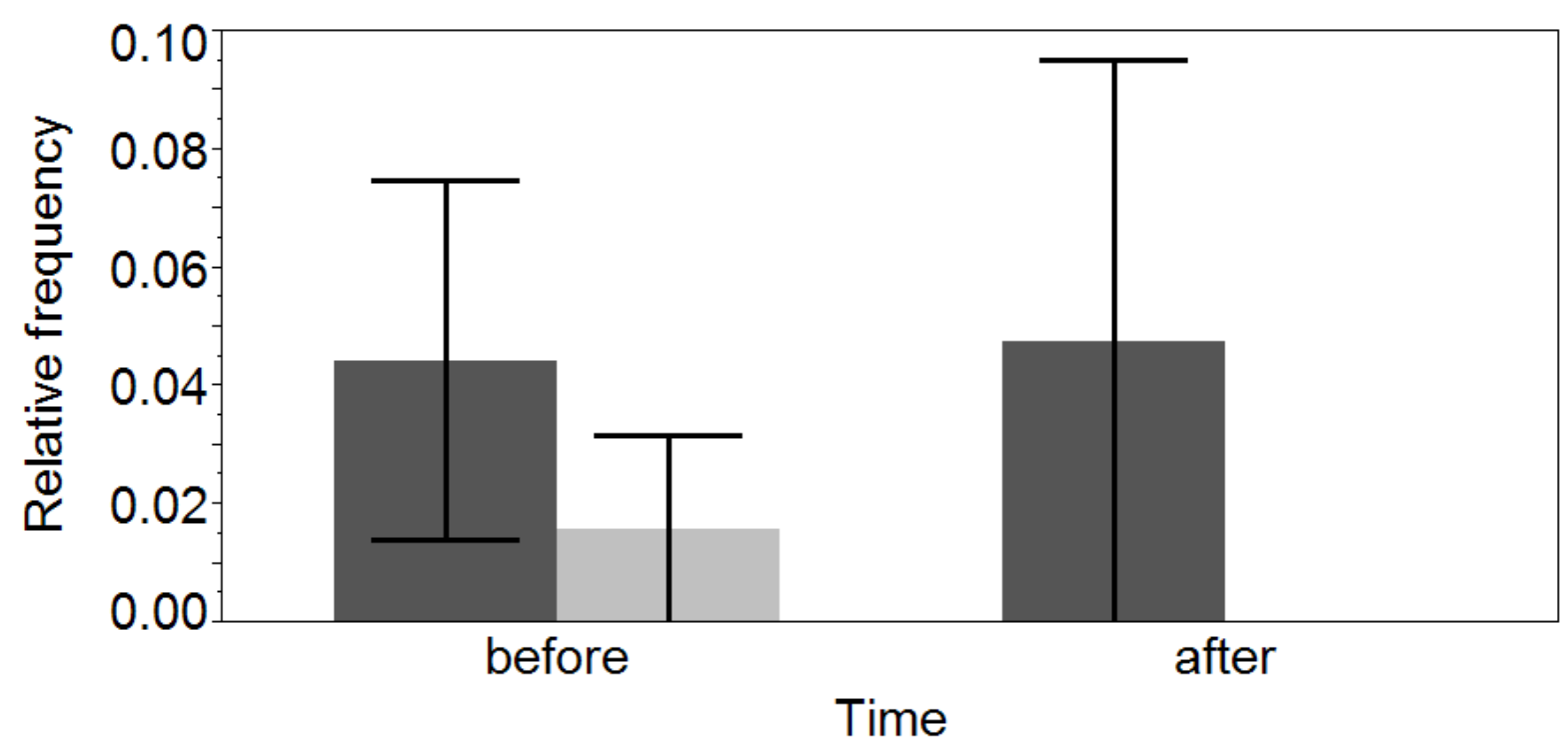

Figure 15: Relative frequency of movement by time (before or after translocation) and treatment group. The relative frequency was calculated as the number of locations on which a snake was observed to be moving, divided by the total number of locations when the snake was seen. The light grey bars indicate the translocated group, while the dark gray bars indicate the control group. Error bars are one standard error of the mean. Due to infrequent observation of movement, parametric analysis was precluded. 


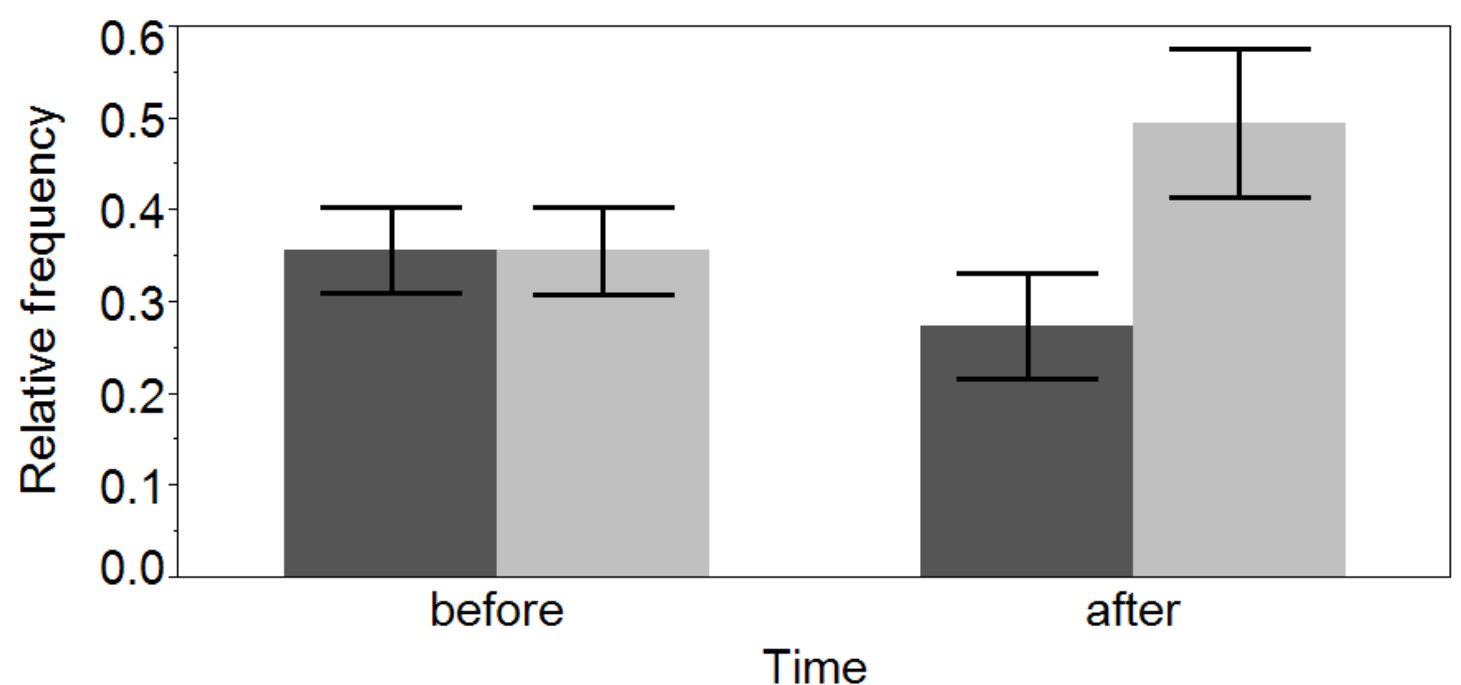

Figure 16: Relative frequency of snake sightings by time (before or after translocation) and treatment group. The relative frequency was calculated as the number of locations on which a snakes was seen, divided by the total number of locations, for that snake. The light grey bars indicate the translocated group, while the dark gray bars indicate the control group. Error bars are one standard error of the mean. The treatment group by time interaction was marginally significant, indicating that translocation was associated with increased visibility. During the period after translocation, the translocated group was visible 1.8 times as often as the control group. However, post-hoc testing found no significant differences. 


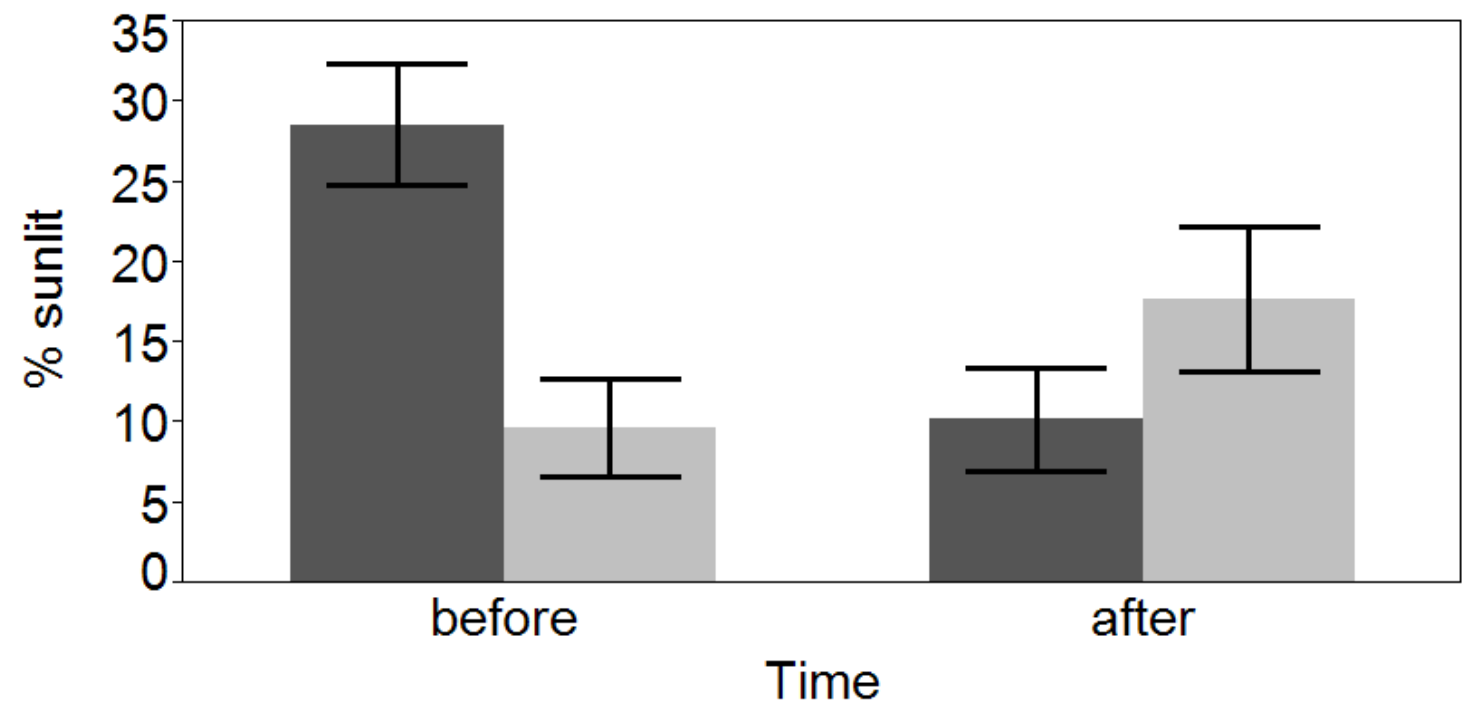

Figure 17: Mean percent body sunlit by time (before or after translocation) and treatment group. Percent body sunlit was only scored if a snake was seen when located. The light grey bars indicate the translocated group, while the dark gray bars indicate the control group. Error bars are one standard error of the mean. The treatment group by time interaction was significant. The control group was 2.8 times more sunlit during the period before translocation than it was during the period following translocation. The translocated group did not change over time. The control group was 2.9 times more sunlit than the translocated group during the pre-translocation period, though no difference existed between the two groups during the post-translocation period. 


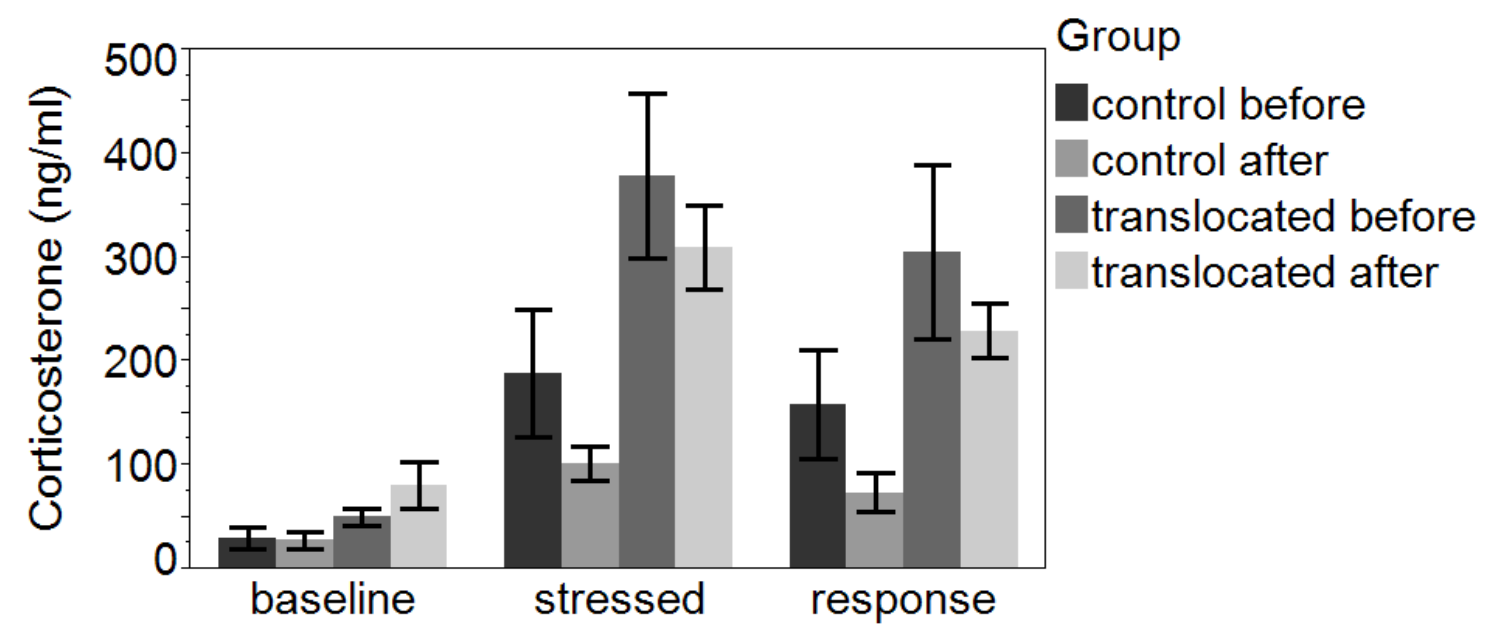

Figure 18: Corticosterone (CORT) by time (before or after translocation) and treatment group. The baseline concentration represents that prior to application of the acute stressor while the stressed concentration is that following application of the acute stressor. The response represents the difference between the baseline and stressed concentrations. Error bars are one standard error of the mean. In each case (baseline, stressed, and response) a significant main effect of treatment group was observed, with CORT concentrations in the translocated group being more than twice those of the control group, across both time periods (before translocation and after translocation). 


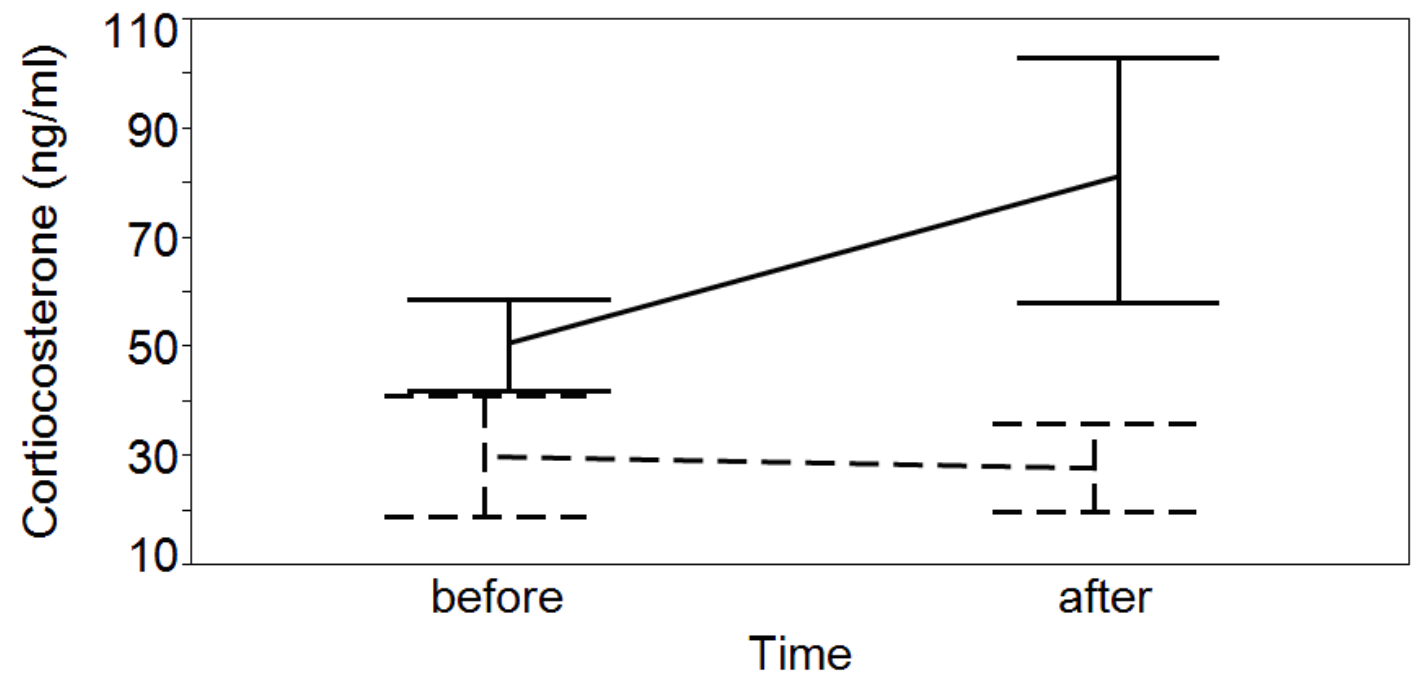

Figure 19: Mean baseline (prior to application of the acute stressor) corticosterone (CORT) by time (before or after translocation) and treatment group. The solid line indicates the translocated group, while the dashed line indicates the control group. Error bars are one standard error of the mean. The main effect of treatment group was significant, with the translocated group being 2.3 times higher than the control group across both time periods. Though the treatment group by time interaction was not significant, the translocated group was higher than the control group, post-translocation. 


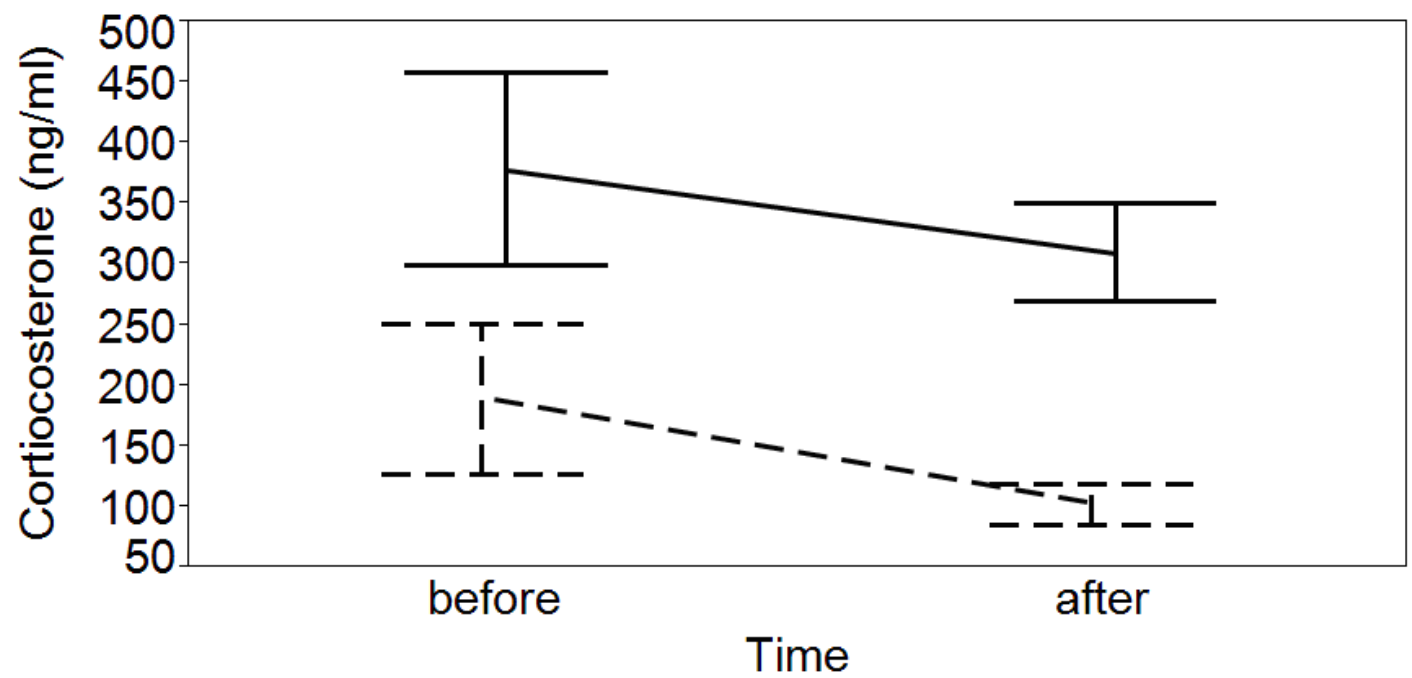

Figure 20: Mean stressed (following application of the acute stressor) corticosterone (CORT) by time (before or after translocation) and treatment group. The solid line indicates the translocated group, while the dashed line indicates the control group. Error bars are one standard error of the mean. The main effect of treatment group was significant, with the translocated group being 2.4 times higher than the control group across both time periods. 


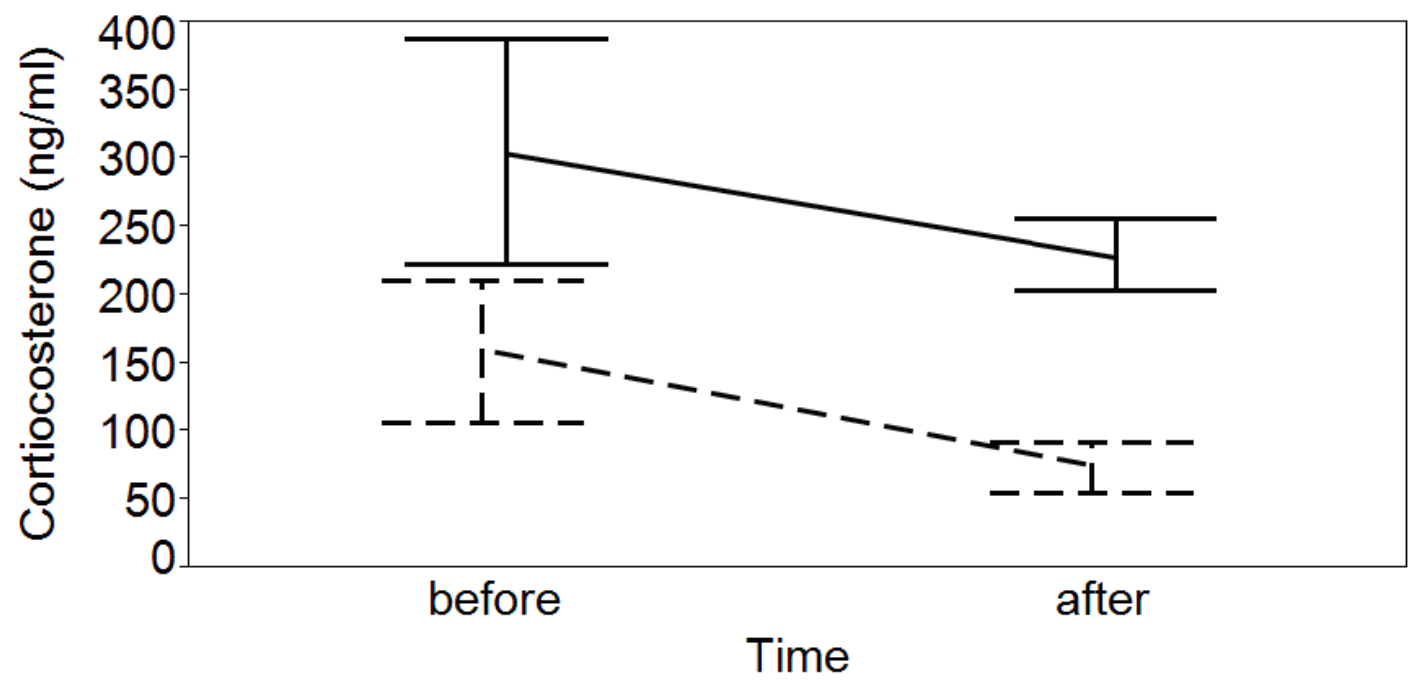

Figure 21: Mean corticosterone (CORT) response (stressed minus baseline) by time (before or after translocation) and treatment group. The CORT response was calculated as the change in CORT from a baseline blood draw to a blood draw that occurred after application of an acute stressor. The solid line indicates the translocated group, while the dashed line indicates the control group. Error bars are one standard error of the mean. The main effect of treatment group was significant, with the translocated group being 2.3 times higher than the control group across both time periods. 


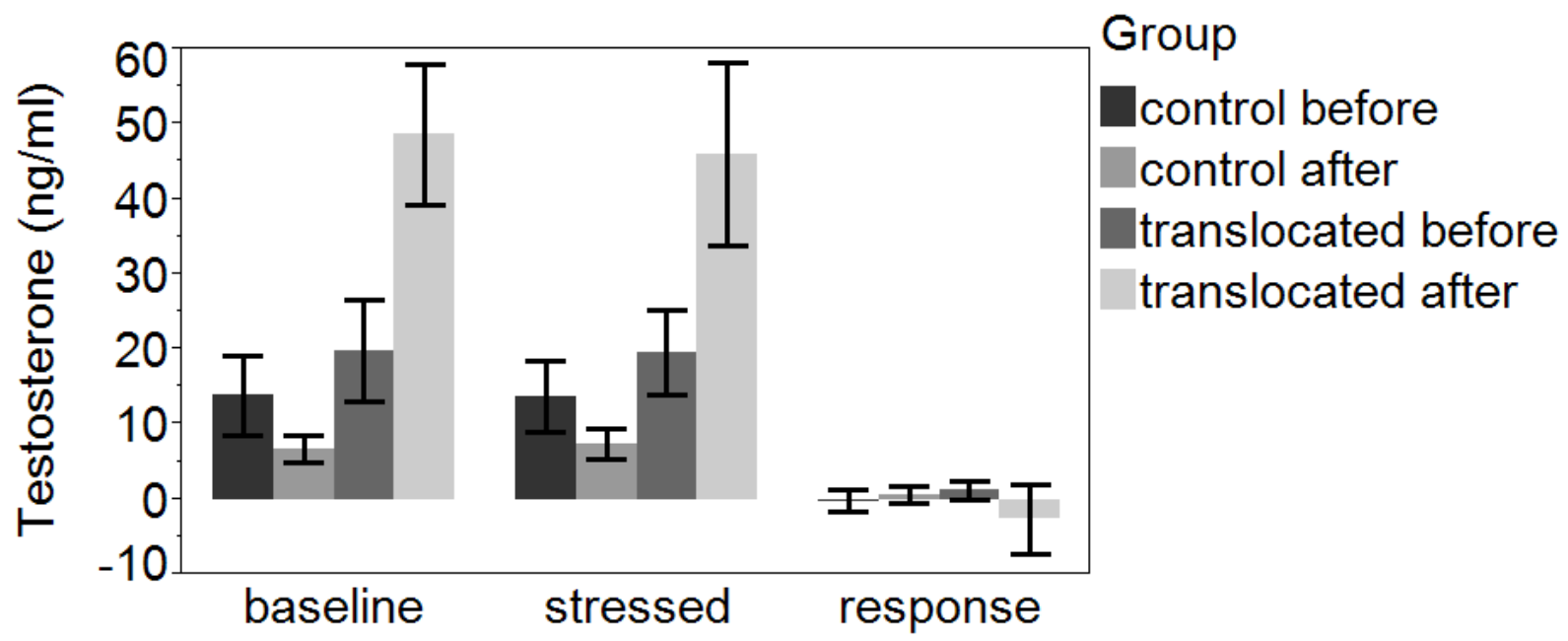

Figure 22: Testosterone (T) by time (before or after translocation) and treatment group. The baseline concentration represents that prior to application of the acute stressor while the stressed concentration is that following application of the acute stressor. The response represents the difference between the baseline and stressed concentrations. Error bars are one standard error of the mean. Significant trends were only observed in baseline T, with the trend in stressed $\mathrm{T}$ being explained by the very similar baseline trend. The two treatment groups were not found to differ before translocation in baseline $\mathrm{T}$, but, following translocation, baseline $\mathrm{T}$ was 7.3 times greater in the translocated group than in the control group. 


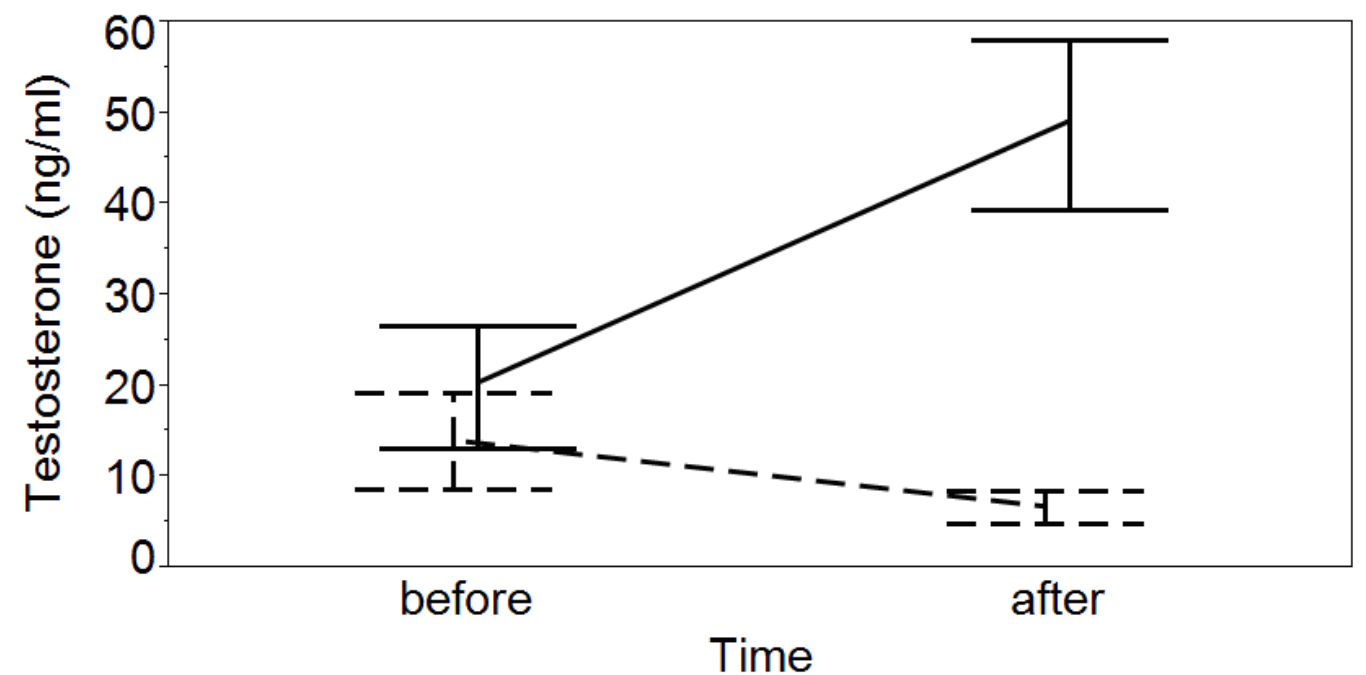

Figure 23: Mean baseline (prior to application of the acute stressor) testosterone (T) by time (before or after translocation) and treatment group. The solid line indicates the translocated group, while the dashed line indicates the control group. Error bars are one standard error of the mean. The treatment group by time interaction was significant. The two groups were not significantly different before translocation, but were after translocation, with the translocated group being 7.3 times higher during that time period. 


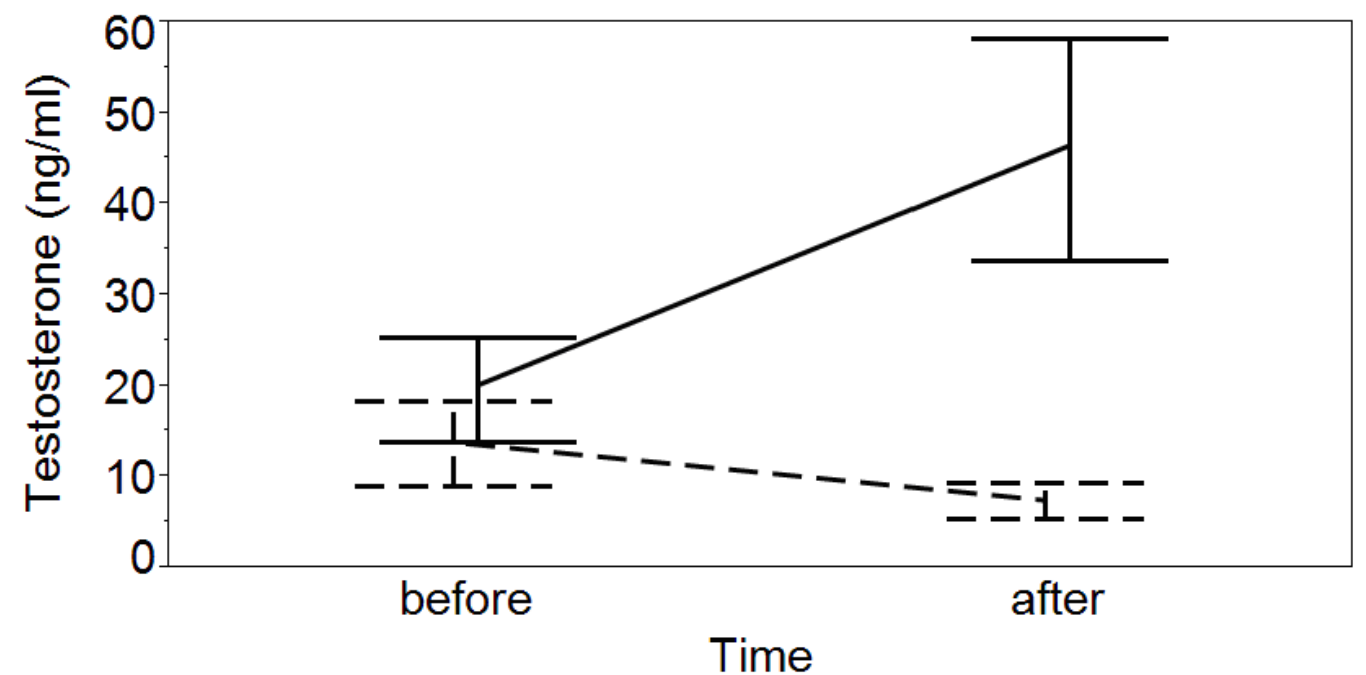

Figure 24: Mean stressed (following application of the acute stressor) testosterone (T) by time (before or after translocation) and treatment group. The solid line indicates the translocated group, while the dashed line indicates the control group. Error bars are one standard error of the mean. There were no significant trends, as the variation in stressed $\mathrm{T}$ was explained by baseline $\mathrm{T}$. 


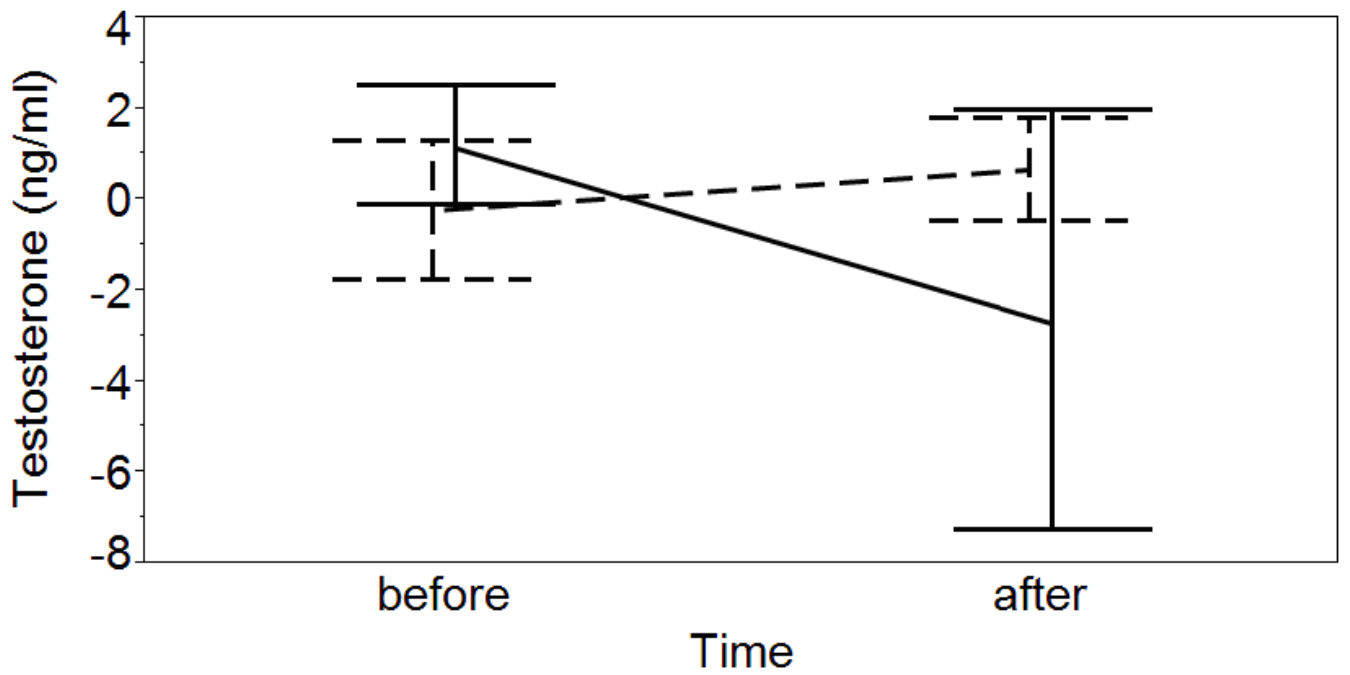

Figure 25: Mean testosterone ( $\mathrm{T}$ ) response by time (before or after translocation) and treatment group. The $\mathrm{T}$ response was calculated as the change in $\mathrm{T}$ from the baseline blood draw to a blood draw that occurred after application of an acute stressor. The solid line indicates the translocated group, while the dashed line indicates the control group. Error bars are one standard error of the mean. No significant trends were observed. 


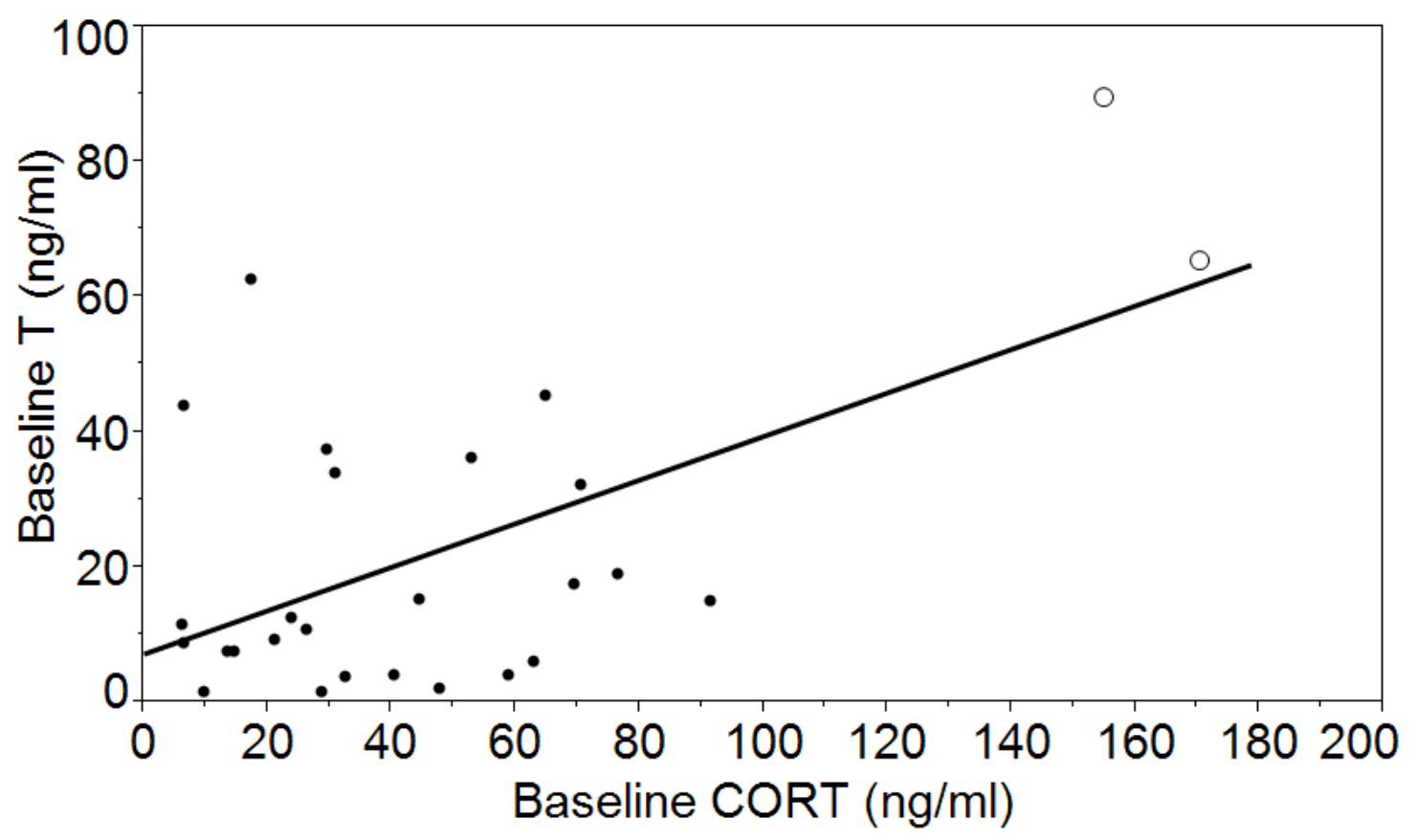

Figure 26: A plot of baseline T on baseline CORT. Individual snake was included as a random effect in the regression model, in order to account for repeated measures (before translocation and after translocation). A significant but weak positive relationship was observed, though it was driven by two influential snakes, which are displayed as open circles. 


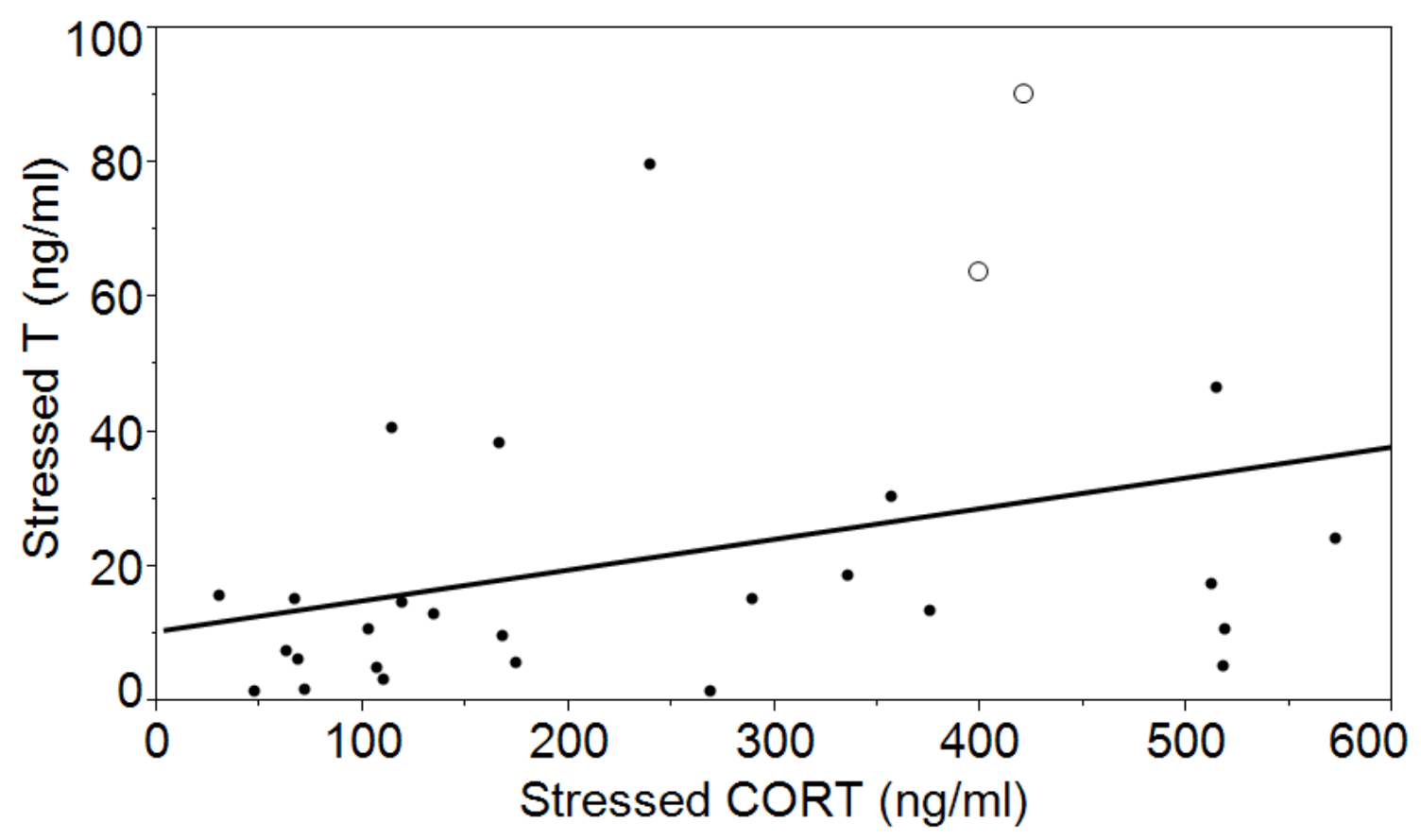

Figure 27: A plot of stressed T on stressed CORT. Individual snake was included as a random effect in the regression model, in order to account for repeated measures (before translocation and after translocation). A significant but weak positive relationship was observed. The two influential snakes from the baseline regression analysis (Figure 26) are displayed as open circles. Their removal changed the significance of the regression F-test here as well (see Figure 29). 


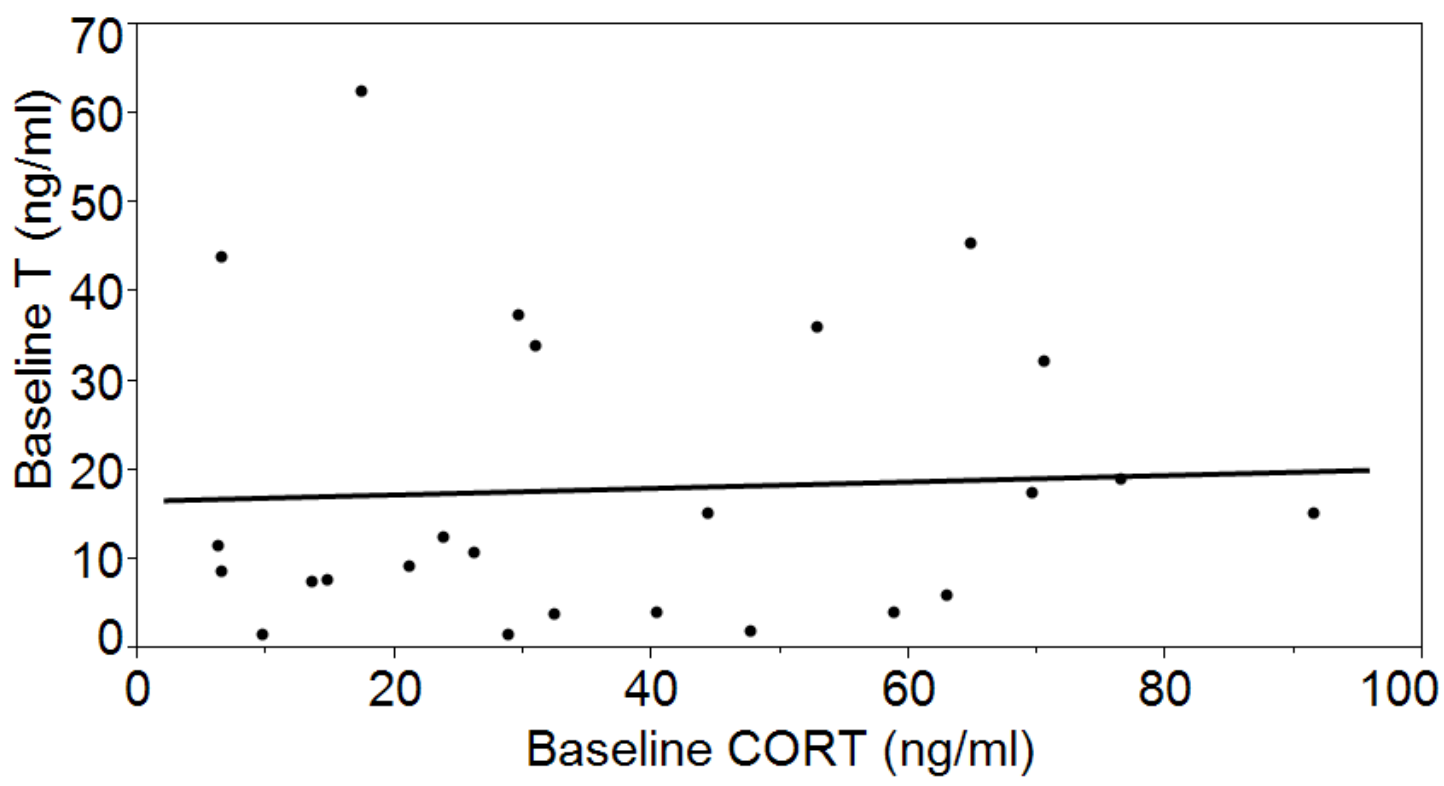

Figure 28: A plot of baseline $\mathrm{T}$ on baseline CORT, minus two influential snakes (see Figure 26). Individual snake was included as a random effect in the regression model, in order to account for repeated measures (before translocation and after translocation). Removal of the influential snakes nullified the significance of the regression F-test. 


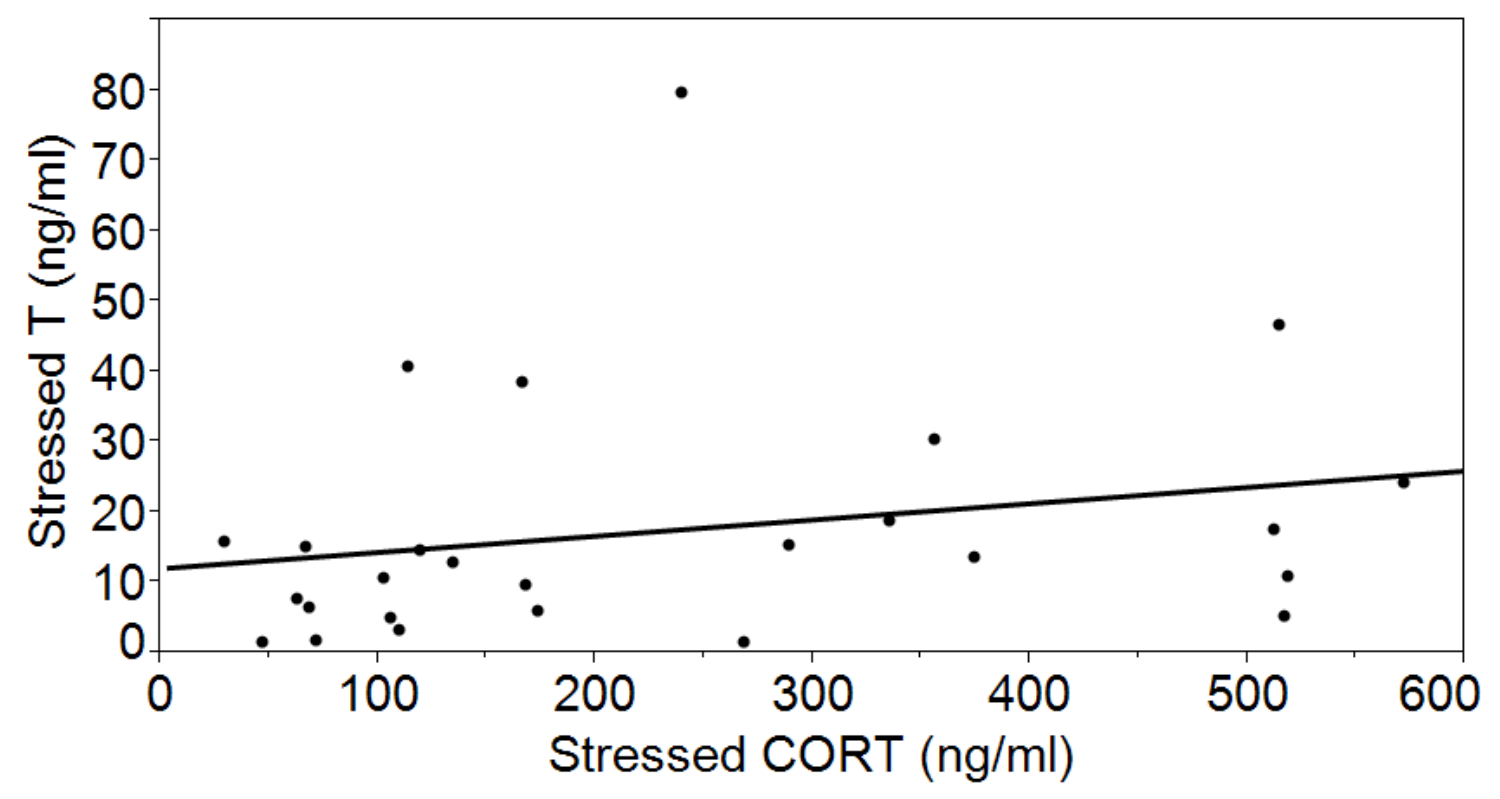

Figure 29: A plot of stressed $T$ on stressed CORT, minus two influential snakes from the baseline regression analysis (Figure 26). Individual snake was included as a random effect in the regression model, in order to account for repeated measures (before translocation and after translocation). Removal of the influential snakes nullified the significance of the regression F-test. 


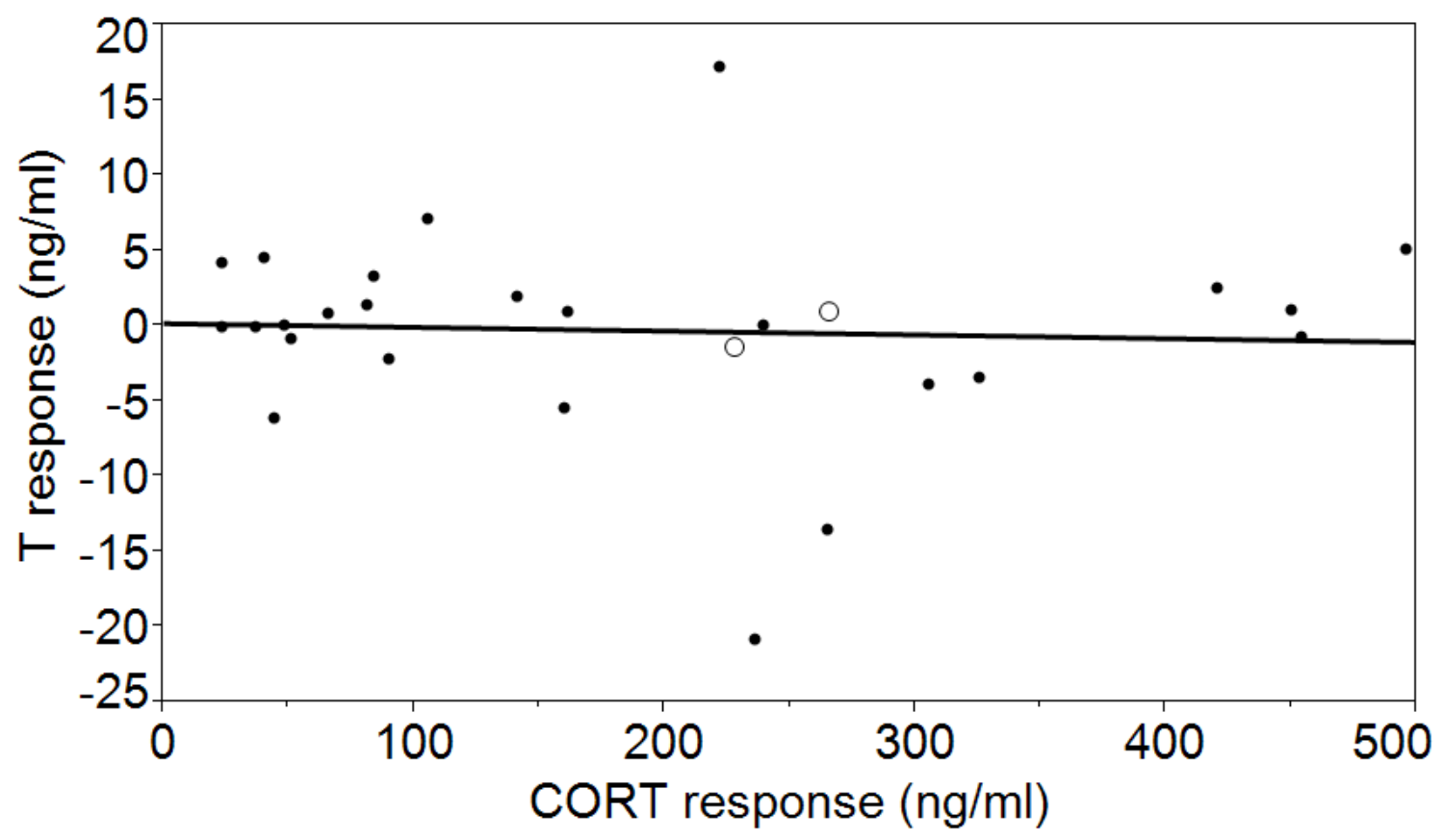

Figure 30: A plot of the T response on the CORT response. Individual snake was included as a random effect in the regression model, in order to account for repeated measures (before translocation and after translocation). There was no significant relationship. The two influential snakes from the baseline regression analysis (Figure 26) are displayed as open circles. Their removal did not change the significance of the regression F-test (see Figure 31). 


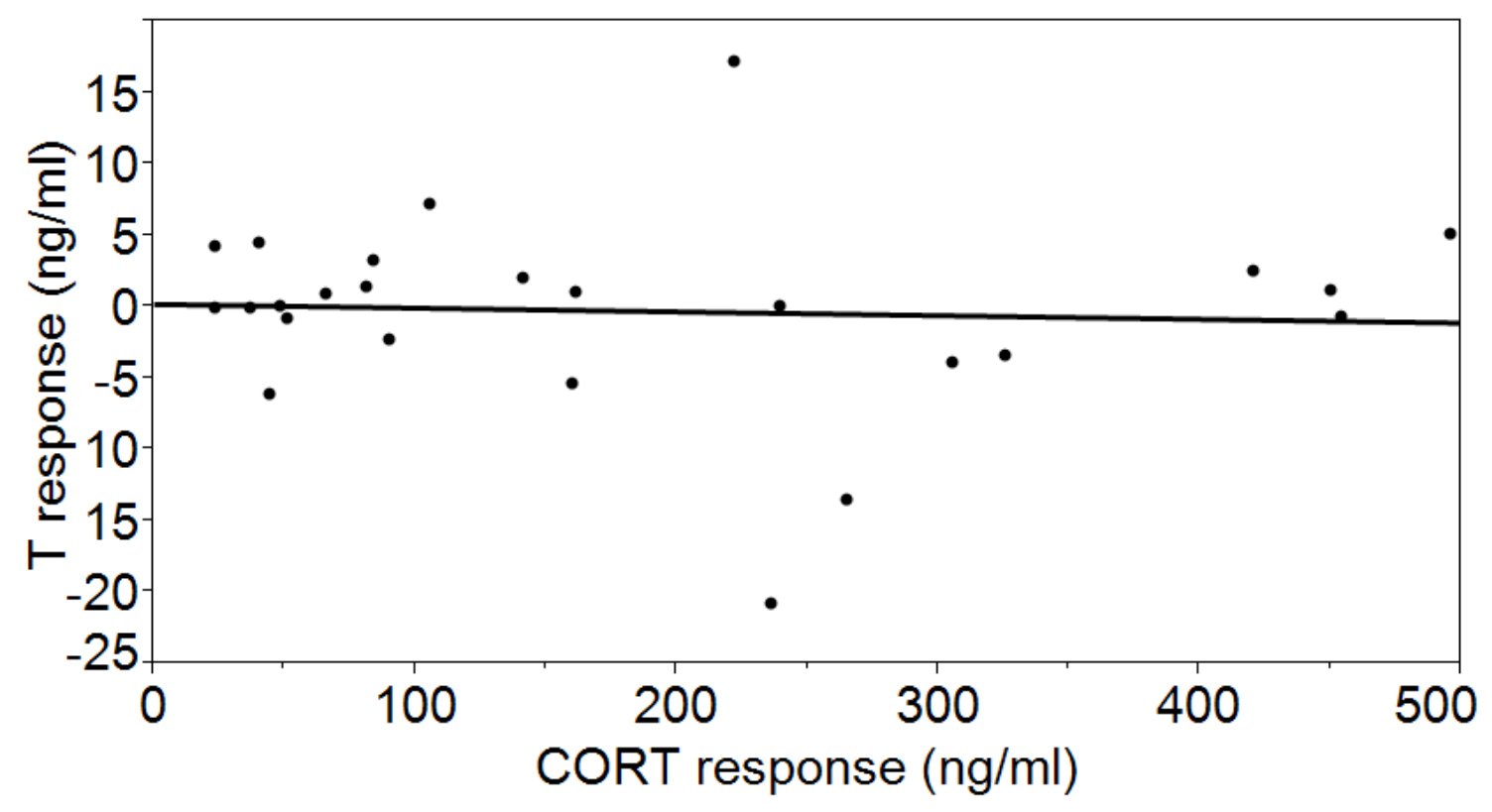

Figure 31: A plot of the T response on the CORT response, minus two influential snakes from the baseline analysis (Figure 26). Individual snake was included as a random effect in the regression model, in order to account for repeated measures (before translocation and after translocation). The relationship was not significant, with or without the influential snakes. 


\section{LITERATURE CITED:}

Aldridge, R.D. 2002. The link between mating season and male reproductive anatomy in the rattlesnakes Crotalus viridis oreganus and Crotalus viridis helleri. Journal of Herpetology 36: 295-300.

Angilletta, M.J. 2009. Thermal Adaptation A Theoretical and Empirical Synthesis. Oxford University Press, New York, New York.

Angilletta, M.J., P.H. Niewiarowski, and C.A. Navas. 2002. The evolution of thermal physiology in ectotherms. Journal of Thermal Biology 27: 249-268.

Ashton, K.G. 2003. Movements and mating behavior of adult male Midget Faded Rattlesnakes, Crotalus oreganus concolor, in Wyoming. Copeia 2003: 190-194.

Bailey, F.C., V.A. Cobb, T.R. Rainwater, T. Worrall, and M. Klukowski. 2009. Adrenocortical effects of human encounters on free-ranging cottonmouths (Agkistrodon piscivorus). Journal of Herpetology 43: 260-266.

Beck, D. B. 1995. Ecology and energetics of three sympatric rattlesnake species in the Sonoran Desert. Journal of Herpetology 29: 211-223. 
Besson, A.A. and A. Cree. 2010. Integrating physiology into conservation: an approach to help guide translocations of a rare reptile in a warming environment. Animal Conservation 14: 28-37.

Blouin-Demers, G. and P.J. Weatherhead. 2001. Thermal ecology of Black Rat Snakes (Elaphe obsoleta). Ecology 82: 3025-3043.

Bodnoff, S.R., A.G. Humphreys, J.C. Lehman, D.M. Diamond, G.M. Rose, and M.J. Meaney. 1995. Enduring effects of chronic corticosterone treatment on spatial learning, synaptic plasticity, and hippocampal neuropathology in young and midaged rats. Journal of Neuroscience 15: 61-69.

Brown, G.P. and P.J. Weatherhead. 2000. Thermal ecology and sexual size dimorphism in northern water snakes, Nerodia sipedon. Ecological Monographs 70: 311-330.

Brown, J.R., Bishop, C.A., and Brooks, R.J, 2009. Effectiveness of short-distance translocation and its effects on Western Rattlesnakes. Journal of Wildlife Management 73: 419-425. 
Brown, T.K., J.M. Lemm, and J. Montagne, J.A. Tracey, and A.C. Alberts. 2008. Spatial ecology, habitat use, and survivorship of resident and translocated red diamond rattlesnakes (Crotalus ruber). In: W.K. Hayes, K.R. Beaman, M.D. Cardwell, and S.P. Bush (Eds.), The Biology of the Rattlesnakes. Loma Linda University Press, Loma Linda, California, pp. 377-394.

Brown, W.S. and W.S. Parker. 1976. Movement ecology of Coluber constrictor near communal hibernacula. Copeia 1976: 225-242.

Brown, W.S. 1982. Overwinter body temperatures of Timber Rattlesnakes (Crotalus horridus) in northeastern New-York. Journal of Herpetology 16: 145-150.

Burkitt, J., D. Widman, and D.M Saucier. 2007. Evidence for the influence of testosterone in the performance of spatial navigation in a virtual water maze in women but not in men. Hormones and Behavior 51: 649-654.

Burnham, K.P. and D.R. Anderson. 2002. Model selection and multimodel inference: a practical information-theoretic approach. Springer-Verlag Incorporated, New York, New York.

Butler, H., B. Malone, and N. Clemann. 2005. Activity patterns and habitat preferences of translocated and resident tiger snakes (Notechis scutatus) in a suburban landscape. Wildlife Research 32: 157-163. 
Cartledge, V.A and S. Jones. 2007. Does adrenal responsiveness vary with sex and reproductive status in Egernia whitii, a viviparous skink?. General and Comparative Endocrinology 150: 132-139.

Cherrier, M.M., S. Asthana, L.D. Baker, S. Plymate, A. Matsumoto, E. Peskind, M.A. Raskind, K. Brodkin, W. Bremner, A. Petrova, S. Latendresse, and S. Craft. 2001. Testosterone supplementation improves spatial and verbal memory in healthy older men. Neurology 57: 80-88.

Cherrier, M.M., A.M. Matsumoto, J.K. Amory, M. Johnson, S. Craft, E.R. Peskind, and M.A. Raskind. Characterization of verbal and spatial memory changes from moderate to supraphysiological increases in serum testosterone in healthy older men. Psychoneuroendocrinology 32: 72-79.

Christian, K.A. and B.W. Weavers. 1996. Thermoregulation of monitor lizards in Australia: an evaluation of methods in thermal biology. Ecological Monographs 66: 139-157.

Cobb, V.A. and C.R. Peterson. 2008. Thermal ecology of hibernation in a population of Great Basin Rattlesnakes, Crotalus oreganus lutosus. In: W.K. Hayes, K.R. Beaman, M.D. Cardwell, and S.P. Bush (Eds.), The Biology of the Rattlesnakes. Loma Linda University Press, Loma Linda, California, pp. 291-302. 
Cope, W.G. and D.L. Waller. 1995. Evaluation of fresh-water mussel relocation as a conservation and management strategy. Regulated Rivers: Research and Management 11: 147-155.

Cree, A., A.P. Amey, and J.M. Whittier. 2000. Lack of consistent hormonal response to capture during the breeding season of the Bearded Dragon, Pogona barbata. Comparative Biochemistry and Physiology 126: 275-285.

Davidson, A.J., F. Aujard, B. London, M. Menaker, and G.D. Block. 2003. Thermochron iButtons: an inexpensive method for long-term recording of core body temperature in untethered animals. Journal of Biological Rhythms 18: 430-432.

DeGregorio, B.A., K.A. Buhlmann, and T.D. Tuberville. 2012. Overwintering of Gopher Tortoises (Gopherus polyphemus) translocated to the northern limit of their teographic range: temperatures, timing, and survival. Chelonian Conservation and Biology 11: 84-90.

de Kloet, E.R., M.S. Oitzl, and M. Joëls. 1999. Stress and cognition: are corticosteroids good or bad guys? Trends in Neurosciences 10: 422-426. 
Dhabhar, F.S. and B.S. McEwen. 1997. Acute stress enhances while chronic stress suppresses cell-mediated immunity in vivo: a potential role for leukocyte trafficking. Brain Behavior and Immunity 11: 286-306.

Dickens, M.J., D.J. Delehanty, and L.M. Romero. 2010. Stress: an inevitable component of animal translocation. Biological Conservation 143: 1329-1341.

Dodd, K. C., and R.A. Seigel. 1991. Relocation, repatriation, and translocations of amphibians and reptiles: are they strategies that work? Herpetologica 47: 336350.

Douglas, M.E., M.R. Douglas, G.W. Schuett, L.W. Porras, and A.T. Holycross. 2002. Phylogeography of the Western Rattlesnake (Crotalus viridis) complex, with emphasis on the Colorado plateau. In: G.W. Schuett, M. Höggren, M.E. Douglas, and H.W. Greene (Eds.), Biology of the Vipers. Eagle Mountain Publishing, Eagle Mountain, Utah, pp. 11-50.

Drake, K.K., K.E. Nussear, T.C. Esque, A.M. Barber, K.M. Vittum, P.A. Medica, C.R. Tracy, and K.W. Hunter Jr. 2012. Does translocation influence physiological stress in the desert tortoise?. Animal Conservation 15: 560-570. 
Drugan, R.C., A.S. Basile, J.H. Ha, D. Healy, and R.J. Ferland. 1997. Analysis of the importance of controllable versus uncontrollable stress on subsequent behavioral and physiological functioning. Brain Research Protocols 2: 69-74.

Dugan, E. A., A. Figueroa, and W.K. Hayes. 2008. Home range size, movements, and mating phenology of sympatric Red Diamond (Crotalus ruber) and Southern Pacific (C. oreganus helleri) Rattlesnakes in southern California. In W. K. Hayes, K. R. Beaman, M. D. Cardwell, and S. P. Bush (eds.), The Biology of Rattlesnakes, pp. 353-364. Loma Linda University Press, Loma Linda, California.

Dunlap, K.D. and J.C. Wingfield. 1995. External and internal influences on indices of physiological stress I. Seasonal and population variation in adrenocortical secretion of free-living lizards, Sceloporus occidentalis. Journal of Experimental Biology 271: 36-46.

Dupoué, A., F. Brischoux, O. Lourdais, and F. Angelier. 2013. Influence of temperature on the corticosterone stress-response: an experiment in the Children's Python (Antaresia childreni). General and Comparative Endocrinology 193: 178-184.

Fischer, J. and D.B. Lindenmayer. 2000. An assessment of the published results of animal relocations. Biological Conservation 96: 1-11. 
French, S.S., R. McLemore, B. Vernon, G.I.H. Johnston, and M.C. Moore. 2007. Corticosterone modulation of reproductive and immune systems trade-offs in female tree lizards: long-term corticosterone manipulations via injectable gelling material. Journal of Experimental Biology 210: 2859-2865.

Germano, J.M. and P.J. Bishop. 2008. Suitability of amphibians and reptiles for translocation. Conservation Biology 23: 7-15.

Graham, S.P., R.L. Earley, S.K. Hoss, G.W. Schuett, and M.S. Grober. 2008. The reproductive biology of male Cottonmouths (Agkistrodon piscivorus): do plasma steroid hormones predict the mating season? General and Comparative Endocrinology 159: 226-235.

Greenwald, O.E. 1974. Thermal dependence of striking and prey capture by Gopher Snakes. Copeia 1974: 141-148.

Hardy, D. L., and H. W. Greene. 1999. Surgery on rattlesnakes in the field for implantation of transmitters. Sonoran Herpetology 12: 25-27.

Hardy, D. L., H.W. Greene, B. Tomberlin, and M. Webster. 2001. Relocation of nuisance rattlesnakes: problems using short-distance translocation in a small rural community. Sonoran Herpetologist 14: 1-3. 
Harvey, D.S. and P.J. Weatherhead. 2006. Hibernation site selection by Eastern Massasauga rattlesnakes (Sistrurus catenatus catenatus) near their northern range limit. Journal of Herpetology 40: 66-73.

Hawley, W.R., E.M. Grissom, R.C. Martin, M.B. Halmos, C.L.S. Bart, and G.P. Dohanich. 2013. Testosterone modulates spatial recognition memory in male rats. Hormones and Behavior 63: 559-565.

Hertz, P.E., R.B. Huey, and R.D. Stevenson. 1993. Evaluating temperature regulation by field-active ectotherms: the fallacy of the inappropriate question. The American Naturalist 142: 796-818.

Holding, M.L., J.A. Frazier, S. Dorr, S.N. Henningsen, I.T. Moore, and E.N. Taylor. in press. The hormonal and behavioral effects of repeated handling and shortdistance translocation on free-ranging northern Pacific rattlesnakes (Crotalus $o$. oreganus). Journal of Herpetology.

Janowsky, J.S., S.K. Oviatt, and E.S. Orwoll. 1994. Testosterone influences spatial cognition in older men. Behavioral Neuroscience 108: 325-332. 
Jenkins, C.L. and C.R. Peterson. 2005. Linking landscape disturbance to the population ecology of Great Basin Rattlesnakes (Crotalus oreganus lutosus) in the Upper Snake River Plain. Idaho BLM Technical Bulletin 2005-2007. Idaho State Office, U.S. Department of the Interior, Bureau of Land Management.

Jones, S.M. and K. Bell. 2004. Plasma corticosterone concentrations in males of the skink Egernia whitii during acute and chronic confinement and over a diel period. Comparative Biochemistry and Physiology 137: 105-113.

Ketterson, E.D., V. Nolan Jr., L. Wolf, C. Ziegenfus, A.M. Duffy Jr., G.F. Ball, and T. Johnsen. 1991. Testosterone and avian life histories: the effect of experimentally elevated testosterone on corticosterone and body mass in dark-eyed juncos. Hormones and Behavior 25: 489-503.

Khorshidahmad, T., K. Tabrizian, G. Vakilzadeh, P. Nikbin, S. Moradi, A. HosseiniSharifabad, A. Roghani, N. Naghdi, and M. Sharifzadeh. 2012. Interactive effects of a protein kinase AII inhibitor and testosterone on spatial learning in the Morris water maze. Behavioural Brain Research 228: 432-439.

King, R., C. Berg, and B. Hay. 2004. A repatriation study of the Eastern Massasauga (Sistrurus catenatus catenatus) in Wisconsin. Herpetologica 60: 429-437. 
Kingsbury, B.A. and O. Attum. 2009. Conservation strategies captive rearing, translocation, and repatriation. In: S.J. Mullen and R.A. Seigel (Eds), Snakes: Ecology and Conservation. Cornell University Press, Ithaca, New York, pp. 201220.

Klauber, L.M. 1949. Some new and revived subspecies of rattlesnakes. Transactions of the San Diego Society of Natural History 11:61-116.

Lenain, D. 2001. Is translocation an effective tool to remove predatory foxes from a desert protected area?. Journal of Arid Environments 48: 205-209.

Leonard, S.T. and P.J. Winsauer. 2011. The effects of gonadal hormones on learning and memory in male mammals: a review. Current Zoology 57: 543-558.

Lind, C.M., J.F. Husak, C. Eikenaar, I.T. Moore, and E.N. Taylor. 2010. The relationship between plasma steroid hormone concentrations and the reproductive cycle in the Northern Pacific Rattlesnake, Crotalus oreganus. General and Comparative Endocrinology 166: 590-599.

Lutterschmidt, W.I., D.I. Lutterschmidt, R.T. Mason, and H.K. Reinert. 2009. Seasonal variation in hormonal responses of Timber Rattlesnakes (Crotalus horridus) to reproductive and environmental stressors. Journal of Comparative Physiology B 179: $747-757$. 
Manzo, C., M. Zerani, A. Gobbetti, M.M. Di Fiore, and F. Angelini. 1994. Is corticosterone involved in the reproductive processes of the male lizard, Podarcis sicula sicula? Hormones and Behavior 28: 117-129.

McConnell, S.E.A, J. Alla, E. Wheat, R.D. Romeo, B. McEwen, and J.E. Thornton. 2012. The role of testicular hormones and luteinizing hormone in spatial memory in adult male rats. Hormones and Behavior 61: 479-486.

McEwen, B.S. and R.M. Sapolsky. 1995. Stress and cognitive function. Current Opinion in Neurobiology 5: 205-216.

Mendl, M. 1999. Performing under pressure: stress and cognitive function. Applied Animal Behaviour Science 65: 221-244.

Miles, D.B., R. Calsbeek, and B. Sinervo. 2007. Corticosterone, locomotor performance, and metabolism in Side-blotched Lizards (Uta stansburiana). Hormones and Behavior 51: 548-554.

Mondal, S., and U. Rai. 2001. In vitro effect of temperature on phagocytic and cytotoxic activities of splenic phagocytes of the wall lizard, Hemidactylus flaviviridis. Comparative Biochemistry and Physiology Part A: 391-398. 
Moore, M.C. and J. Lindzey. 1992. The physiological basis for sexual behavior in male reptiles. In: C. Gans and D. Crews (Eds.), Biology of the Reptilia, volume 18. University of Chicago Press, Chicago, pp. 70-113.

Moore, M.C., C.W. Thompson, and C.A. Marler. 1991. Reciprocal changes in corticosterone and testosterone levels following acute and chronic handling stress in the tree lizard, Urosaurus ornatus. General and Comparative Endocrinology 81: 217-226.

Moore, I.T., M.J. Greene, and R.T. Mason. 2001. Environmental and seasonal adaptations of the adrenocortical and gonadal responses to stress in two populations of the male garter snake, Thamnophis sirtalis. Journal of Experimental Zoology 289: 90-108.

Moore, I.T. and T.S. Jessop. 2003. Stress, reproduction, and adrenocortical modulation in amphibians and reptiles. Hormones and Behavior 43: 39-47.

Moore, I.T., M.P. Lemaster, and R.T. Mason. 2000a. Behavioural and hormonal responses to capture stress in the male red-sided garter snakes (Thamnophis sirtalis parietalis). Animal Behaviour 59: 529-534. 
Moore, I.T., J.P. Lerner, D.T. Lerner, and R.T. Mason. 2000b. Relationships between annual cycles of testosterone, corticosterone, and body condition in male Redspotted Garter Snakes, Thamnophis sirtalis concinnus. Physiological and Biochemical Zoology 73: 307-312.

Naghdi, N., N. Majlessi, and T. Bozorgmehr. 2005. The effect of intrahippocampal injection of testosterone enanthate (an androgen receptor agonist) and anisomycin (protein synthesis inhibitor) on spatial learning and memory in adult, male rats. Behavioural Brain Research 156: 263-268.

Naghdi, N., O. Shahrbanoo, and R. Etemadi. 2003. The study of spatial memory in adult male rats with injection of testosterone enanthate and flutamide into the basolateral nucleus of the amygdala in Morris water maze. Brain Research 972: 18.

Nowak, E.M., T. Hare, and J. McNally. 2002. Management of "nuisance” vipers: effects of translocation on western diamond-backed rattlesnakes (Crotalus atrox). In: G.W. Schuett, M. Hoggren, M.E. Douglas, H.W. Greene, (Eds.), Biology of the Vipers. Eagle Mountain Publishing, Eagle Mountain, Utah, pp. 533-560. 
Peterson, C.R., R.A. Gibson, and M.E. Dorcas. 1993. Snake thermal ecology: the causes and consequences of body temperature variation. In: R.A. Seigel and J.T. Collins (Eds.), Snakes: Ecology and Behavior. McGraw-Hill, New York, New York, pp. 241-314.

Plummer, M.V. and N.E. Mills. 2000. Spatial ecology and survivorship of resident and translocated hognose snakes (Heterodon platirhinos). Journal of Herpetology 34: $565-575$.

Postma, A. G. Meyer, A. Tuiten, J. von Honk, R.P.C. Kessels, and K. Thijssen. 2000. Effects of testosterone administration on selective aspects of object-location memory in healthy young women. Psychoneuroendocrinology 25: 563-575.

Prior, K.A., G. Blouin-Demers, and P.J. Weatherhead. 2001. Sampling biases in demographic analyses in Black Rat Snakes (Elaphe obsoleta). Herpetologica 57: 460-469.

Putman, B. J., C. M. Lind, and E. N. Taylor. 2013. Does size matter? Testing the effects of body size and sex on spatial ecology parameters of Northern Pacific Rattlesnakes (Crotalus oreganus oreganus) in Central California. Copeia 2013: 485-492. 
Pyter, L.M., B.C. Trainor, and R.J. Nelson. 2006. Testosterone and photoperiod interact to affect spatial learning and memory in adult male white-footed mice (Peromyscus leucopus). European Journal of Neuroscience 23: 3056-3062.

Reinert, H.K. and R.R. Rupert Jr. 1999. Impacts of translocation on behavior and survival of timber rattlesnakes, Crotalus horridus. Journal of Herpetology 33: 45-61.

Roe, J.H, M.R. Frank, S.E. Gibson, O. Attum, and B.A. Kingsbury. 2010. No place like home: an experimental comparison of reintroduction strategies using snakes. Journal of Applied Ecology 47: 1253-1261.

Sandstrom, N.J., J.H. Kim, and M.A. Wasserman. 2006. Testosterone modulates performance on a spatial working memory task in male rats. Hormones and Behavior 50: 18-26.

Schneider, G. E. 1986. Geographic variation in the contact zone of two subspecies of the Pacific Rattlesnake, Crotalus viridis oreganus and Crotalus viridis helleri. Unpublished M.S. thesis, University of California, Santa Barbara.

Schuett, G.W. 1997. Annual cycles of testosterone in male Copperheads, Agkistrodon contortrix (Serpentes: Viperidae): relationship to timing of spermatogenesis. Mating and agonistic behavior. General and Comparative Endocrinology 105: 417-424. 
Schuett, G.W., S.L. Carlisle, A.T. Holycross, J.K. O’Leile, D.L. Hardy, Sr., E.A. Van Kirk, and W.J. Murdoch. 2002. Mating system of male Mojave Rattlesnakes (Crotalus scutulatus): seasonal timing of mating, agonistic behavior, spermatogenesis, sexual segment of the kidney, and plasma sex steroids. In: G.W. Schuett, M. Höggren, M.E. Douglas, and H.W. Greene (Eds.), Biology of the Vipers. Eagle Mountain Publishing, Eagle Mountain, Utah, pp. 515-532.

Schuett, G.W., D.L. Hardy Sr., H.W. Greene, R.L. Earley, M.S. Grober, E.A. Van Kirk, and W.J. Murdoch. 2005. Sympatric rattlesnakes with contrasting mating systems show differences in seasonal patterns of plasma sex steroids. Animal Behaviour 70: $257-266$.

Silverman, I., D. Kastuk, J. Choi, and K. Phillips. 1999. Testosterone levels and spatial ability in men. Psychoneuroendocrinology 24: 813-822.

Smith, C.F., G.W. Schuett, R.L. Earley, and K. Schwenk. 2009. The spatial and reproductive ecology of the Copperhead (Agkistrodon contortrix) at the northeastern extreme of its range. Herpetological Monographs 23: 45-73.

Spritzer, M.D., E.D. Daviau, M.K. Coneeny, S.M. Engelman, W.T. Prine, and K.N. Rodriguez-Wisdom. Effects of testosterone on spatial learning and memory in adult male rats. Hormones and Behavior 59: 484-496. 
Stebbins, R. C. 2003. A Field Guide to Western Reptiles and Amphibians. Houghton Mifflin Company, Boston, Massachusetts.

Stevenson, R.D. 2006. Ecophysiology and conservation: the contribution of energetics introduction to the symposium. Integrative and Comparative Biology 46: 10881092.

Stevenson, R.D., C.R. Peterson, and J.S. Tsuji. 1985. The thermal dependence of locomotion, tongue flicking, digestion, and oxygen consumption in the Wandering Garter Snake. Physiological Zoology 58: 46-57.

Summers, C.H. and M.F. Norman.1988. Chronic low humidity-stress in the lizard Anolis carolinensis: changes in diurnal corticosterone rhythms. Journal of Experimental Zoology 247: 271-278.

Taylor, E.N., D.F. DeNardo, and D.H. Jennings. 2004. Seasonal steroid hormone levels and their relation to reproduction in the Western Diamond-backed Rattlesnake, Crotalus atrox (Serpentes: Viperidae). General and Comparative Endocrinology 136: $328-337$. 
Taylor, E.N., M.A. Malaway, D.M. Browning, S.V. Lemar, and D.F. DeNardo. 2005. Effects of food supplementation on the physiological ecology of female Western Diamond-backed Rattlesnakes (Crotalus atrox). Oecologia 144: 206-213.

Taylor, E.N. and G.W. Schuett. 2004. Effect of temperature and storage duration on the stability of steroid hormones in blood samples from western diamond-backed rattlesnakes (Crotalus oreganus). Herpetological Review 35: 14-17.

Tokarz, R.R. and C.H. Summers. 2011. Stress and reproduction in reptiles. In: D.O. Norris and K.H. Lopez (Eds.), Hormones and Reproduction in Vertebrates, Vol. 3, Reptiles, pp. 169-213.

Tracy, C.R., K.E. Nussear, T.C. Esque, K. Dean-Bradley, C.R. Tracy, L.A. DeFalco, K.T. Castle, L.C. Zimmerman, R.E. Espinoza, and A.M. Barber, 2006. The importance of physiological ecology in conservation biology. Integrative and Comparative Biology: 46, 1191-1205.

Troy, R. 2013. Survival of mountain quail translocated from two distinct source populations. Journal of Wildlife Management 77: 1031-1037. 
van Marken Licktenbelt, W.D., H.A.M. Daanen, L. Wouters, R. Fronczek, R.J.E.M Raymann, N.M.W. Severens, and E.J.W. Van Someren. 2006. Evaluation of wireless determination of skin temperature using iButtons. Physiology and Behavior 88: 489-497.

Werner, Y.L., 1976. Optimal temperatures for inner-ear performance in gekkonid lizards. Journal of Experimental Zoology 195: 319-352.

Wikelski, M. \& Cooke, S.J. 2006. Conservation physiology. Trends in Ecology and Evolution 21: 38-45.

Wilson, B.S. and J.C. Wingfield.1992. Correlation between female reproductive condition and plasma corticosterone in the lizard Uta stansburiana. Copeia 3: 691-697.

Wilson, B.S. and J.C. Wingfield. 1994. Seasonal and interpopulational variation in plasma levels of corticosterone in the Side-blotched Lizard (Uta stansburiana). Physiological Zoology 67: 1025-1049.

Woodley, S.K., D.L. Painter, M.C. Moore, M. Wikelski, and L.M. Romero. 2003. Effect of tidal cycle and food intake on the baseline plasma corticosterone rhythm in intertidally foraging Marine Iguanas. General and Comparative Endocrinology 132: $216-222$. 


\section{APPENDIX:}

\section{SITE ONE PHOTOS}

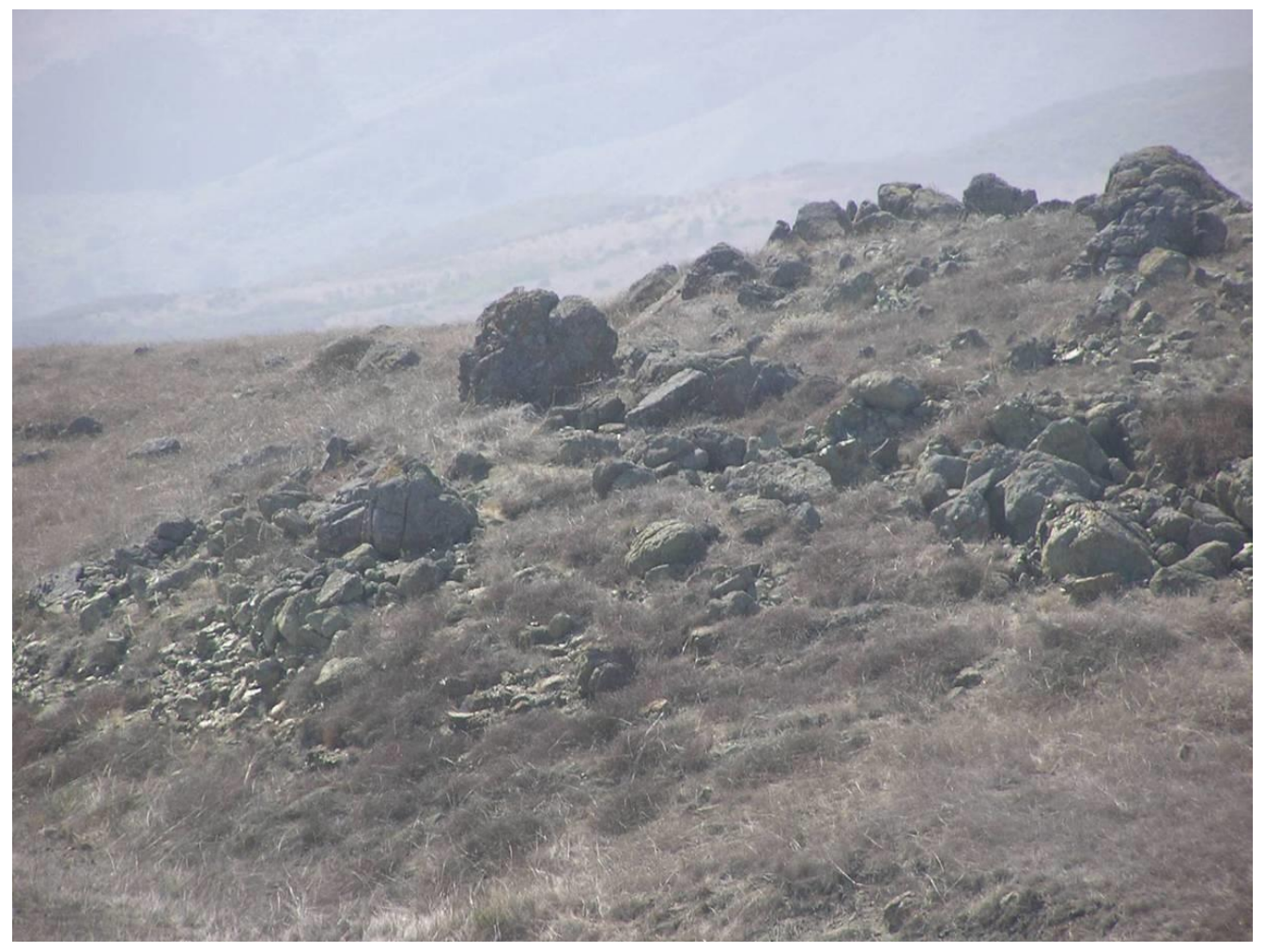



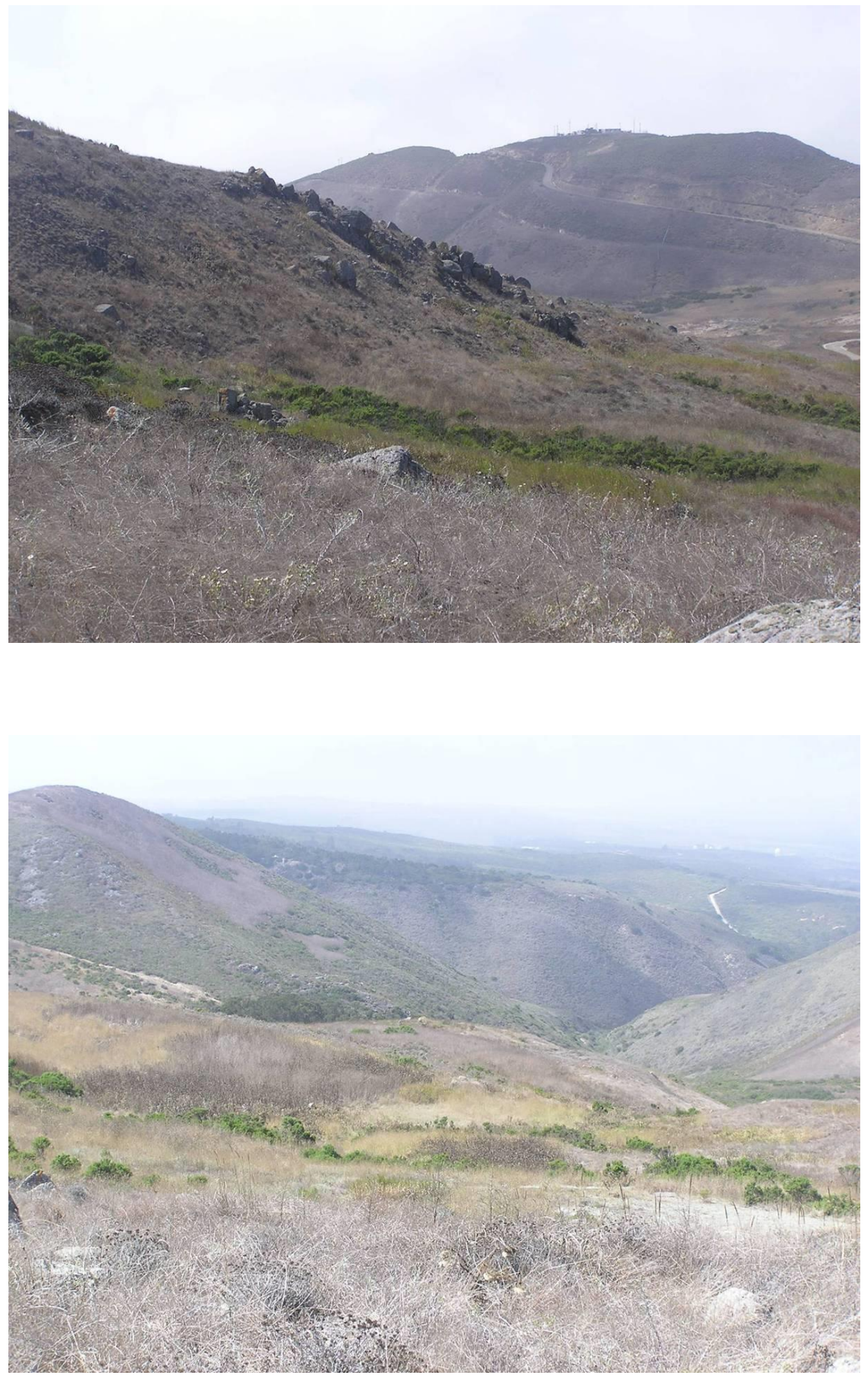
SITE TWO PHOTOS

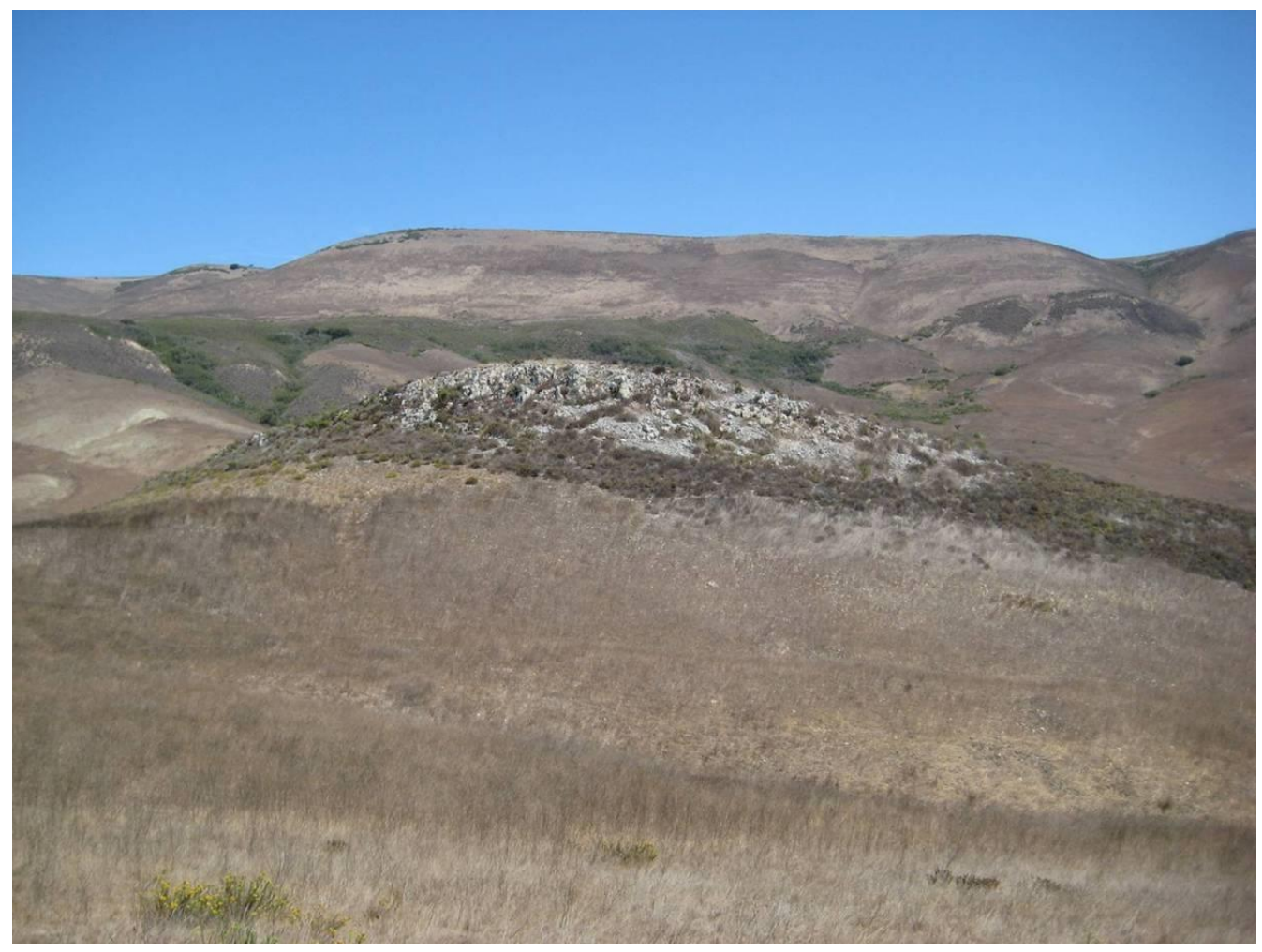



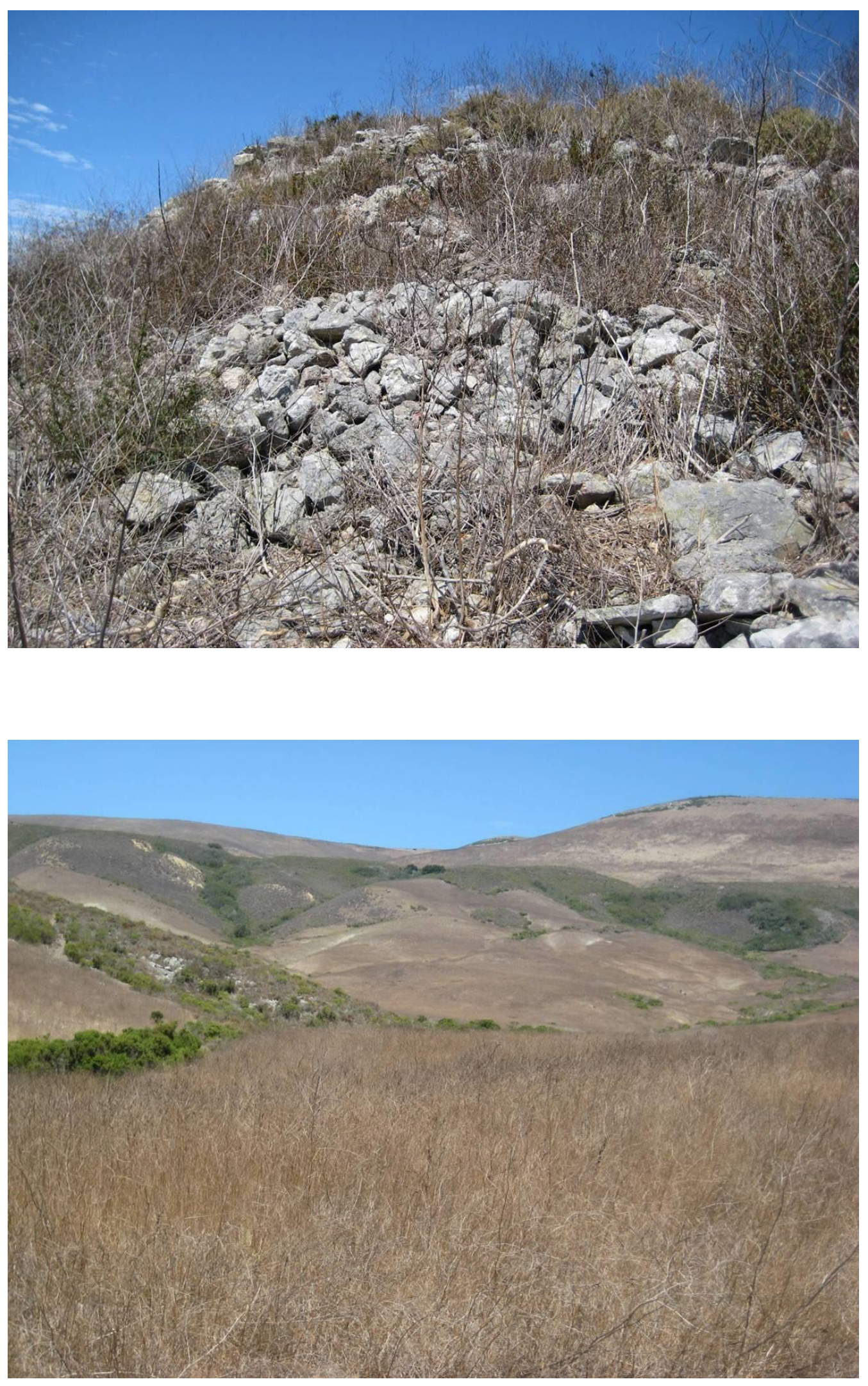